\title{
IS-T- -1801
}

\section{Synthesis of organosilicon compounds}

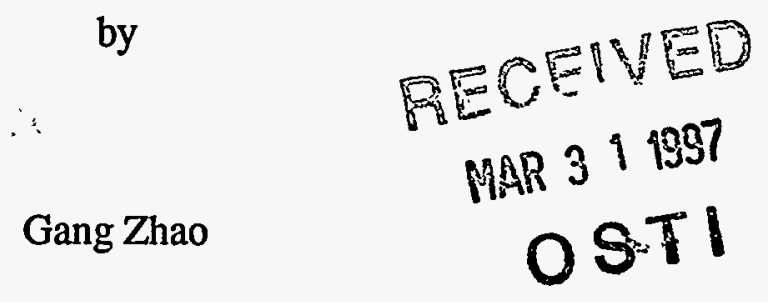

A thesis submitted to the graduate faculty

in partial fulfilment of the requirements for the degree of

MASTER OF SCIENCE

Major: Organic Chemistry

Major Professor: Thomas J. Barton

DISTRIBUTION OF THIS DOCURBENT IS URLMITED ph

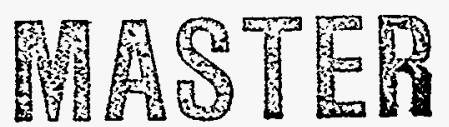

Iowa State University

Ames, Iowa

1996 


\section{DISCLAIMER}

This report was prepared as an account of work sponsored by an agency of the United States Government. Neither the United States Government nor any agency thereof, nor any of their employees, makes any warranty, express or implied, or assumes any legal liability or responsibility for the accuracy, completeness or usefulness of any information, apparatus, product, or process disclosed, or represents that its use would not infringe privately owned rights. Reference herein to any specific commercial product, process, or service by trade name, trademark, manufacturer, or otherwise, does not necessarily constitute or imply its endorsement, recommendation, or favoring by the United States Government or any agency thereof. The views and opinions of authors expressed herein do not necessarily state or reflect those of the United States Government or any agency thereof.

This report has been reproduced directly from the best available copy.

AVAILABILITY:

To DOE and DOE contractors: Office of Scientific and Technical Information

\section{P.O. Box 62}

Oak Ridge, TN 37831

prices available from: (615) 576-8401

FTS: $626-8401$

To the public:

National Technical Information Service

U.S. Department of Commerce

5285 Port Royal Road

Springfield, VA 22161 


\section{DISCLAIMER}

Portions of this document may be illegible in electronic image products. Images are produced from the best available original document. 


\section{Graduate College}

Iowa State University

This is to certify that the Master's thesis of

Gang Zhao

has met the thesis requirements of Iowa State University

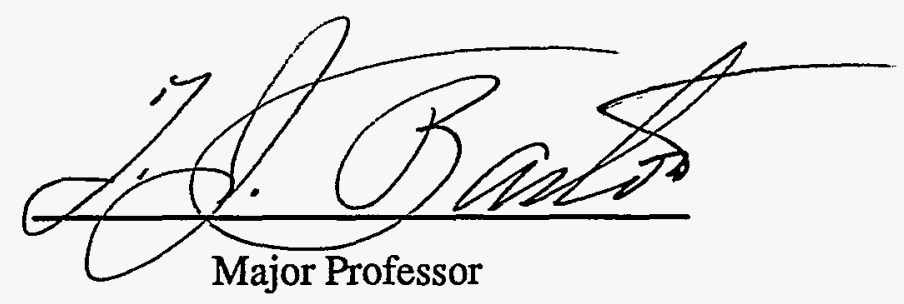

For the Major Department

For the Graduate College 


\section{TABLE OF CONTENTS}

GENERAL INTRODUCTION 1

I. SYNTHESIS OF CARBOSILANE DENDRITIC POLYMERS 2

Literature Survey 2

$\begin{array}{ll}\text { Results and Discussion } & 13\end{array}$

$\begin{array}{lr}\text { Conclusions } & 40\end{array}$

$\begin{array}{ll}\text { Experimental } & 40\end{array}$

$\begin{array}{ll}\text { References } & 56\end{array}$

II. SYNTHESIS OF CERAMIC PRECURSOR POLYMERS 61

$\begin{array}{ll}\text { Literature Survey } & 61\end{array}$

$\begin{array}{ll}\text { Results and Discussion } & 67\end{array}$

$\begin{array}{ll}\text { Conclusions } & 72\end{array}$

$\begin{array}{ll}\text { Experimental } & 73\end{array}$

$\begin{array}{ll}\text { References } & 79\end{array}$

GENERAL CONCLUSIONS $\quad, \quad 82$

$\begin{array}{ll}\text { ACKNOWLEDGMENTS } & 83\end{array}$ 


\section{GENERAL INTRODUCTION}

Silicon-containing polymers have been a focus of synthesis and study in Dr. Barton's group because of their basic chemistry and properties which are not offered by other systems or materials. For example, the polymer $-\left[-\mathrm{SiMe}_{2} \mathrm{C} \equiv \mathrm{C}-\right]_{\mathrm{n}}-$ can be easily processed to films or fibers from melt or solution, and thermally converted to a SiCcontaining ceramic in high yield at high temperature. In recent years, carbosilane dendritic polymers have been of great interests in many research groups. However, no synthesis of carbosilane dendrimers with functionalities both inside and outside the dendrimer has been reported. Functionality is very important in the synthesis of preceramic polymers. This thesis will be devoted to exploring several new organosilicon polymer systems.

\section{Thesis Organization}

Two separate studies are included in this thesis. The first section of this thesis addressees the synthetic study of carbosilane dendritic polymers, which involves the first synthesis of silylene-vinylene dendrimers.

The second section deals with the synthetic study of ceramic precursor polymers which have the 1:1 ratio of $\mathrm{Si}$ to $\mathrm{C}$ and have the functionalities in the structure. 


\section{SYNTHESIS OF CARBOSILANE DENDRITIC POLYMERS}

\section{Literature Survey}

There has been great interest in recent years in polymers with a regular/irregular,

three dimensional, treelike structures. Such polymers are called dendritic polymers. ${ }^{1.5}$ It is estimated that at least 120 groups worldwide are working with dendritic polymers, ${ }^{6}$ which come in two basic structure types. The first type of dendritic structure is the dendrimer, which was first made by Tomalia and co-workers. ${ }^{1}$ Dendrimers have a regular structure in which well defined branches radiate from a central core, becoming more branched and crowded as they extended out to the periphery. A typical dendrimer structure is depicted in Figure 1. ${ }^{7}$

In Figure 1, four branches emanate from a central point, the initiator core with $\mathrm{N}_{\mathrm{I}}$ $=4$, which means the center atom could be $\mathrm{C}, \mathrm{Si}$, Ge etc.. Each branch in its turn contains further branch sites. In this example the degree of branch, $N_{B}$, is three. Each new layer of branches that is constructed upon the old branch points is called a generation $\mathrm{G}$; which starts numbering at 0 . Repetition of this branch-growing process, i.e. going to high generations, eventually will result in a highly branched molecule with an increasing number of end groups. As already shown in Figure 1, the end groups become more and more densely packed with each subsequent generation and the overall shape of the dendrimer becomes spherical, with all end groups residing on the outside of the molecule. 
Eventually, this process will result in surface congestion, which will prevent further growth from all branch points so that the growing process of dendrimers will be stopped.

Structure and properties of the dendrimer can be altered by changing the initiator core, initiator multiplicity $\mathrm{N}_{\mathrm{I}}$, the degree of branching $\mathrm{N}_{b}$, and the length 1 of the branch segments. Because the generation number at which surface congestion occurs will depend on these parameters. Thus by selecting the proper parameters one can design and synthesize a dendrimer of specific dimensions and properties.

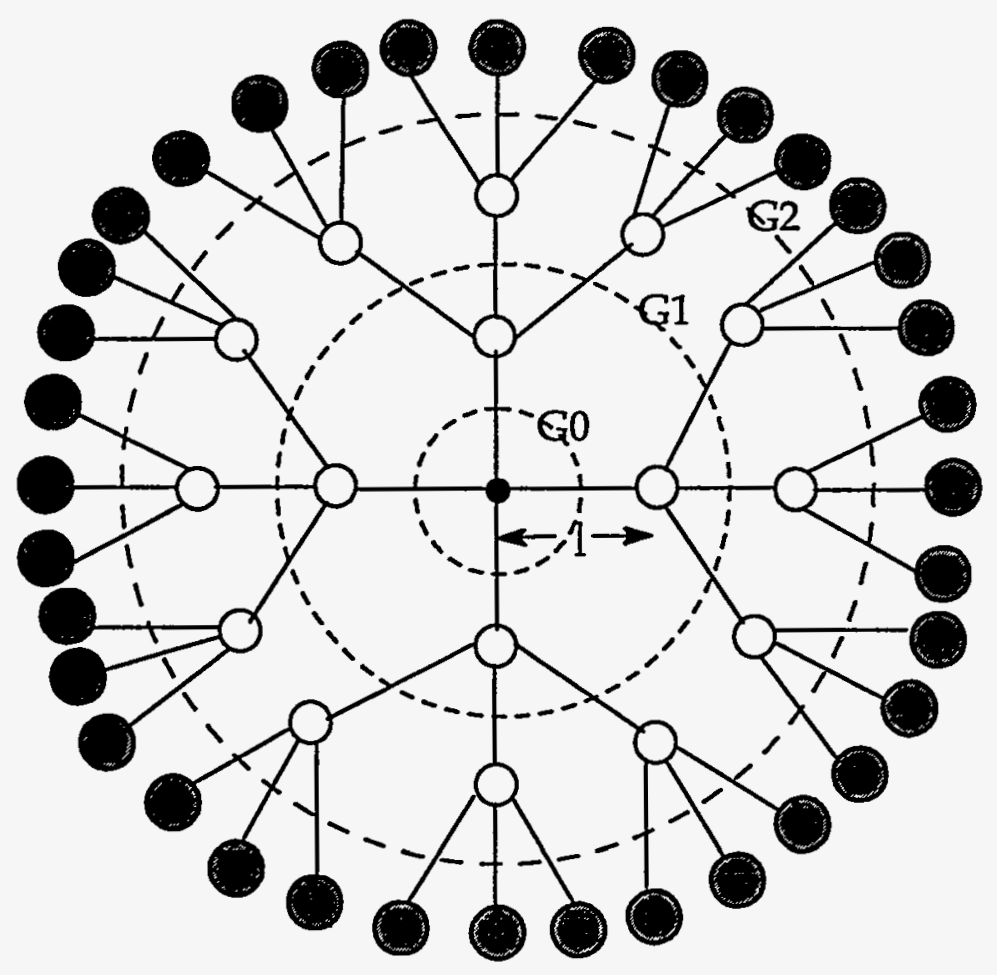

Figure. 1. Schematic structure of a typical dendrimer; $\bullet=$ initiator core from which four main branches emanate $\left(\mathrm{N}_{\mathrm{I}}=4\right), \quad=$ branch point $B$ from which three branches grow $\left(\mathrm{N}_{B}=3\right), Q$ =end group, l=length of a branch, $\mathrm{G}_{\mathrm{n}}=$ generation number. 
The second type of dendritic structure is the hyperbranched polymer, which was developed by Young H. Kim and Owen W. Webster at DuPont, ${ }^{8}$ and by other groups. ${ }^{3,9,10}$ This type of polymer also has a fractal pattern of chemical bonds, but its branches don't emanate from a central core, it can have either random or fairly regular architectures. In fact the structure of hyperbranched polymers is intermediate between those of linear polymers and dendrimers. ${ }^{3}$

An important difference between linear polymers and dendritic polymers is that a linear polymer consists of an entanglement of single molecular chains. In dendritic polymers, by contrast, the many branches give rise to a very high number of terminal functional groups in each molecule. Because of this specialty, dendritic molecules can be built with discrete domains having different properties. For example, a dendrimer can be designed to have large hydrophobic cavities in its interior and a hydrophilic surface, or vice versa.

Now the rapidly growing international community of researchers is exploring or developing a variety of uses for dendritic polymers. These include catalysts and reaction vessels, micelle mimics, magnetic resonance imaging agents, immuno-diagnostics, agents for delivering drugs or genes into cells, chemical sensors, information-processing materials, high performance polymers, adhesives and coatings, dental materials, separation media, and molecular antennae for absorbing light energy and funneling it to a central core. Researchers also are enthusiastic about using dendritic molecules as building blocks to synthesize even more complex supermolecules. 
Mechanical properties of dendritic polymers are usually inferior to those of the linear polymers. However, the employment of allyl carbosilane dendrimers as composite additives in siloxane rubbers (1-2\% of the rubber weight) has led to a $20 \%$ increase in the tensile strength and a twofold increase in the tear strength of the resultant material. ${ }^{11}$

Homogeneous catalysts based on silane dendrimer-functionalized arylnickel (II) complexes have been shown to be effective for Kharasch addition. ${ }^{12}$ With the precise sizes and shapes the dendrimer-based catalysts offer some advantages over conventional polymer-based catalysts as all the metal catalytic sites are exposed to the reagents and substrate, catalytic quality is easily controlled, and easy separation and recovery from the reaction mixture. Wells and Crooks covalently attached a fourth-generation poly(amidoamine)dendrimer having amine end groups to a self-assembled monolayer of mercaptoundecanoic acid on gold via amide bond formation. ${ }^{13}$ The dendrimer monolayers are suitable interfaces for chemical sensing applications because this system has some of the essential attributes of an ideal chemical sensor: the response to test chemicals is very rapid and typically is completely reversible, and the device has an excellent signal to noise ratio.

The potential of dendrimers as vessels or hosts for other molecules was first clearly demonstrated by Meijer and coworkers. ${ }^{14,15}$ They have presented evidence that a shape selective liberation of guests encapsulated in a dendritic box can be accomplished by a two-step process. Their dendritic boxes are constructed from a flexible poly(propylene imine) dendrimer with 64 amine end groups and an L-phenylalanine derivative. First, two guests that differ in size are encapsulated in the box, and dialysis is used to remove 
adhered and excess guest. Next, the shell is partially perforated, yielding a modified dendritic box in which only the larger guest is entrapped and from which the smaller guest is liberated. Subsequent removal of the shell liberates the larger guests, and the starting poly(propylene imine) dendrimer is recovered. Their results show that a pathway for finetuning is available.

With dendritic macromolecules, high molecular weight and a high level of structural control are possible with tremendous synthetic efficiency. Moore and coworkers have synthesized a large-size phenylacetylene dendrimer, with molecular diameter up to $12.5 \mathrm{~nm}^{16}$ They also synthesized a stiff dendritic macromolecule with a molecular weight in excess of $14 \mathrm{kDa}$, which is thought to be the largest pure hydrocarbon known. ${ }^{17}$ They are modifying these phenylacetylene-based dendrimers for a molecular light funneling device. ${ }^{18}$

There are two specific methods in the synthesis of dendritic polymers. The first one accomplishes the synthesis of regular dendritic polymers by successive, layer by layer, or controlled synthesis. These polymers are constructed in repeatable synthetic steps (repetitive synthesis strategy). Both divergent and convergent synthetic approaches have been employed ${ }^{8}$ in this method. The divergent approach begins with a poly-functional initiator core from which a number of branches are radiated outward. In the next step, the ends of the branches are functionalized and then act as reactive branch points from which new branches can be grown. In a subsequent step, these reactive branch points are reacted with new branches, the ends of which can be functionalized again, and so on. Thus in the divergent approach the dendrimer grows layer-by-layer from the "inside out". 
In essence, the convergent approach is the reverse of the divergent method: now the dendrimer grows from the "outside in". In both approaches it is essential that all reactions and transformations must proceed with very high selectivity and yield. The controlled synthesis method can produces well-defined, large dendritic molecules whose structures and properties can be altered by changing the center core or building block. It also allows functional group variation. Today most dendritic polymers are made by this synthetic strategy.

The second method includes uncontrolled synthesis, which is also called the "selfregulating" process (single synthesis strategy). This process involves polymerization of monomers containing at least three polymerizable functional groups. ${ }^{19}$ The highly branched polymers are obtained under the conditions of uncontrolled single-stage synthesis in which the initial monomers employed are compounds of the type A-R-B $(x \geq$ 2), where $A$ and $B$ are functional groups of two types, which under certain conditions enter into a polycondensation or polyaddition reaction with formation of $A-B$ bonds. Highly branched polyesters were prepared by condensation polymerization in a single step from aliphatic dihydroxy monoacids ${ }^{20}$ or by thermal self-condensation of $3,5-$ bis(trimethylsiloxy)benzoyl chloride. ${ }^{21}$ Zimmerman and coworkers prepared a wedge-like molecule with a dendritic tail and allowed six of these wedges to assemble themselves into a disk-shaped hydrogen-bonded aggregate, ${ }^{22}$ which has a $9 \mathrm{~nm}$ diameter and a $2 \mathrm{~nm}$ thickness. Its size and molecular mass (34,000 daltons) are comparable to that of small proteins. 
Silicon chemistry offers a number of reactions with quantitative yields, which are suitable for dendritical polymer synthesis, such as replacement of chlorines in alkylchlorosilanes by Grignard reagents or hydrosilation. The advantage of using silicon chemistry to synthesize dendritic polymers is that the electrophilic silicon ( $\left.\mathrm{Si}^{+}\right)$can be easily accessed by nucleophilic species. A few organosilicon dendritic polymers have been prepared. Dendrimers based upon siloxane chemistry were introduced first. Zhdanov and co-workers ${ }^{23}$ reacted $\mathrm{CH}_{3} \mathrm{SiCl}_{3}$ with $(\mathrm{EtO})_{2} \mathrm{CH}_{3} \mathrm{SiONa}$ and subsequently with $\mathrm{SOCl}_{2}$. By repetitive $(\mathrm{EtO})_{2} \mathrm{CH}_{3} \mathrm{SiONa}$ and $\mathrm{SOCl}_{2}$ reaction steps, the synthesis of a dendrimer containing 46 silicon atoms, 1 , was effected.

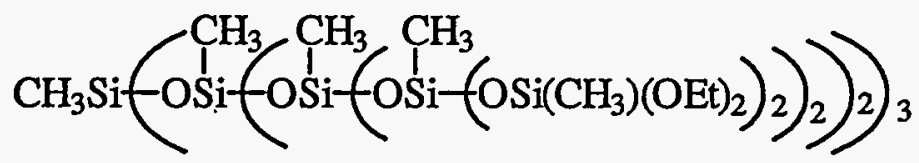

1

Masamune and co-workers ${ }^{24}$ prepared dendritic polysiloxanes that had a "coating" of Si-H groups, 2. Polysiloxane dendrimers containing $\mathrm{Si}-\mathrm{H}$ end groups were also reported by Mathias and Carothers. ${ }^{25}$ In their synthesis $\mathrm{CH}_{2}=\mathrm{CHCH}_{2} \mathrm{Si}\left(\mathrm{OSi}\left(\mathrm{CH}_{3}\right)_{2} \mathrm{H}\right)_{3}$ was polymerized by stirring it with a platinum catalyst. Although this reaction has the advantage of being basically a one-pot procedure, the molecular weight distribution and uniformity of branching could not be strictly controlled. A similar polysiloxane, 3, was prepared by Morikawa et al. ${ }^{26}$ 


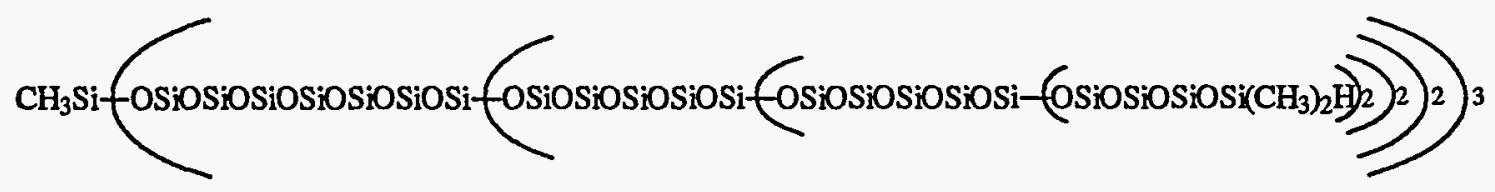

2 (interior silicon atoms have attached methyl groups)

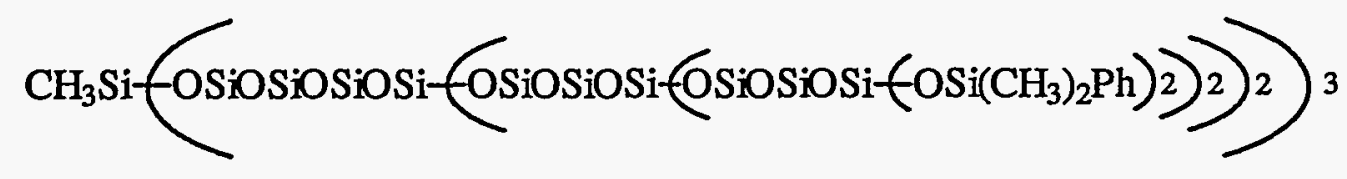

3 (interior silicon atoms have attached methyl groups)

Carbosilane dendrimers consist of alkyl groups linked to silicon atoms, that represent the branching points for the following generation. Using tetraallylsilane as a core, van der Made and van Leeuwen ${ }^{27}$ applied hydrosilylation and allylation steps to grow dendrimer 4 (Scheme 1). Roovers et al. ${ }^{28}$ carried out a similar synthesis using tetravinylsilane as the core molecule and methyldichlorosilane in the hydrosilylation step. Dendrimers up to the fourth generation with well-defined 32- and 64-arm were prepared. In further studies, ${ }^{28 \mathrm{C}}$ dendrimers with 64 and 128 surface $\mathrm{Si}-\mathrm{Cl}$ bonds were used as coupling reagents for monodisperse poly(butadienyl)lithium. Two series star polybutadienes with 64 and 128 arms were prepared. The arm molecular weight was between 6400 and 72,000 .

A dendrimer containing $324 \mathrm{Si}-\mathrm{H}$ bonds was synthesized by Seyferth and Son. ${ }^{29}$ Starting with tetravinylsilane as the core molecule, a succession of alternate Pt-catalyzed hydrosilylations of all vinyl groups with $\mathrm{HSiCl}_{3}$ and vinylations of all the $\mathrm{SiCl}$ groups thus 


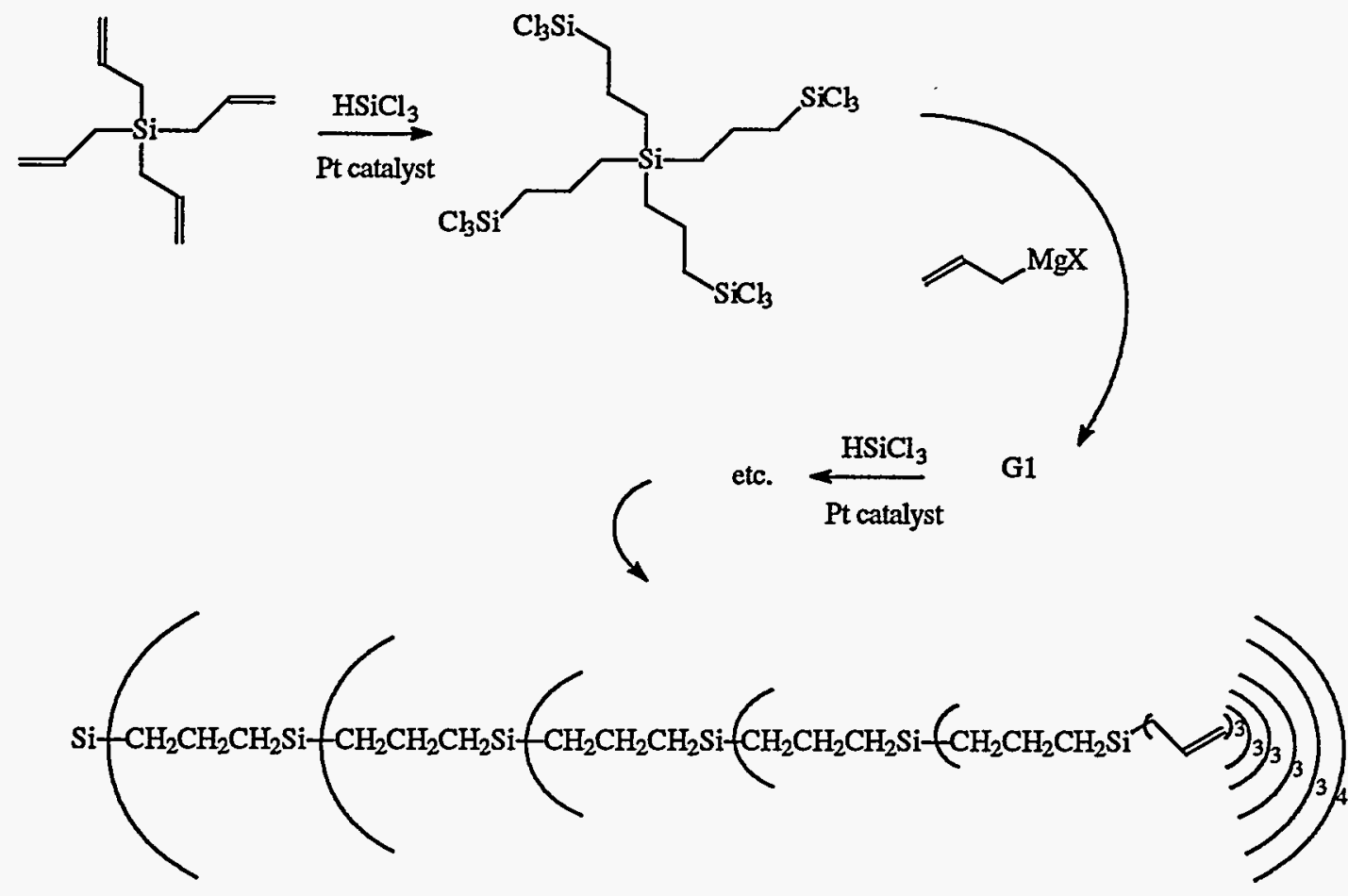

4

Scheme 1

introduced with $\mathrm{CH}_{2}=\mathrm{CHMgBr}$ in THF provided a divergent synthesis of four generations of polycarbosilane dendrimers in which the $\mathrm{Si}$ atoms are linked by $\mathrm{CH}_{2} \mathrm{CH}_{2}$ group. The chlorosilane of each generation was reduced with $\mathrm{LiAlH}_{4}$ to the corresponding silicon hydride. In further studies, ${ }^{30}$ they prepared small (first- and second-generation) dendrimers ( $\left.\mathrm{Si}\left[\mathrm{CH}_{2} \mathrm{CH}_{2} \mathrm{SiMe}_{2} \mathrm{C}=\mathrm{CH}\right]_{4}, 5 ; \mathrm{Si}_{2} \mathrm{CH}_{2} \mathrm{CH}_{2} \mathrm{SiMe}(\mathrm{C} \equiv \mathrm{CH})_{2}\right]_{4}, \mathbf{6}$; $\mathrm{Si}\left[\mathrm{CH}_{2} \mathrm{CH}_{2} \mathrm{Si}\left(\mathrm{CH}_{2} \mathrm{CH}_{2} \mathrm{SiMe}_{2} \mathrm{C} \equiv \mathrm{CH}\right)_{3}\right]_{4}, 7$ ) that contain peripheral ethynyl groups. 
Reaction of $\mathrm{Co}_{2}(\mathrm{CO})_{8}$ with all the $\mathrm{C} \equiv \mathrm{CH}$ groups in 5 and 7 gave the corresponding acetylenedicobalt hexacarbonyl complexes.

Treating chlorosilane dendrimers with ferrocenyllithium, or $\beta$-aminoethylferrocene, Cuadrado and coworkers have synthesized a novel family of ferrocenyl-containing organosilicon dendrimers. ${ }^{31}$ By quantitative hydroboration of carbosilane dendrimers with allyl end groups, dendritic polyols were synthesized. ${ }^{32}$ The novel polyols bear up to 108 hydroxyl groups on the surface.

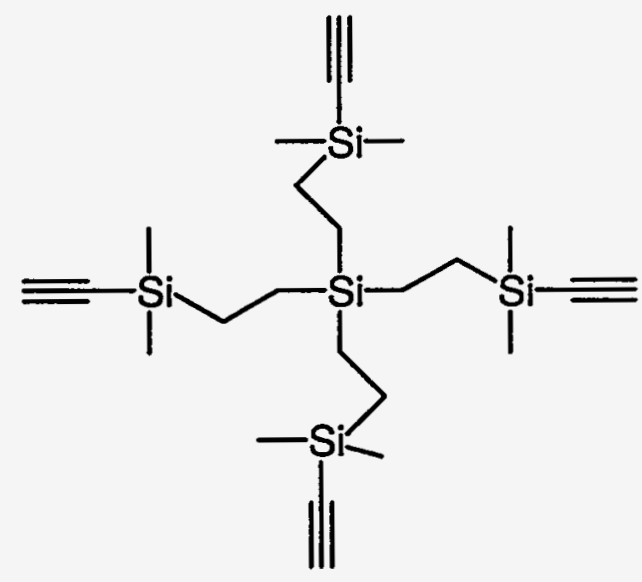

5

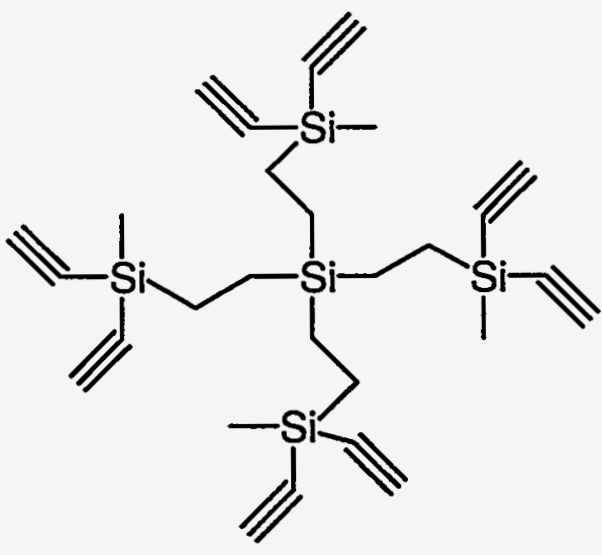

6

$\left[\left(\mathrm{Me}_{3} \mathrm{Si}_{3}\right)_{3} \mathrm{SiSiMe}_{2}\right]_{3} \mathrm{SiMe}, 8$, the first polysilane dendrimer, was synthesized by Lambert and coworkers. ${ }^{33}$ In further studies,${ }^{34}$ several first-generation dendritic polysilane were synthesized. Crystal structures have been obtained for three such molecules in which the core silicon is bonded to three silicon and each polysilyl wing branches once(one dendrimer generation). Despite having no all-anti pathway, these dendrimers show long- 

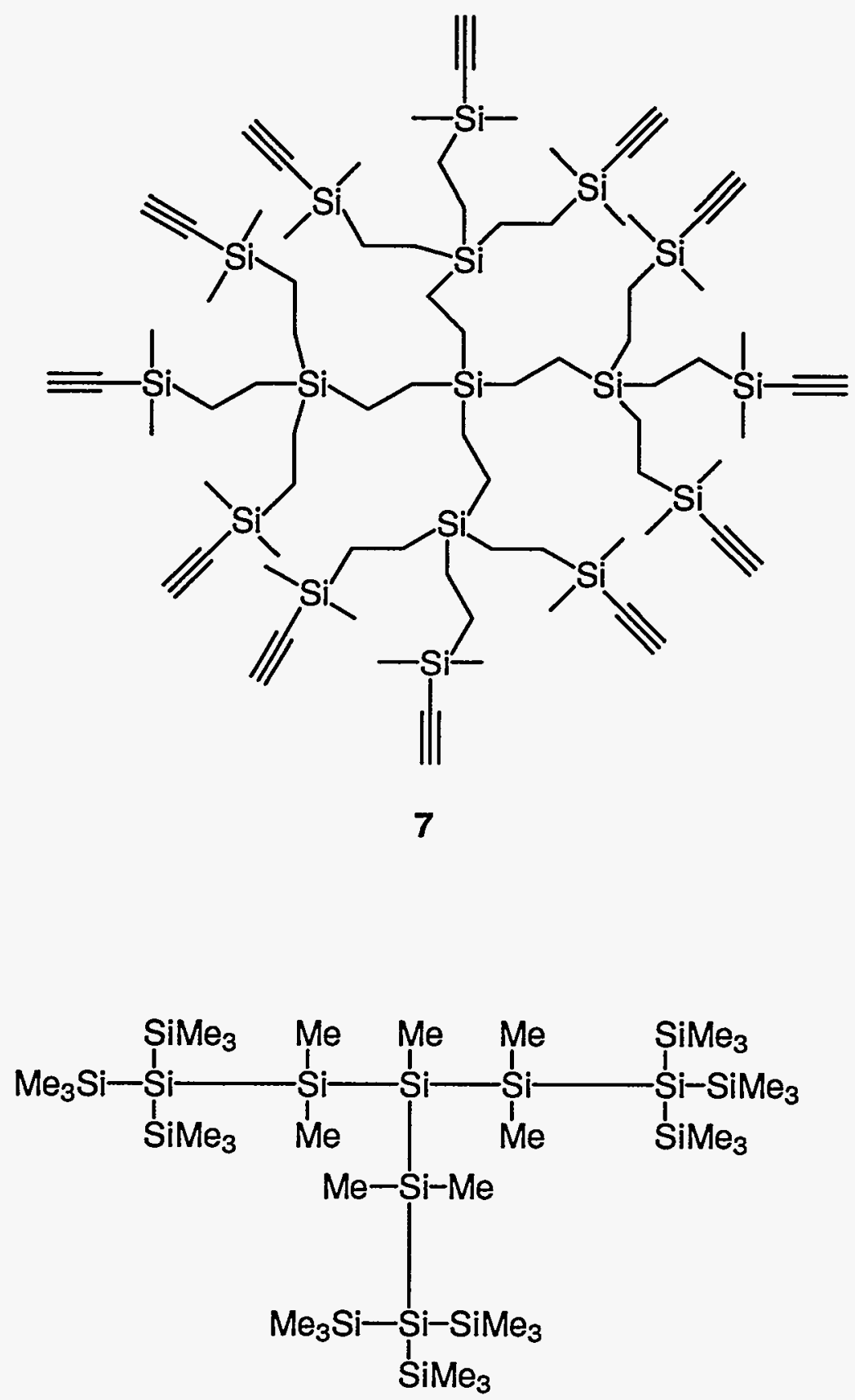

8 
wavelength ultraviolet absorption. Because of the multiplicity of polysilane pathways, the ultraviolet absorption is intense, in one case one order of magnitude higher than for a comparable linear polysilane. The dendrimers are nonfluorescent at room temperature. Sekiguchi and coworkers ${ }^{35}$ synthesized polysilane dendrimers up to the second generation with a molecular weight of 1832.9. Polysilane dendrimer, [2,2-( $\left.\left.\mathrm{Me}_{3} \mathrm{Si}_{2}\right)_{2} \mathrm{Si}_{3} \mathrm{Me}_{5}\right]_{3} \mathrm{SiMe}$, was reported by Suzuki and coworkers. ${ }^{36}$

Introduction of some unsaturated functionalities in the dendritic polymer, might make it easier to be further cross-linked in making adhesive and other kind of high performance materials. This section of the thesis is devoted to the synthetic studies of this type of dendritic polymers including the first synthesis of novel silylene-vilylene dendrimers.

\section{Results and Discussion}

Synthesis of silylene-vinylene dendrimers

To our knowledge, there is no report on the synthesis of carbosilane dendritic polymers which contain unsaturated bonds inside the macromolecules. The presence of unsaturation in the polymer chain should allow for relatively low temperature crosslinking. For silylene-vinylene dendrimers, which have a lot of terminal acetylene groups on the outside and a lot of unsaturated bonds inside the molecule, they should be easily to further polymerize. This process should produce little dimensional change because of both inside cross-linking and outside surface congestion. This is essential for making dental materials and some other special materials. 
A divergent, controlled step growth approach was used in this first synthesis of silylene-vinylene dendrimers. In order to introduce unsaturated bonds in the dendritic polymers, tetraethynylsilane was chosen as the initial core molecule. There are some reports on the synthesis of tetraethynylsilane. In one method $\mathrm{SiCl}_{4}$ was reacted with $\mathrm{NaC} \equiv \mathrm{CH}$ to afford tetraethynylsilane in less than $1 \%$ yield. ${ }^{37}$ Another report used $\mathrm{SiCl}_{4}$ to react with $\mathrm{ClMgC} \equiv \mathrm{CH}$ to afford tetraethynylsilane in a yield of $17 \%$, but no experiment details were given. ${ }^{38}$ As shown in Scheme 2, our synthesis started with the exhaustive ethynylation of tetrachlorosilane with three fold excess of ethynylmagnesium chloride in THF at $0^{\circ} \mathrm{C}$ to produce tetraethynylsilane (G0) in a yield of $46 \%$. The ethynyl groups of tetraethynylsilane were then hydrosilated with methyldichlorosilane in the presence of chloroplatinic acid (CPA) as catalyst to generate $\mathrm{G1}-\mathrm{Cl}$ with 8 silicon chloride functional groups. All the silicon chloride groups were then reacted with ethynylmagesium chloride to give the first generation with eight ethynyl groups connecting to four silicon atoms (G1).

The hydrosilylation reaction, an addition reaction of a Si-H group to a carboncarbon unsaturated bond, found its first application as early as $1957 .^{39}$ It has proved to be a very convenient method for forming silicon-carbon bonds. Using chloroplatinic acid as the hydrosilylation catalyst, the reaction can be stopped at the vinylsilane, because a triple bond is more reactive than a double bond to hydrosilylation. The direct hydrosilylation of tetraethynylsilane with dichloromethylsilane was carried out in THF at room temperature for 1 hour first, then the reaction mixture was slowly heated to $55^{\circ} \mathrm{C}$ and was stirred at $55^{\circ}$ for 4 hours under argon with CPA catalyst. A sealed flask was used in this reaction, 


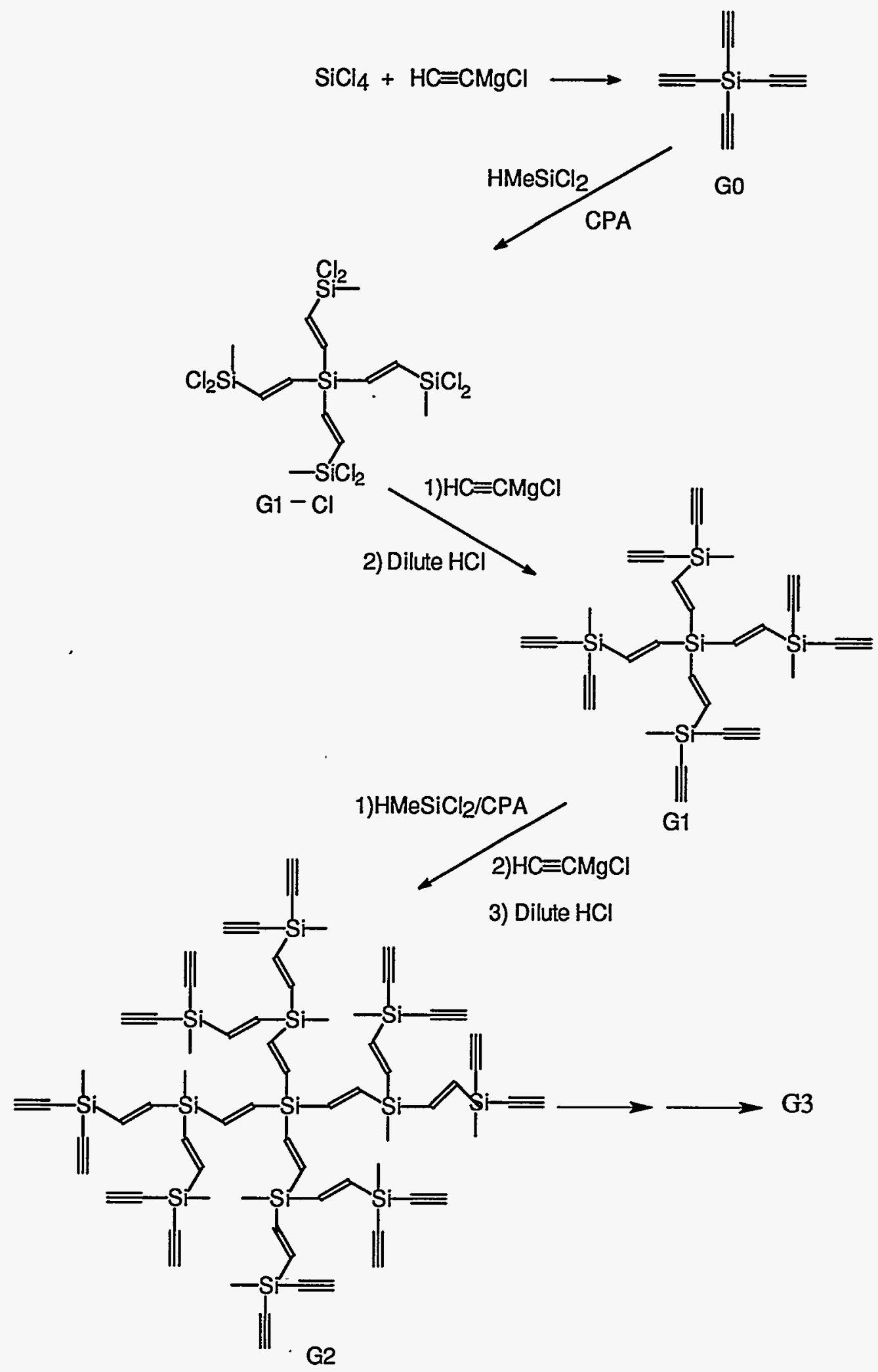

Scheme 2 


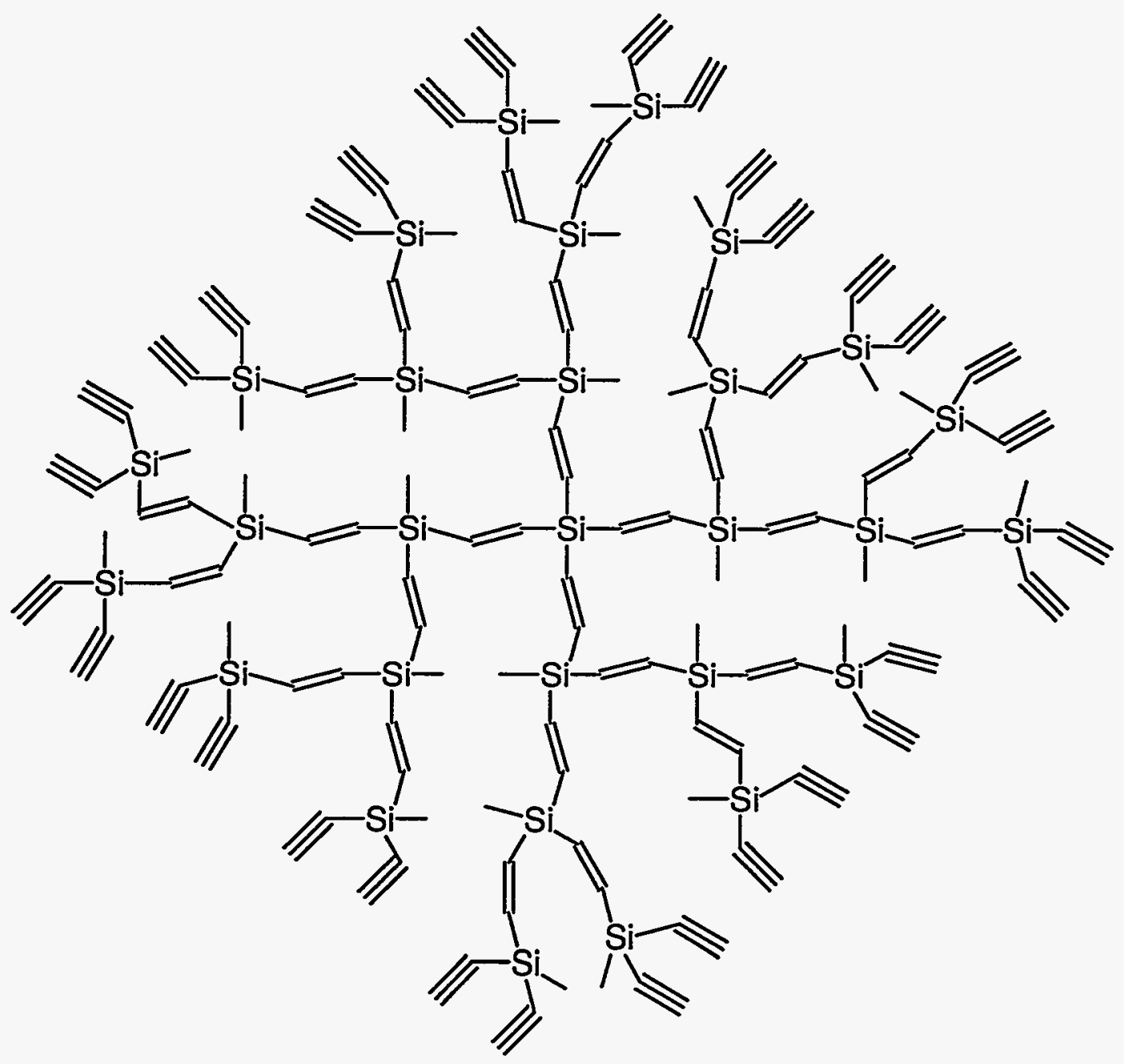

G3

because the tetraethynylsilane has high vapor pressure and is sublimed at room

temperature. Both dichloromethylsilane and anhydrous THF were distilled immediately before use. Excess dichloromethylsilane was used to enhance completion of the reaction. The reaction is very exothermic. Some times an ice bath was used to cool a large scale 
synthesis at the beginning of the reaction. The degree of completion of the reaction and the formation of side products were monitored by ${ }^{1} \mathrm{H}-\mathrm{NMR}$ and ${ }^{13} \mathrm{C}-\mathrm{NMR}$. Very symmetric spectra of the products were obtained. Incomplete reactions and structural defects would destroy the spectral symmetry.

The conversion of silyl chlorides to ethynyl silanes was performed by reacting the hydrosilylation product with ethynylmagesium chloride in THF. After the hydrosilylation, the excess dichloromethylsilane and solvent were removed under vacuum. The isolated product was redissolved in anhydrous THF. Then this solution was added slowly to a ethynylmagnesium chloride/THF solution at room temperature. The reaction mixture was stirred at room temperature for 1 day. Dilute $\mathrm{HCl}$ solution (2M) was used for work up. Hexanes were used to extract the products. After the remaining reagents were removed through evaporation, the final products were purified by flash column chromatography on regular silica gel columns eluted with a solution of hexane/ethyl acetate (ratio: 4 to 1). The isolated yield were $73 \%, 80 \%$ and $76 \%$ for G1, G2, and G3 respectively. Each final product showed a single spot on TLC plates developed by hexane-ethyl acetate mixtures (ratio: 4 to 1). The $\mathrm{G} 1$ and $\mathrm{G} 2$ were white solids, but $\mathrm{G} 3$ was oily product, containing an unassigned peak in ${ }^{1} \mathrm{H}-\mathrm{NMR}$ at $1.404 \mathrm{ppm}$ and an unassigned peak in ${ }^{13} \mathrm{C}-\mathrm{NMR}$ at 30.28 ppm. Attempted preparations of G4-Cl and G4 were tried, but without success. An oily G4-Cl product was synthesized. The NMR spectra revealed that there were no alkynyl groups left, but a lot of unassigned peaks were present. After ethynylation with ethynylmagnesium chloride, and purification by flash column chromatography, an oily 
product was obtained. Its ${ }^{1} \mathrm{H}-\mathrm{NMR}$ and ${ }^{13} \mathrm{C}-\mathrm{NMR}$ spectra contained many peaks which could not be assigned.

As shown in Scheme 3, attempts to use trichlorosilane as the hydrosilylation reagent for synthesis of dendrimers failed. First, trichlorosilane was used to directly hydrosilylate $\mathrm{G} 0$ to make a first generation. The products always contained some unassigned peaks in their ${ }^{1} \mathrm{H}-\mathrm{NMR}$ and ${ }^{13} \mathrm{C}-\mathrm{NMR}$ spectra. Different methods of purification, such as flash column chromatography and crystallization, have been tried, but none worked. Next dendrimer $\mathrm{G} 1$ and dendrimer $A$ were synthesized, and trichlorosilane was used to hydrosilylate in the next step. The same problem happened again. This is likely because steric congestion in the periphery hindered complete reaction. There are a lot of unsaturated double bonds in the interior structure of dendrimers, so cross-linking reactions were likely happened.

Hydrosilylation of $\mathrm{G} 1$ with dimethylchlorosilane, followed by treatment of the resulting adduct with $\mathrm{HC} \equiv \mathrm{CMgCl}$ gave dendrimer $\mathrm{A}$ in $76 \%$ yield (Scheme 4). Alternatively, hydrosilylation with methyldichlorosilane followed by reaction with $\mathrm{HC} \equiv \mathrm{CMgCl}$ gave dendrimer $\mathrm{B}$ in $55 \%$ yield. Dendrimer B contains 16 peripheral ethynyl groups, the same number as dendrimer $\mathrm{G} 2$. Then hydrosilylation of dendrimer B with dimethylchlorosilane followed by reaction with $\mathrm{HC} \equiv \mathrm{CMgCl}$ gave dendrimer $\mathrm{C}$ in $44 \%$ yield. Attempted hydrosilylations of dendrimer $\mathrm{C}$ with methyldichlorosilane followed by reaction with $\mathrm{HC} \equiv \mathrm{CMgCl}$ were tried without success. The final products contained a lot of unassigned peaks in their NMR spectra. Flash column chromatography and crystallization methods were tried to purify the product, none worked. Dendrimers A, B, 


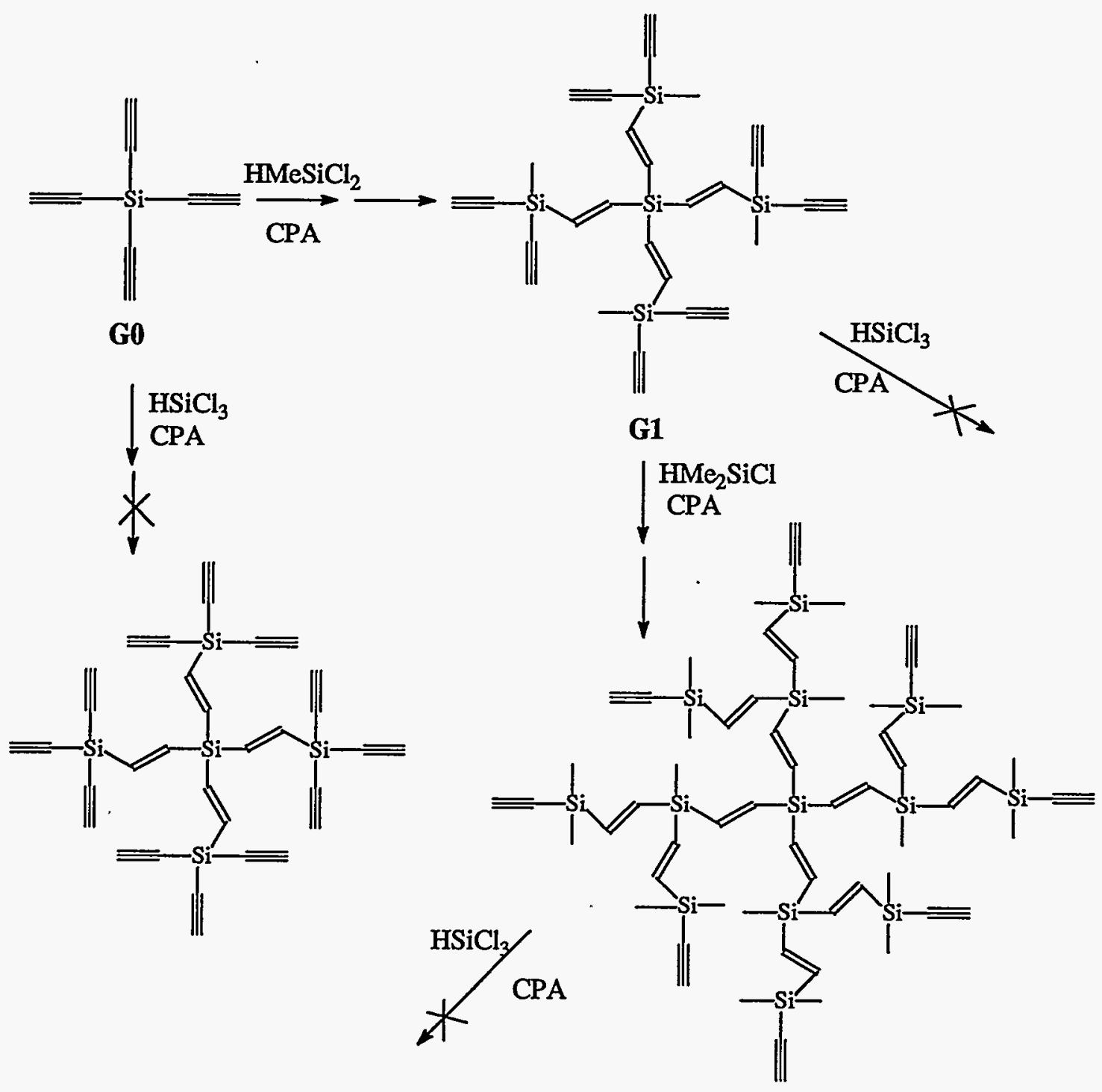

$\mathbf{A}$

Scheme 3

and $\mathrm{C}$ are all solid products. All of the dendrimers exhibited ready solubility in a wide range of solvents including hexane, diethyl ether, THF, chloroform, acetonitrile, ethyl 

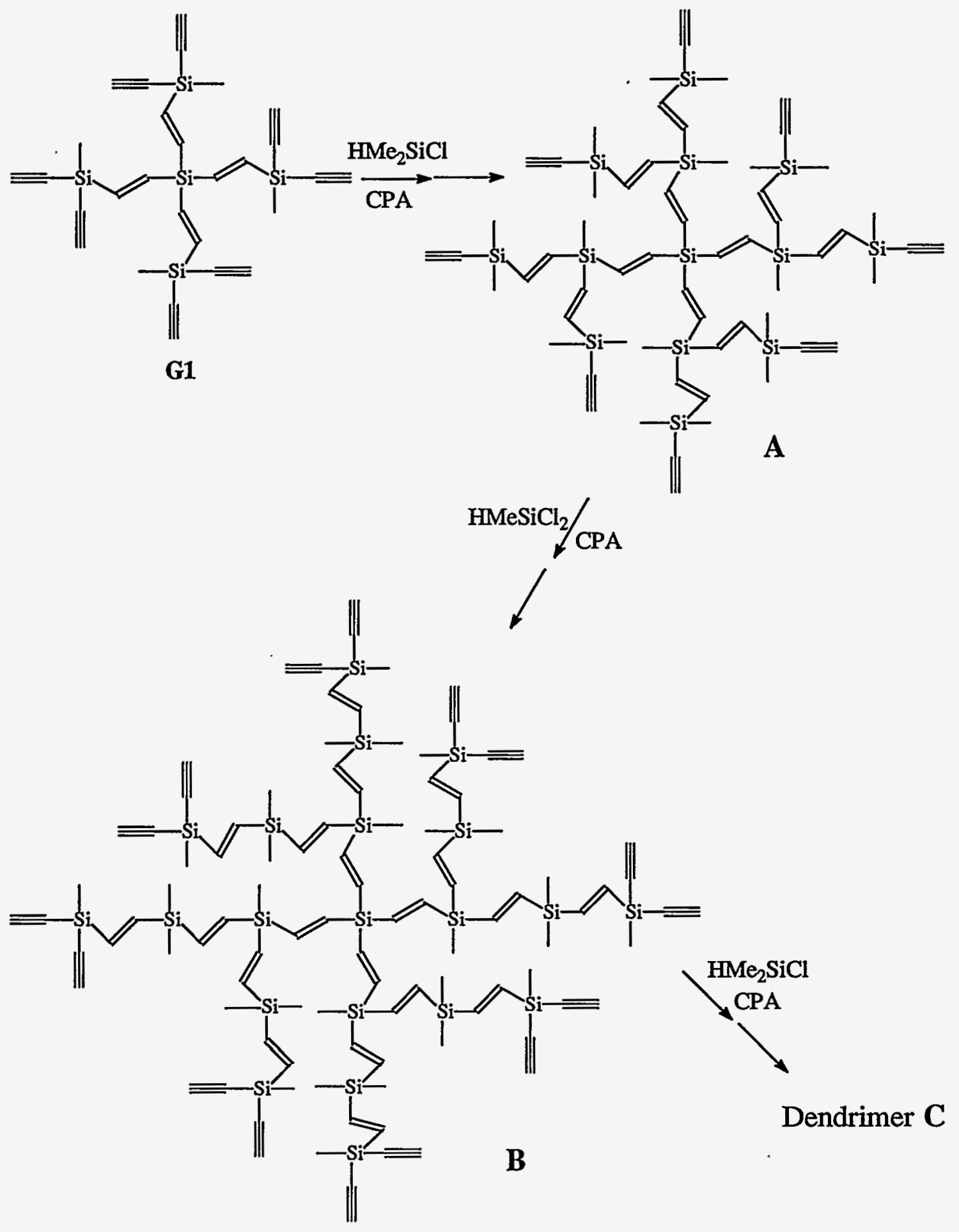

Scheme 4 


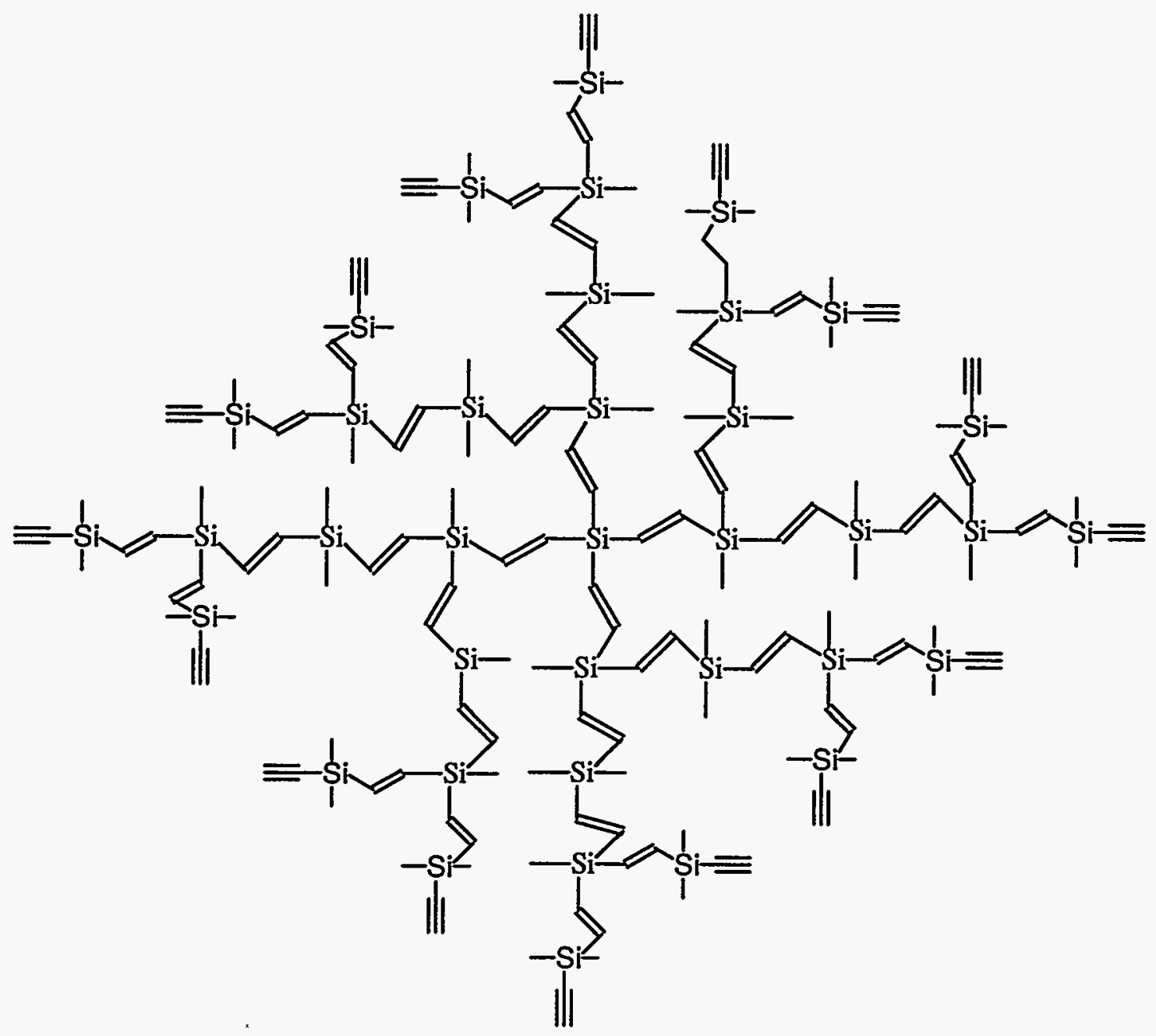

Dendrimer C

acetate and dimethylformamide. The molecular information for all the dendrimers are summarized in Table 1.

As mentioned above, in each step of synthesis only perfect growth and pure products give simple, symmetric, and well-defined NMR spectra. For each generationthere are three types of hydrogens and carbons. The exterior alkynyl protons and carbons are quite easily distinguished in both the proton and carbon NMR spectra. 
Table 1 Molecular information for silylene-vinylene dendrimers

Dendrimer Formula $\quad \mathrm{FM} \quad \mathrm{MW}_{\text {obs }}$ Ethynyl groups m.p. $\left({ }^{\circ} \mathrm{C}\right)^{i}$ Yield (\%)

\begin{tabular}{ccccccc}
\hline $\mathrm{G} 1$ & $\mathrm{C}_{28} \mathrm{H}_{28} \mathrm{Si}_{5}$ & 504.96 & 504.2 & 8 & $85.5-86.5$ & 73 \\
$\mathrm{G} 2$ & $\mathrm{C}_{68} \mathrm{H}_{76} \mathrm{Si}_{13}$ & 1258.46 & 1258.6 & 16 & $112.5-113.5$ & 80 \\
$\mathrm{G} 3$ & $\mathrm{C}_{148} \mathrm{H}_{172} \mathrm{Si}_{29}$ & 2765.47 & $\mathrm{~N} \mathrm{~A}$ & 32 & oily & 76 \\
$\mathrm{~A}$ & $\mathrm{C}_{60} \mathrm{H}_{92} \mathrm{Si}_{13}$ & 1178.5 & 1178.7 & 8 & $107.5-108.5$ & 76 \\
$\mathrm{~B}$ & $\mathrm{C}_{100} \mathrm{H}_{140} \mathrm{Si}_{21}$ & 1932.0 & 1946 & 16 & $94-95$ & 55 \\
$\mathrm{C}$ & $\mathrm{C}_{164} \mathrm{H}_{268} \mathrm{Si}_{37}$ & 3279.1 & 3323.7 & 16 & $54-55$ & 44 \\
\hline
\end{tabular}

The methyl groups which are attached to silicons are also easily recognized in the spectra. Only the vinyl groups give a more complex spectrum, but it is not difficult to distinguish them in the proton and carbon spectra.

As shown in Figure 2, the ${ }^{1} \mathrm{H}$ spectrum of $\mathrm{G} 1$ shows an alkynyl proton at 2.55 $\mathrm{ppm}$. The methyl group give a single peak at $0.43 \mathrm{ppm}$. The two vinyl protons split each other to give a double peaks at 6.60 and $6.96 \mathrm{ppm}$. The spin-coupling constant is $22 \mathrm{~Hz}$, which indicates that the two protons are in trans positions. This means the CPA catalytic hydrosilylation of tetraethynysilane is a cis-addition reaction. For G2, the single alkynyl proton is at $2.54 \mathrm{ppm}$. There are also two single peaks (ratio 1 to 2 ) for the two methyl groups, the one at $0.30 \mathrm{ppm}$ is for interior methyl groups, and the other at $0.42 \mathrm{ppm}$ is for 

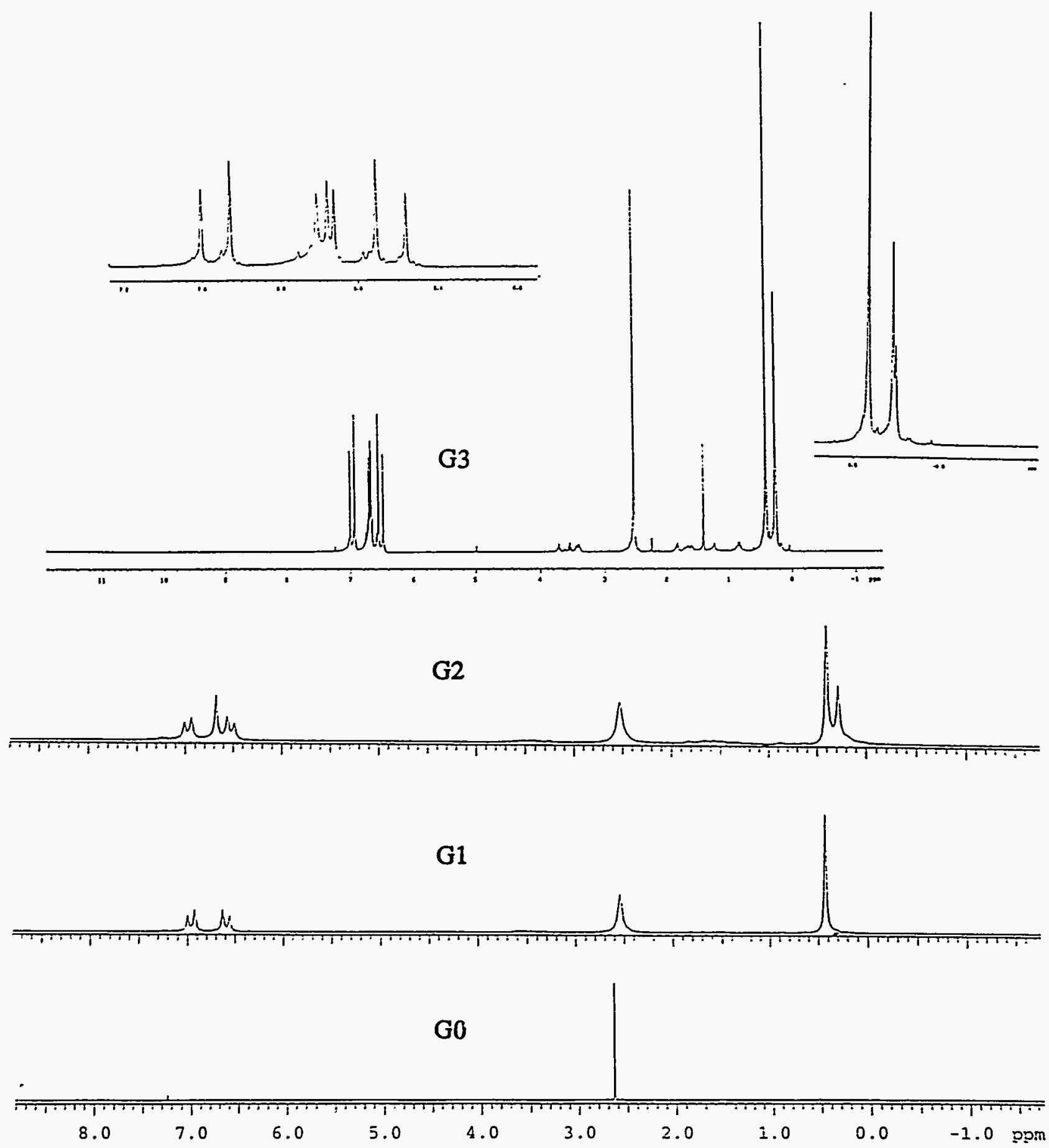

Figure 2 The ${ }^{1} \mathrm{H}-\mathrm{NMR}$ spectra of G0, G1, G2 and G3. 
exterior methyl groups. This indicates that the methyl groups near the central core are further upfield. There are two kinds of vinyl groups, the protons of interior vinyl groups give a single broad peak, the two protons of exterior vinyl groups split each other into doublets whose coupling constant is $22 \mathrm{~Hz}$. For G3, the single alkynyl proton is at 2.53 $\mathrm{ppm}$. The three single peaks for the three kinds of methyl groups are at $0.251,0.267$ and $0.410 \mathrm{ppm}$. Their ratio is $1: 2: 4$. This indicates again that the methyl groups near the central core are further upfield. G3 has three vinyl groups. The two protons of exterior vinyl groups split each other into doublets whose coupling constant is $22 \mathrm{~Hz}$. The two protons of the middle vinyl groups show two single broad peaks which are at 6.662 and $6.707 \mathrm{ppm}$. The protons of the interior vinyl groups show only one single broad peak. A small single peak (at $1.404 \mathrm{ppm}$ ) is unassigned.

The proton spectra of dendrimers A, B, and C are shown in Figure 3. For dendrimers $\mathrm{A}$ and $\mathrm{C}$, the peripheral ethynyl groups are connected to dimethylsilane, their ${ }^{1} \mathrm{H}$-NMR spectra are near 2.4 ppm, which are slight different from B, G1, G2 and G3, whose ethynyl groups are connected to methylsilane, and the chemical shifts are about 2.5 ppm. For dendrimer A, the two kinds of methyl groups only show a single peak at 0.24 ppm. The vinyl groups are similar to $\mathrm{G} 2$, the protons of interior vinyl groups give a single broad peak, the two protons of exterior vinyl groups split each other into doublets, whose coupling constant $(J)$ is $21 \mathrm{~Hz}$. For dendrimer B, the three kinds of methyl groups show three single peaks which are at $0.15,0.22$ and $0.44 \mathrm{ppm}$. Their ratio is $4: 1: 2$. The exterior methyl groups are further downfield, the interior methyl groups are in the middle, and the methyl groups of dimethylsilane are further upfield. The two protons of exterior 


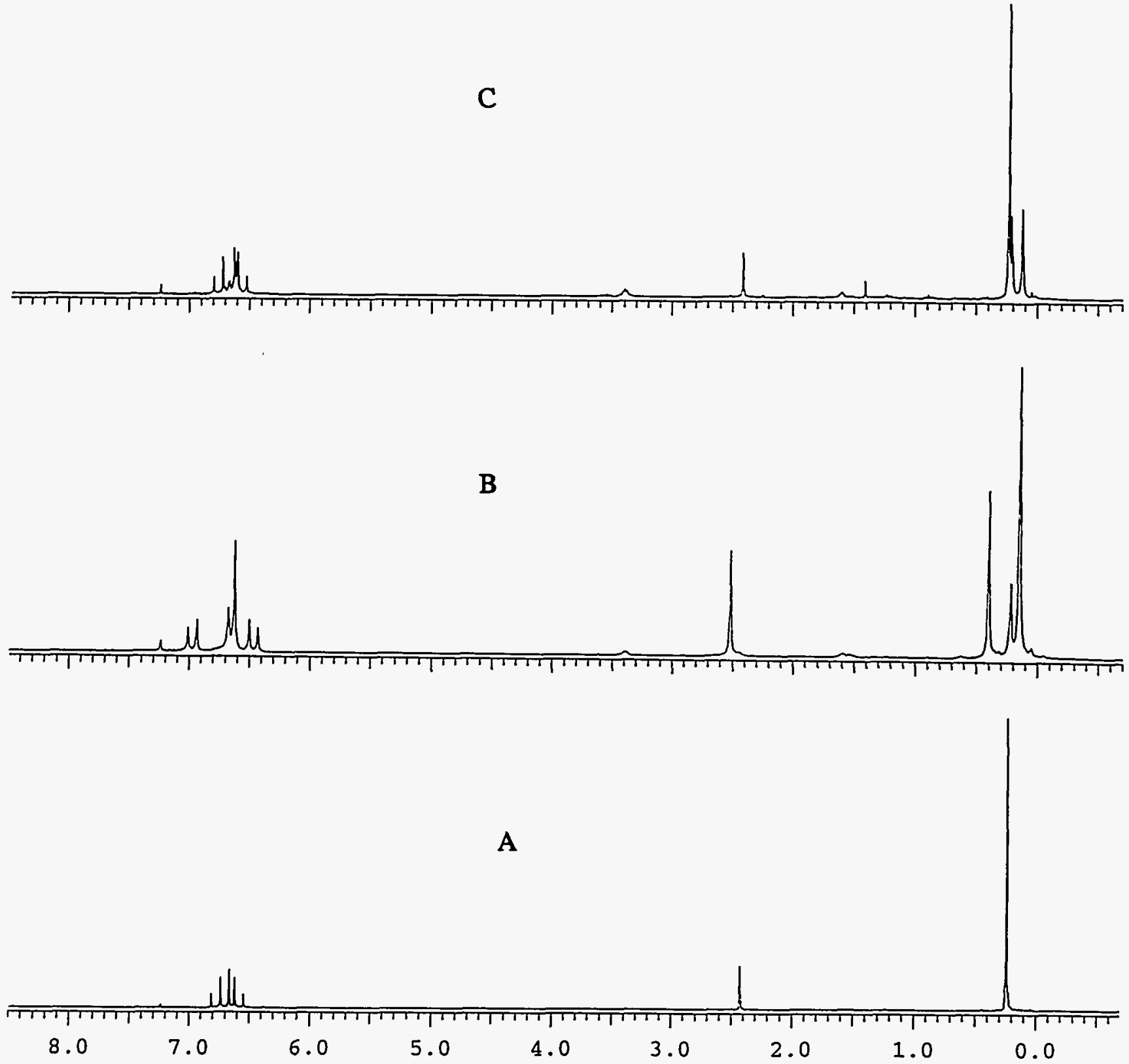

Figure 3. ${ }^{1} \mathrm{H}-\mathrm{NMR}$ spectra of dendrimers $\mathrm{A}, \mathrm{B}$, and C 
vinyl groups split each other into doublets whose coupling constant is $21 \mathrm{~Hz}$. The two kinds of interior vinyl groups show two single peaks which are at 6.62 and $6.68 \mathrm{ppm}$. The vinyl groups near the central core are further downfield (at $6.68 \mathrm{ppm}$ ). For dendrimer $\mathrm{C}$, the four kinds of methyl groups only show three single broad peaks. The downfield large broad peak (at $0.24 \mathrm{ppm}$ ) is from the exterior methyl groups. As we know, the exterior methyl groups of both dendrimer $\mathrm{A}$ and $\mathrm{C}$ come from dimethylsilane, their signals are very strong. Overlap may happen, which makes it resonable for less peaks to be observed. There are four kinds of vinyl groups, which show multiplet peaks from 6.52 to $6.79 \mathrm{ppm}$. The ${ }^{13} \mathrm{C}$-NMR spectra of $\mathrm{G} 0, \mathrm{G} 1, \mathrm{G} 2$ and $\mathrm{G} 3$ are shown in Figure 4. The ${ }^{13} \mathrm{C}$ NMR spectra of dendrimers A, B, and C are shown in Figure 5. All of the dendrimers have very similar ${ }^{13} \mathrm{C}$-NMR spectra. The two alkynyl carbons are found at 80.1 and 96.2 ppm for G0; about 84.5 and $95.5 \mathrm{ppm}$ for $\mathrm{G} 1, \mathrm{G} 2, \mathrm{G} 3$, and $\mathrm{B}$, in which the terminal alkynyl groups connected to methylsilane; about 88.2 and $94.4 \mathrm{ppm}$ for $\mathrm{A}$ and $\mathrm{C}$, in which the ending alkynyl groups connected to the dimethylsilane. The methyl carbons are at $1.38 \mathrm{ppm}$ for $\mathrm{G} 1$, at -5.43 and $-1.30 \mathrm{ppm}$ for $\mathrm{G} 2$, at $-5.35,-4.61$, and $-1.30 \mathrm{ppm}$ for $\mathrm{G} 3$, at $-5.26,-1.66 \mathrm{ppm}$ for $\mathrm{A}$, at $-4.93,-3.4$, and $-1.33 \mathrm{ppm}$ for $\mathrm{B}$, at $-5.36,-4.91,-3.17,-3.10$ and $-1.67 \mathrm{ppm}$ for $\mathrm{C}$. The exterior methyl carbons of dendrimer $\mathrm{G} 1, \mathrm{G} 2, \mathrm{G} 3$ and $\mathrm{B}$ which are from methylsilane are downfield at about $-1.3 \mathrm{ppm}$. The exterior methyl carbons of dendrimer $\mathrm{A}$ and $\mathrm{C}$ which are from dimethylsilane are downfield at $-1.66 \mathrm{ppm}$. The vinyl carbons are slightly more complicated, but still can be distinguished. The two carbons of the same vinyl group show very symmetrical spectra. For G3, only one peak at $30.28 \mathrm{ppm}$ is unassigned. For other dendrimers, all the peaks are easily assigned. As the dendrimer 


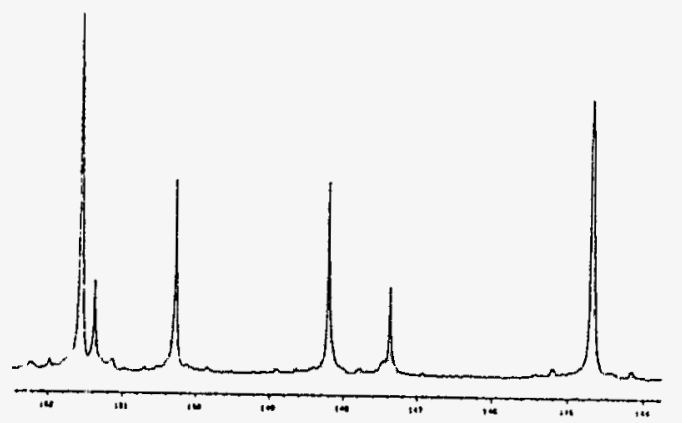

G3

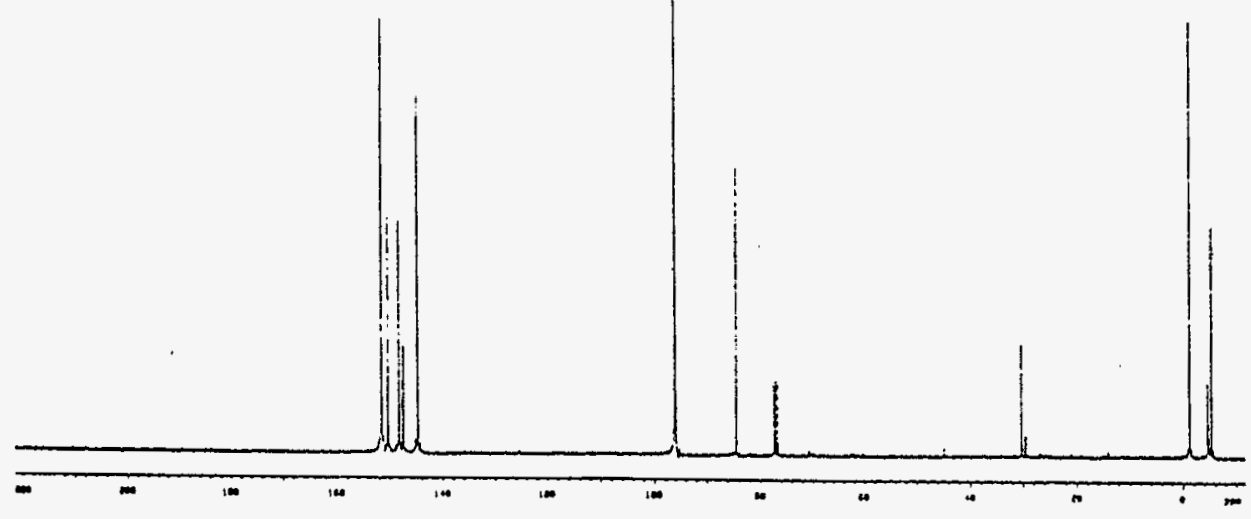

G2

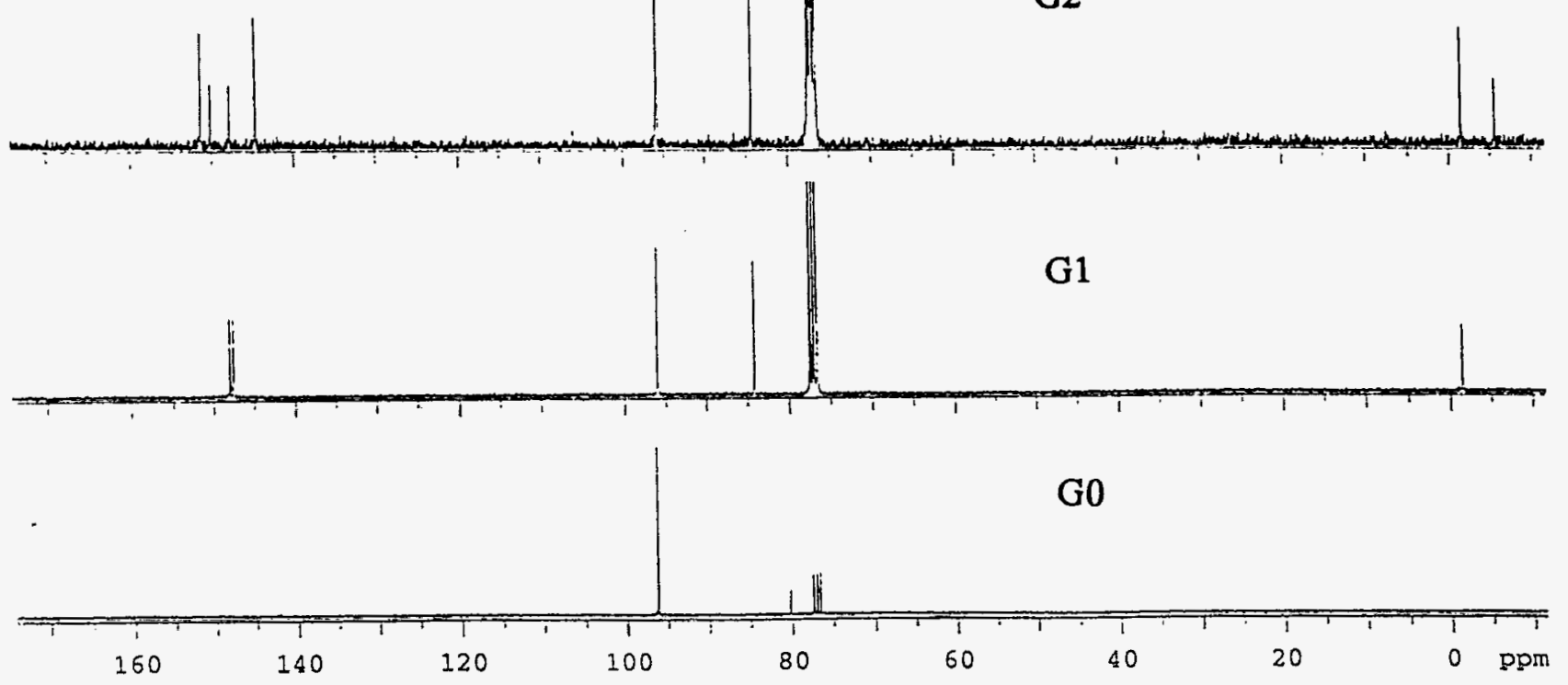

Figure $4 .{ }^{13} \mathrm{C}$-NMR spectra of dendrimers $\mathrm{G} 0, \mathrm{G} 1, \mathrm{G} 2$ and $\mathrm{G} 3$ 

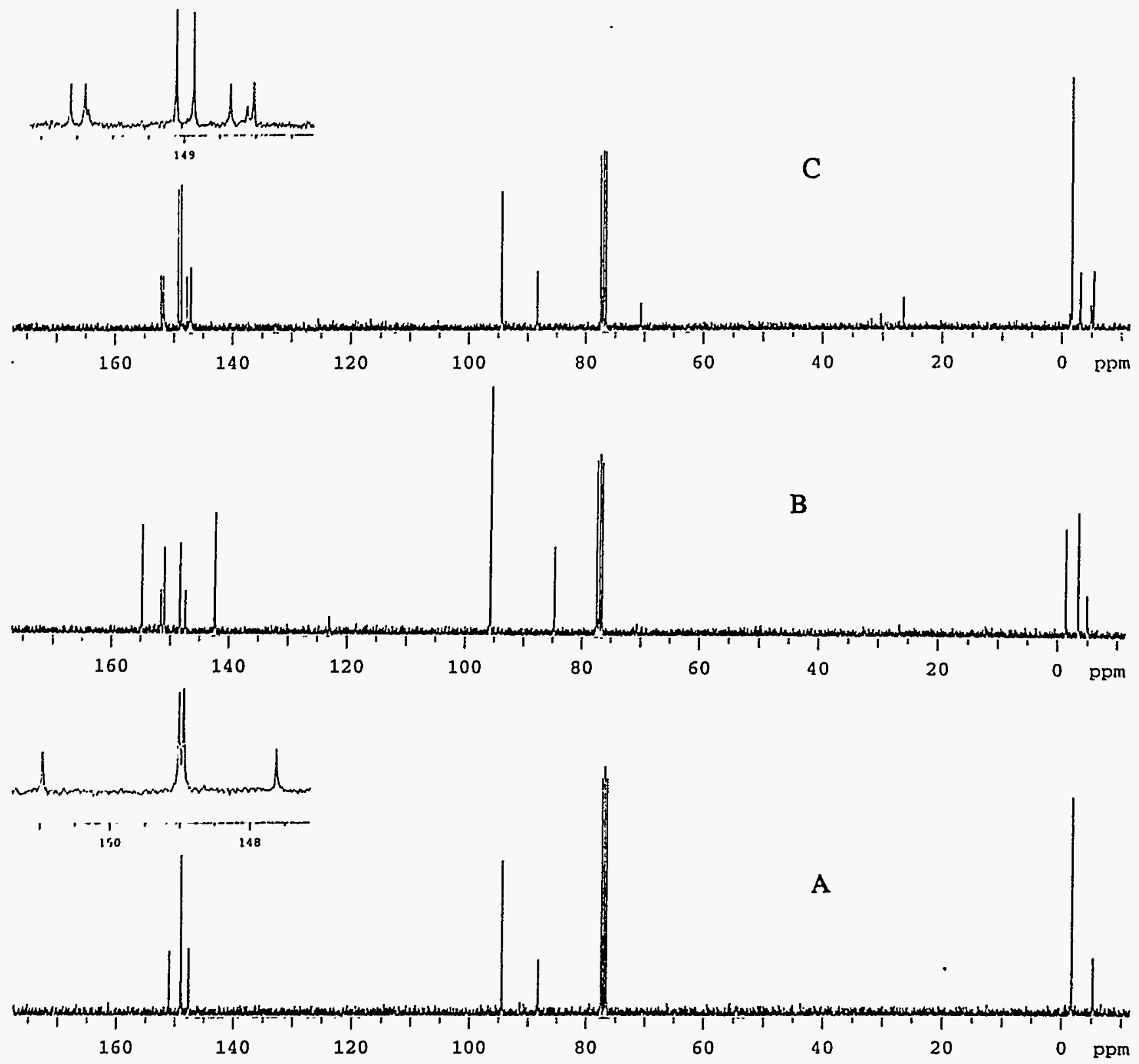

Figure 5. ${ }^{13} \mathrm{C}-\mathrm{NMR}$ spectra of dendrimers $\mathrm{A}, \mathrm{B}$, and C. 
grows bigger, the concentration of the two carbons which connect to the central silicon becomes lower, and the intensity of the peaks for these carbons decrease.

Figure 6 is the ${ }^{29}$ Si-NMR spectra for dendrimers G1, G2, A and B. For G0, the only $\mathrm{Si}$ is at $-94.0 \mathrm{ppm}$. For $\mathrm{G} 1$, the core $\mathrm{Si}$ atom is at $-30.76 \mathrm{ppm}$, the outside $\mathrm{Si}$ at $-47.86 \mathrm{ppm}$. For $\mathrm{G} 2$, the core $\mathrm{Si}$ atom is at $-31.42 \mathrm{ppm}$, the middle $\mathrm{Si}$ atom at -21.72 $\mathrm{ppm}$, and the outermost Si atom at $-47.12 \mathrm{ppm}$. For dendrimer $\mathrm{A}$, the core Si atom is at $31.89 \mathrm{ppm}$, the middle Si atom at $-22.78 \mathrm{ppm}$, and the outermost Si atom at $-25.26 \mathrm{ppm}$. As expected, for dendrimer $\mathrm{B}$, the ${ }^{29} \mathrm{Si}-\mathrm{NMR}$ spectra showed 4 resonances: The core $\mathrm{Si}$ atom is at $-32.15 \mathrm{ppm}$, the next further out $\mathrm{Si}$ atom at $-23.49 \mathrm{ppm}$, the $\mathrm{Si}$ atom in the next layer at $-14.61 \mathrm{ppm}$, and the outermost $\mathrm{Si}$ atom at -47.53 . Assignments were made on the basis of peak intensities. From the spectra we can see that the signal of the core silicon (around -31 ppm) is very low. This is why it is difficult to get the correct ${ }^{29} \mathrm{Si}-\mathrm{NMR}$ spectra for dendrimers G3 and C. The outermost Si atom is always the furtherest upfield. Molecular weights of dendrimers were determined by mass spectroscopy. For G0, an exact mass of 128 was obtained from an EI in a high resolution level. The molecular weights of G1 and A were obtained from an CI-MS in a high resolution level and are almost the same as their formula weights. The molecular weight of G2 was obtained from a CI-MS in a low resolution level and is almost the same as its formula weight. A matrix assisted laser desorption/ionization (MALDI) technique was required to obtain the molecular ions of dendrimer $\mathrm{B}$ and $\mathrm{C}$. The masses of the dendrimer $\mathrm{B}$ and $\mathrm{C}$ were obtained when $\alpha$-cyano-4-hydroxycinamic acid was used as a matrix and $\mathrm{G} 2$ was used as a reference. All the results are summarized in Table 1. As shown in Table 1, the 

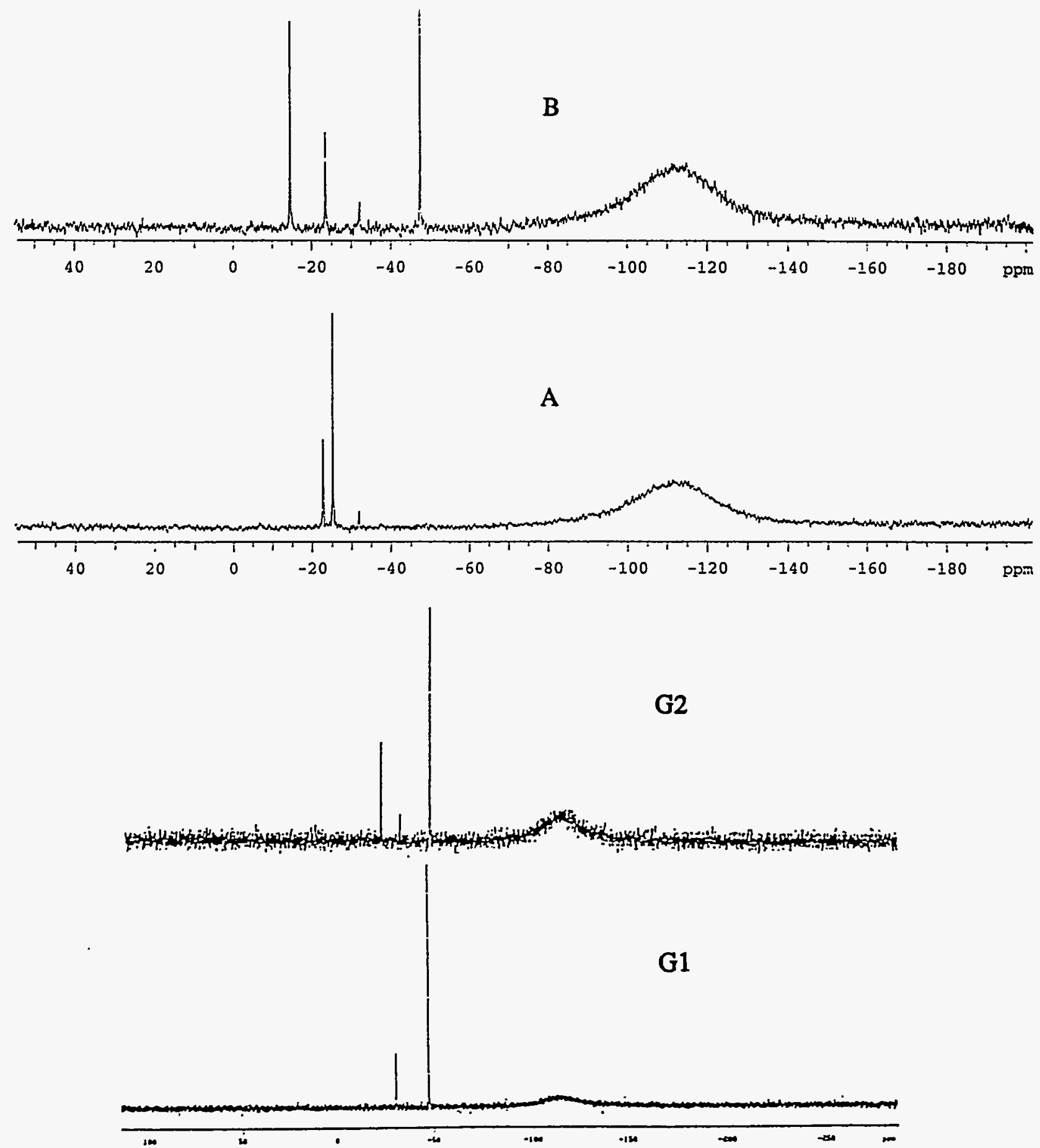

Figure $6{ }^{29}$ Si-NMR spectra of dendrimers G1, G2, A and B 
experimental molecular weights are very comparable to their calculated numbers, within the experimental errors. It should be noted that so far, generally, no mass spectroscopic assessment of the perfection of carbosilane dendrimers has been carried out. Comparing the methods of CI-MS, GPC, SEC (size exclusion chromatography) and MALDI, MALDI technique give better results for high molecular weight dendrimers.

The melting points of dendrimers $\mathrm{A}, \mathrm{B}$, and $\mathrm{C}$ are $108,94.5$ and $54.5^{\circ} \mathrm{C}$ respectively, as shown in Table 1 . The melting points decrease as the molecular weight increase. Dendrimers G1 and G2 are solid products. whereas G3 is an oily product. This unusual phenomenon has also been observed by Freg and coworkers. ${ }^{32}$ In their carbosilane-based dendritic polyols, the G0-OH (4-polyol) was obtained as a crystalline white solid, the higher generation polyols were obtained as transparent, highly viscous liquids after purification.

Synthesis of carbosilane dendrimers by a convergent approach

In the previously described syntheses of silylene-vinylene dendrimers, a divergent, controlled step growth approach was used where dendrimers were grown layer-by-layer from "inside out". Next a convergent approach was used to synthesize carbosilane dendrimers with the dendrimers being grown from the "outside in". The convergent method for carbosilane dendrimer synthesis is shown in Scheme 5.

First, trimethylchlorosilane was reacted with ethynylmagesium chloride to give (trimethylsilyl)acetylene. ${ }^{40}$ Then the (trimethylsilyl)acetylene was treated with 


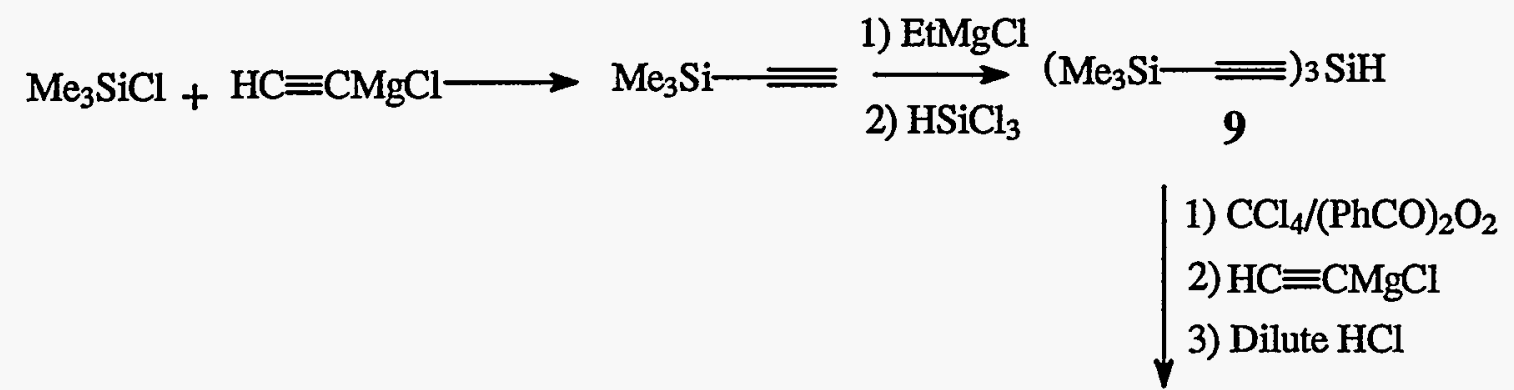

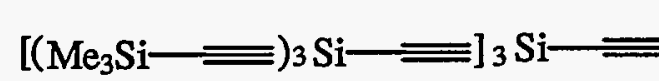

11

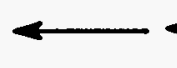

$<$

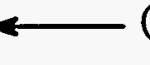
$\left(\mathrm{Me}_{3} \mathrm{~S}\right.$

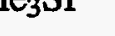

Scheme 5

ethylmagnesium chloride to give (trimethylsilyl)ethynylmagnesium chloride, and quenched with trichlorosilane to afford a white, solid compound tris[(trimethylsilyl)ethynyl]silane, 9 , in yield of $61.6 \%$. The structure of compound 9 was confirmed by ${ }^{1} \mathrm{H}-\mathrm{NMR},{ }^{13} \mathrm{C}-\mathrm{NMR}$, IR and GC-MS spectra. The ${ }^{1} \mathrm{H}-\mathrm{NMR}$ showed two single peaks: the large peak at 0.19 ppm is from the protons of methyl group, the small peak at $4.48 \mathrm{ppm}$ is from the proton of $\mathrm{Si}-\mathrm{H}$. Because the Si-H coupling is very large $(192 \mathrm{~Hz})$, there are some satellite peaks around the single peak. The ${ }^{13} \mathrm{C}-\mathrm{NMR}$ showed three peaks. The large peak at $-0.55 \mathrm{ppm}$ is for methyl carbon which connected to $\mathrm{Si}$. The two small peaks at 102.43 and 118.09 $\mathrm{ppm}$ are from the carbons of the disubstituted ethynylene. The ${ }^{29} \mathrm{Si}-\mathrm{NMR}$ showed two peaks, their ratio is 3 to 1 . The large peak at $-16.89 \mathrm{ppm}$ is the outside $\mathrm{Si}$ atom of $\mathrm{Me}_{3} \mathrm{Si}$, and the small peak at $-92.82 \mathrm{ppm}$ is the $\mathrm{Si}$ atom of $\mathrm{SiH}$. The IR showed clearly the $\mathrm{Si}-\mathrm{H}$ 
bond, $\mathrm{C} \equiv \mathrm{C}$ bond and $\mathrm{Si}-\mathrm{CH}_{3}$ bond. The GC-MS gave the correct molecular weight of compound 9.

Two synthetic routes were used to synthesize compound 10. The first route is shown in Scheme 5. The solution of tris[(trimethylsilyl)ethynyl]silane in $\mathrm{CCl}_{4}$ with the presence of benzoyl peroxide was refluxed under argon for $24 \mathrm{~h}$ to produce tris[(trimethylsilyl)ethynyl]chlorosilane. Then the chlorosilane was reacted with ethynylmagesium chloride at room temperature for 2 days, followed by work up with dilute $\mathrm{HCl}$ solution (2M), extraction with hexane, drying by $\mathrm{MgSO}_{4}$, and purification by flash column chromatographyty to give solid tris[(trimethylsilyl)ethynyl]silylacetylene, 10, in yield of $24.9 \%$. In this route the first chlorination step is crucial. GC was used to follow the reaction. The amount of benzoyl peroxide used is much greater than a catalytic amount.

A far more convenient route to synthesize 10 is shown in Scheme 6. Tris[(trimethylsilyl)ethynyl]silane was directly reacted with ethynylmagesium chloride in THF solution at room temperature for $26 \mathrm{~h}$ to give a mixture of tris[(trimethylsilyl)ethynyl]ethynylsilane, tetra[(trimethylsilyl)ethynyl]silane, and bis[(trimethylsilyl)ethynyl]diethynylsilane. Tris[(trimethylsilyl)ethynyl]silylacetylene, 10, was obtained in yield of $27.9 \%$ after purification by flash chromatography, and recrystalization from hexane. The product was $90 \%$ pure from GC analysis. Purification is crucial for this route. Repeative flash column chromatography and crystallization methods have been used here. More tetra[(trimethylsilyl)ethynyl]silane was obtained when the reaction was run under refluxing temperature 
$\left(\mathrm{Me}_{3} \mathrm{Si}=\right)_{3} \mathrm{SiH}+\mathrm{HC} \equiv \mathrm{CMgCl}$

9

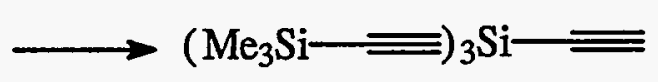

10

Scheme 6

The structure of compound 10 was confirmed by $\mathbb{R}$, GC-MS, ${ }^{1} \mathrm{H}-\mathrm{NMR}$ and ${ }^{13} \mathrm{C}$ NMR spectra. The IR showed clearly the terminal $\mathrm{C} \equiv \mathrm{CH}$ group (2046 and $3281 \mathrm{~cm}^{-1}$ ) and the $\mathrm{Si}_{-} \mathrm{CH}_{3}$ bond $\left(1264 \mathrm{~cm}^{-1}\right)$. The GC-MS gave the correct molecular weight for compound 10. The ${ }^{1} \mathrm{H}-\mathrm{NMR}$ showed two single peaks: the large peak at $0.19 \mathrm{ppm}$ is for methyl protons, and the small peak at $2.58 \mathrm{ppm}$ is for the acetylene proton. The ${ }^{13} \mathrm{C}-\mathrm{NMR}$ showed five peaks. The large peak at $-0.61 \mathrm{ppm}$ is for methyl carbon connected to Si. The two peaks at 103.08 and $117.49 \mathrm{ppm}$ are from the carbons of the disubstituted ethynylene. The two peaks at 81.6 and $95.19 \mathrm{ppm}$ are for terminal ethynylene carbons.

An attempted synthesis of dendrimer 11 from dendrimer 10 was tried without success. First dendrimer 10 was treated with ethylmagnesium chloride, then was quenched with trichlorosilane. An inseparable final product mixture was obtained. Different reaction conditions were used, but none worked. This is likely because the dendrimer 10 has nine methyl groups residing on the outside of the molecule, which will result in surface congestion. Even if the metallation step was a success, it would still be difficult to completely replace the three chloride groups in the trichlorosilane. 
Attempted synthesis of cyclotetrasilane-based dendrimers

Synthesis of carbosilane dendrimers based on using cyclotetrasilane as core molecule was tried. One concern might be the ring strain of four-membered ring compared to the five- and six-membered rings. However, it is known that the thermodynamic stability of the small ring is enhanced with bulky substituents. ${ }^{41}$ With large substituents like phenyl-, trimethylsilyl-, isopropyl, cyclohexyl, or t-Bu- groups, the fourmembered ring becomes quite stable. Known cyclotetrasilanes substituted with only one kind of substituents are listed in Table 2.

Octaphenylcyclotetrasilane was synthesized according to the literature methods. ${ }^{42 a}$ As shown in scheme 7, reductive elimination of halogens in dichlorodiphenylsiane by magnesium metal gave the octaphenylcyclotetrasilane in yield of $47 \%$.

Table 2 Cyclotetrasilanes with the same substituents on the ring

\begin{tabular}{llll}
\hline \multicolumn{1}{c}{ Compound } & ref(s) & Compound & ref(s) \\
\hline $\mathrm{Si}_{4} \mathrm{Ph}_{8}$ & 42 & $\mathrm{Si}_{4}(\mathrm{sec}-\mathrm{Bu})_{8}$ & 49 \\
$\mathrm{Si}_{4} \mathrm{p}-\mathrm{Tol}_{8}$ & 43 & $\mathrm{Si}_{4}(\mathrm{i}-\mathrm{Bu})_{8}$ & 49 \\
$\mathrm{Si}_{4} \mathrm{Me}_{8}$ & 44 & $\mathrm{Si}_{4} \mathrm{Cl}_{8}$ & 50 \\
$\mathrm{Si}_{4} \mathrm{Et}_{8}$ & 45 & $\mathrm{Si}_{4} \mathrm{Br}_{8}$ & 51 \\
$\mathrm{Si}_{4} \mathrm{i}-\mathrm{Pr}_{8}$ & 46 & $\mathrm{Si}_{4} \mathrm{I}_{8}$ & 52 \\
$\mathrm{Si}_{4}\left(\mathrm{cyclohexyl}_{8}\right.$ & 47 & $\mathrm{Si}_{4}\left(\mathrm{SiMe}_{3}\right)_{8}$ & 53 \\
$\mathrm{Si}_{4}\left(\mathrm{t}-\mathrm{BuCH}_{2}\right)_{8}$ & 48 & $\mathrm{Si}_{4}\left(\mathrm{Me}_{2} \mathrm{Et}_{8}\right.$ & 54 \\
& & $\mathrm{Si}_{4}\left(\mathrm{CH}_{2} \mathrm{SiMe}_{3}\right)_{8}$ & 55 \\
\hline
\end{tabular}




$$
\mathrm{Ph}_{2} \mathrm{SiCl}_{2}+\mathrm{Mg} \underset{\mathrm{THF}}{\stackrel{\mathrm{MgB}_{2}}{\longrightarrow}} \begin{gathered}
\mathrm{Ph} \mathrm{Ph} \\
\mathrm{Ph}-\mathrm{Si}-\mathrm{Si}-\mathrm{Ph} \\
\mathrm{Ph}-\mathrm{Si}-\mathrm{Si}-\mathrm{Ph} \\
1 \\
\mathrm{Ph} \mathrm{Ph}
\end{gathered}
$$

Scheme 7

Octachlorocyclotetrasilane was chosen as the starting material for the preparation of other new derivatives. It was formed in the reaction of octaphenylcyclotetrasilane with anhydrous hydrogen chloride in the presence of anhydrous aluminum chloride as catalyst. As shown in Scheme 8, perchloronated tetrasilane, $\mathrm{Si}_{4} \mathrm{Cl}_{10}, \mathbf{1 4}$, was obtained instead of octachlorocyclotetrasilane when the literature procedure ${ }^{50}$ was followed for the first several times. The reason was when the procedures of flowing $\mathrm{HCl}$ for $1 \mathrm{~h}$, filtering off the salt and polymers were complete, there was still some excess $\mathrm{HCl}$ left in the solution. In the next step of solvent distillation, the ring-opening reactions of octachlorocyclotetrasilane in the presence of $\mathrm{HCl}$ yielded perchloronated tetrasilane, $\mathrm{Si}_{4} \mathrm{Cl}_{10}$. Ring-opening reactions are quite generally observed for rather strained cyclotetrasilane systems. Hengge and coworkers found that ring-opening reactions of octaphenylcyclotetrasilane with halogens $(\mathrm{X}=\mathrm{Cl}, \mathrm{Br}, \mathrm{D})$ or $\mathrm{PX} \mathrm{X}_{5}(\mathrm{X}=\mathrm{Cl}, \mathrm{Br})$ in the presence of $\mathrm{HCl} / \mathrm{AlX}_{3}$ yield perhalogenated tetrasilane, $\mathrm{Si}_{4} \mathrm{X}_{10}\left(\mathrm{X}=\mathrm{Cl}, \mathrm{Br}, \mathrm{I}^{56}\right.$ which otherwise are very difficult to prepare. Apparently the combination of $\mathrm{HCl}$ and the $80^{\circ} \mathrm{C}$ distillation temperature caused ring-opening to give $\mathrm{Si}_{4} \mathrm{Cl}_{10}$. When $\mathrm{Ar}$ was bubbled through the 
<smiles>c1ccc([Si](c2ccccc2)(c2ccccc2)[Si](c2ccccc2)(c2ccccc2)c2ccccc2)cc1</smiles>

12
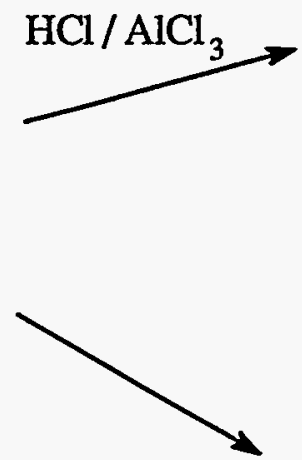

\section{$\mathrm{Cl}_{3} \mathrm{SiSiCl}_{2} \mathrm{SiCl}_{2} \mathrm{SiCl}_{3}$}

\section{4}

Scheme 8

solution for 30 minutes after completion of the addition of $\mathrm{HCl}$ gas, pure 13, octachlorocyclotetrasilane, was obtained in yield of $49.5 \%$.

The high reactivity of the $\mathrm{Si}-\mathrm{Cl}$ bond of octachlorocyclotetrasilane makes it a very attractive starting materials for the preparation of other derivatives like octamethylcyclotetrasilane. The methylation of $\mathrm{Si}_{4} \mathrm{Cl}_{8}$ with dimethylzinc or trimethylaluminum gives octamethylcyclotetrasilane in a high yield. ${ }^{44 b}$ Synthesis of octaethynylcyclotetrasilane and octaallylcyclotetrasilane was tried, as shown in Scheme 9. Ethynylmagesium chloride and allylmagesium chloride were used to react with $\mathrm{Si}_{4} \mathrm{Cl}_{8}$. Although a variety of reaction conditions, such as reaction time, reaction temperature and solvent, were tried, 16 and 17 were not obtained. However, when propargyl alcohol was used to react with $\mathrm{Si}_{4} \mathrm{Cl}_{8}$ in benzene solvent in the presence of imidazole, 
<smiles>Cl[Si]1(Cl)[Si](Cl)(Cl)[Si](Cl)(Cl)[Si]1(Cl)Cl</smiles>

\section{3}

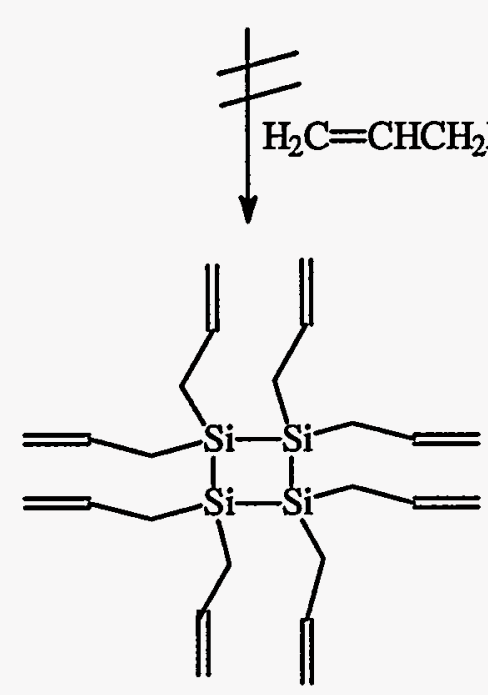

17
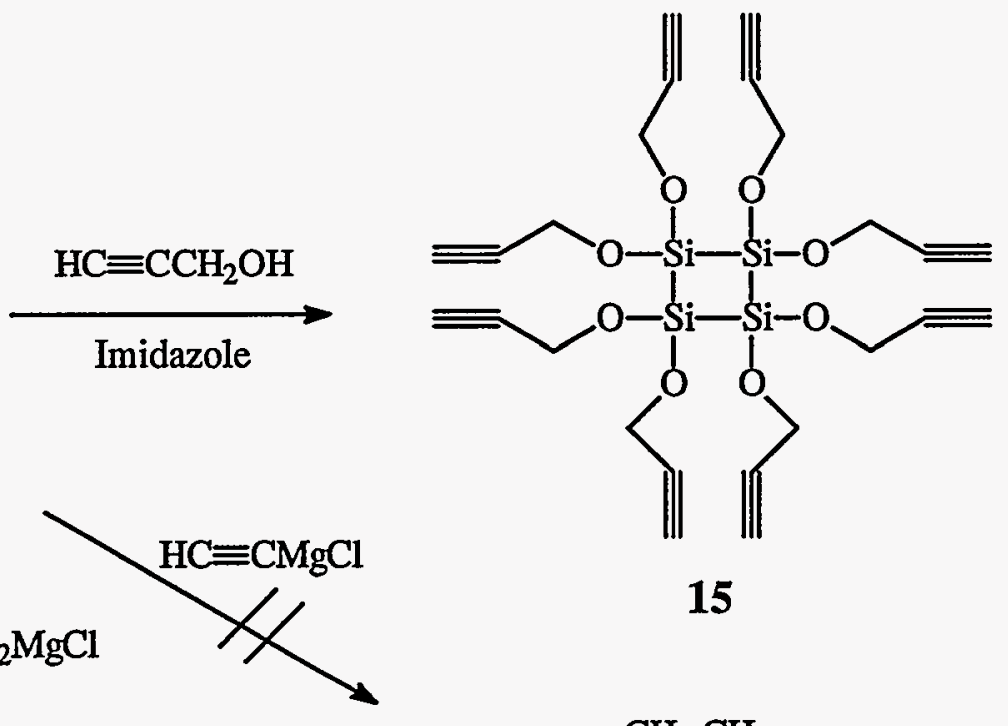

15<smiles>C#CC1(C#C)[Si](C#C)(C#C)[Si](C#C)(C#C)[Si]1(C#C)C#C</smiles>

16

Scheme 9

octapropargyloxycyclotetrasilane, 15 , was obtained in almost quantitative yield. The structure of compound 15 was confirmed by $I R$ and NMR spectra. The IR showed clearly the terminal $\mathrm{C} \equiv \mathrm{CH}$ group (2124.5 and $\left.3289.5 \mathrm{~cm}^{-1}\right)$. The ${ }^{1} \mathrm{H}-\mathrm{NMR}$ showed two kinds of peaks. The methylene protons coupled with the terminal acetylene protons to give a doublet at $4.47 \mathrm{ppm}$ and a triplet at $2.45 \mathrm{ppm}$, whose coupling constant is $3 \mathrm{~Hz}$. The ${ }^{13} \mathrm{C}$ NMR showed three peaks. The peak at $51.88 \mathrm{ppm}$ is from methylene carbon. The two 
peaks at 73.87 and $80.43 \mathrm{ppm}$ are from the terminal ethynylene carbons. ${ }^{29} \mathrm{Si}-\mathrm{NMR}$ showed only one peak at $-82.84 \mathrm{ppm}$.

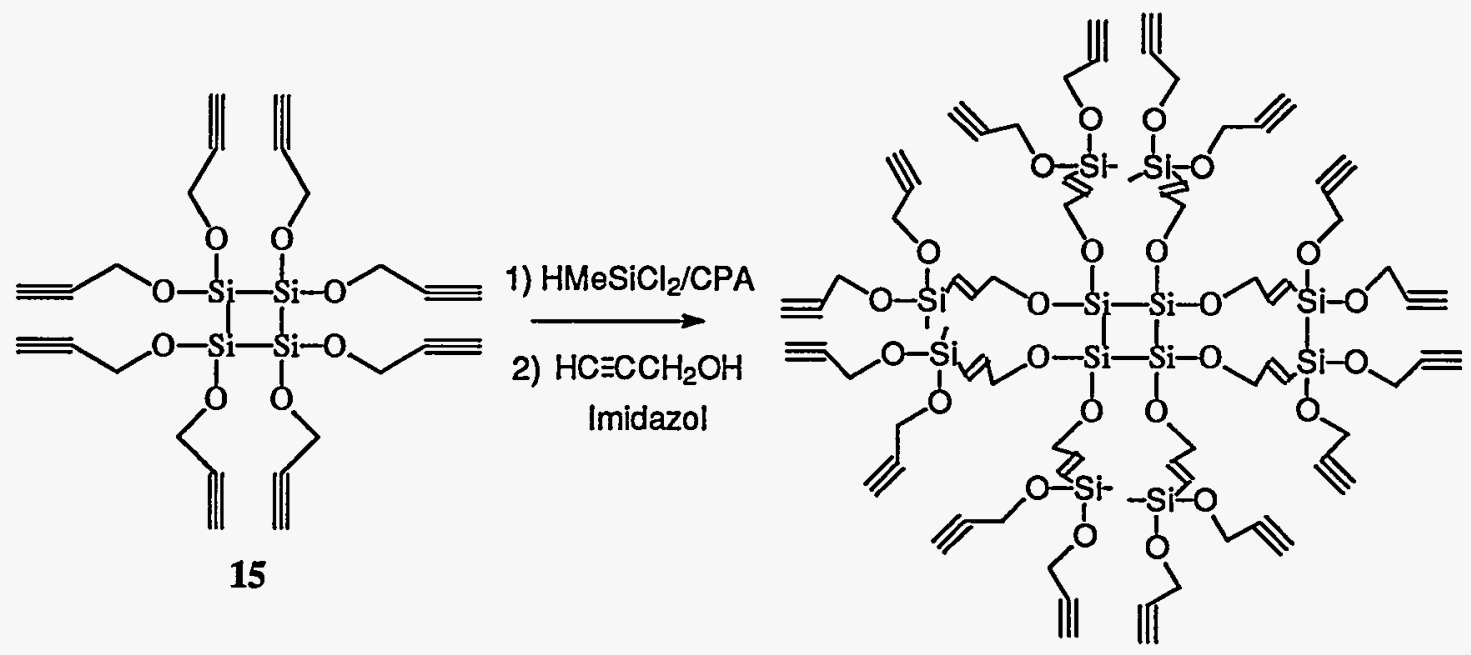

18

Scheme 10

Using octapropargyloxycyclotetrasilane as a central core to synthesize dendrimers was tried as shown in scheme 10 . The procedures were similar to the procedures of preparation of silylene-vinylene dendrimers decribed earlier. After hydrosilylation of compound 15 with dichloromethylsilane, then conversion of silyl chlorides to propargyloxy groups by reacting the hydrosilylation product with propargyl alcohol. An inseparable final product mixture was obtained. 


\section{Conclusions}

A series of carbosilane dendritic polymers were synthesized and characterized. In the synthesis of silylene-vinylene dendrimers, a divergent hydrosilation/Grignard reaction sequence was employed, tetraethynysilane was used as the central core molecule, dichloromethylsilane and chlorodimethylsilane were used as the propagation units. A convergent approach was also used to synthesize carbosilane dendrimers. The reaction conditions for hydrosilylation must be well controlled. After purification by flash column chromatography pure products for each generation were obtained. The $I R,{ }^{1} \mathrm{H}-\mathrm{NMR},{ }^{13} \mathrm{C}$ NMR. and ${ }^{29}$ Si-NMR spectra are consistent with the proposed structures.

Octapropargyloxycyclotetrasilane was synthesized from octachlorocyclotetrasilane. Synthesis of carbosilane dendrimers based on using octapropargyloxycyclotetrasilane as a core molecule was tried.

\section{Experimental}

Characterizations of synthesized compounds were based on MS, IR, ${ }^{1} \mathrm{H}-\mathrm{NMR}$, ${ }^{13} \mathrm{C}-\mathrm{NMR}$. and ${ }^{29} \mathrm{Si}-\mathrm{NMR}$. The masses were obtained from a Kratos MS 50 mass spectrometer. The infrared spectra were recorded on a Bio-Rad Digilab FTS-7 spectrometer from neat samples. The ${ }^{1} \mathrm{H}$ and ${ }^{13} \mathrm{C}$ NMR spectra were collected on a Varian VXR-300 MHz spectrometer in deuterated chloroform solution unless otherwise specified. ${ }^{13} \mathrm{C}$ NMR spectra are proton decoupled. The ${ }^{29} \mathrm{Si}-\mathrm{NMR}$ spectra were collected on a BRUKER AC-200 MHz spectrometer. Reactions were monitored by Hewlett 
Packard 5890 series II GC and Hewlett Packard tandem GC-IR-MS (5890A GC-5965A IR-5970 Series MS ).

THF was distilled over Na-benzophenone, while ether and all chlorosilane reagents were distilled over $\mathrm{CaH}_{2}$ immediately before use. Commercially available reagents were used as received unless otherwise specified. Scientific Adsorbents $40 \mu$ silica gel was utilized in flash column chromatography.

\section{Tetraethynysilane, G0}

A $2 \mathrm{~L}$ three neck round bottom flask equipped with a mechanical stirrer, and an addition funnel, was charged with dry THF $(1 \mathrm{~L})$ and was cooled to $0^{\circ} \mathrm{C}$ by an ice bath. Acetylene gas was introduced into the THF bubbling for 40 minutes. While acetylene gas bubbling was continued, methylmagnesium chloride $(450 \mathrm{~mL}, 3 \mathrm{M})$ was slowly added into the flask through an addition funnel over 2 hours. After addition was complete, acetylene gas was bubbled for an additional hour. Then under Ar atmosphere, tetrachlorosilane $(35.21 \mathrm{~g}, 0.21 \mathrm{~mol}$ ) was slowly added into the flask in $15 \mathrm{~min}$. The mixture was stirred at $0^{\circ} \mathrm{C}$ for $3 \mathrm{~h}$, then stirred at room temperature overnight. Dilute aqueous $\mathrm{HCl}(2 \mathrm{M})$ was used for worked up, pentane $(300 \mathrm{~mL})$ was used for extraction. After the solvent was removed, crude red crystals were purified by sublimation at room temperature to give $12.42 \mathrm{~g}$ white crystals in $46 \%$ yield (literature yield $17 \%$ ). (The product is very explosive. A safety shield was used while handling this material.) m.p.: 88-89 ; GC-MS $m / z 128$ (75, M), 102 (100), 77, 53; ${ }^{1} \mathrm{H}-\mathrm{NMR}\left(300 \mathrm{MHz}, \mathrm{CDCl}_{3}\right) \delta(\mathrm{ppm}) 2.63(4 \mathrm{H}, \mathrm{s}, \equiv \mathrm{CH})$; 
${ }^{13} \mathrm{C}-\mathrm{NMR}\left(300 \mathrm{Mhz}, \mathrm{CDCl}_{3}\right) \delta(\mathrm{ppm}) 80.1$ (sp-C), 96.2 (sp-CH). ${ }^{29} \mathrm{Si}-\mathrm{NMR}:(200 \mathrm{Mhz}$, $\left.\mathrm{CDCl}_{3}\right) \delta(\mathrm{ppm})-94.0$.

G1

Into a $100 \mathrm{~mL}$ round bottom flask was added $1.45 \mathrm{~g}(11.3 \mathrm{mmol})$ of tetraethynysilane, $8 \mathrm{~mL}$ (76.8 mmol) of dichloromethylsilane, $15 \mathrm{~mL}$ of anhydrous THF and a catalytic amount of CPA. Then the flask was sealed by a teflon stopcock. A safety shield was used while doing this experiment. The reaction mixture was stirred at room temperature for $1 \mathrm{~h}$, sometimes a cooling bath was needed if the reaction solution refluxed vigorously. The temperature was controlled to let the exothermic reaction gently reflux. Then the reaction system was slowly heated to $55^{\circ} \mathrm{C}$ by an oil bath, and was kept at $55^{\circ} \mathrm{C}$ for $4 \mathrm{~h}$. After cooling to room temperature, the reaction flask was connected to a vacuum system. The excess dichloromethylsilane and all THF were removed, white, solid G1-Cl product was obtained. Then $30 \mathrm{~mL}$ of fresh anhydrous THF was transferred to the flask under Ar. This solution was added dropwise into $450 \mathrm{~mL}, 0.5 \mathrm{M}$ ethynylmagesium chloride/THF solution through an addition funnel. The mixture was stirred at room temperature overnight. Then about $250 \mathrm{~mL}$ hexane was added, and the mixture was washed with $1 \mathrm{~L}$ of dilute aqueous $\mathrm{HCl}(2 \mathrm{M})$ five times. The organic solution was dried over anhydrous $\mathrm{MgSO}_{4}$. After the solvent was removed through evaporation, the product was first purified by flash chromatography on a silica gel column eluted with a solution of hexane/ethyl acetate (ratio: 4 to 1), then recrystallized from hexane to give $4.17 \mathrm{~g}$ pure 
white, solid product $\mathrm{G} 1$ in $73 \%$ yield. m.p.: $85.5-86.5^{\circ} \mathrm{C}$; CI-MS $\left(\mathrm{M}+\mathrm{NH}_{4}{ }^{\dagger}\right) \mathrm{m} / \mathrm{z} 524$ (29.5), 523 (52.9), 522 (100), 338 (13), 271 (3.44), 198 (6.26); IR: (cm $\left.{ }^{-1}\right), 705.0,741.1$, $804.8,824.8,1010.9,1106.4,1175.7,1265.5,1363.3,2040.0$ (vs, $C=C$ ), 2864.5, 2963.7, 3052.9, 3282.9 (vs, $\equiv \mathrm{C}-\mathrm{H}) ;{ }^{1} \mathrm{H}-\mathrm{NMR}\left(300 \mathrm{MHz}, \mathrm{CDCl}_{3}\right) \delta(\mathrm{ppm}) 0.43\left(12 \mathrm{H}, \mathrm{s}, \mathrm{CH}_{3}\right)$, $2.55(8 \mathrm{H}, \mathrm{s}, \equiv \mathrm{CH}), 6.60(4 \mathrm{H}, \mathrm{d}, \mathrm{J} 22 \mathrm{~Hz},=\mathrm{CH}), 6.96(4 \mathrm{H}, \mathrm{d}, \mathrm{J} 22 \mathrm{~Hz},=\mathrm{CH}) ;{ }^{13} \mathrm{C}-\mathrm{NMR}$ $\left(300 \mathrm{MHz}, \mathrm{CDCl}_{3}\right) \delta(\mathrm{ppm})-1.38\left(\mathrm{CH}_{3}\right), 84.24$ (sp-C), 95.95 (sp-CH), $147.6\left(\mathrm{sp}^{2}-\mathrm{CH}\right)$, $148.1\left(\mathrm{sp}^{2}-\mathrm{CH}\right) ;{ }^{29} \mathrm{Si}-\mathrm{NMR}\left(300 \mathrm{MHz}, \mathrm{CDCl}_{3}\right) \delta(\mathrm{ppm})-47.86(4 \mathrm{Si}),-30.76(1 \mathrm{Si})$.

G2

Into a $100 \mathrm{~mL}$ round bottom flask was added $2.04 \mathrm{~g}(4.04 \mathrm{mmol})$ of $\mathrm{G} 1,20 \mathrm{~mL}$ ( $0.192 \mathrm{~mol})$ of dichloromethylsilane, $15 \mathrm{~mL}$ of anhydrous THF and a catalytic amount of CPA. Then the flask was sealed by a teflon stopcock. A safety shield was used while doing this experiment. The reaction system was heated to about $55^{\circ} \mathrm{C}$ by an oil bath. The oil bath was removed (sometimes a cooling bath was needed) as soon as the reaction solution started to reflux. The temperature was controlled to let the exothermic reaction gently reflux. After the exothermic period, the oil bath was replaced to keep the temperature at $55^{\circ} \mathrm{C}$ for $20 \mathrm{~h}$. After cooling to room temperature, the reaction flask was connected to a vacuum system. The excess dichloromethylsilane and all THF were removed, and the white, solid $\mathrm{G} 2-\mathrm{Cl}$ product was obtained. Then $30 \mathrm{~mL}$ of fresh anhydrous THF was transferred to the flask under Ar. Then this,solution was added dropwise into $200 \mathrm{~mL}, 0.5 \mathrm{M}$ ethynylmagesium chloride/THF solution through an addition 
funnel. The mixture was stirred at room temperature for 1 day. Then about $200 \mathrm{~mL}$ hexane was added, and the mixture was washed with $1 \mathrm{~L}$ of dilute aqueous $\mathrm{HCl}(2 \mathrm{M})$ five times. The organic solution was dried over anhydrous $\mathrm{MgSO}_{4}$. After the solvent was removed through evaporation, the product was first purified by flash chromatography on a silica gel column eluted with a solution of hexane/ethyl acetate (ratio: 4 to 1), then recrystallized from hexane to give $4.07 \mathrm{~g}$ pure white, solid product $\mathrm{G} 2$ in $80 \%$ yield.

m.p.: $112.5-113.5^{\circ} \mathrm{C}$; CI-MS $\left(\mathrm{M}+\mathrm{NH}_{4}{ }^{\dagger}\right) \mathrm{m} / \mathrm{z} 1278(5.3), 1277$ (5.2), $1276(6.4), 470$ (20), 428 (100), 391 (46)253 (64), 181 (38), 108(47); IR (cm $\left.{ }^{-1}\right): 705.8,740.3,802.0$, $1011.0,1175.0,1256.2,1420.1,2038.9$ (vs, C $\equiv C$ ), 2956.7, 2984.2, 3052.6, 3281.5 (vs, 三C-H); ${ }^{1} \mathrm{H}-\mathrm{NMR}\left(300 \mathrm{MHz}, \mathrm{CDCl}_{3}\right) \delta(\mathrm{ppm}) 0.30\left(12 \mathrm{H}, \mathrm{s}, \mathrm{CH}_{3}\right), 0.42\left(24 \mathrm{H}, \mathrm{s}, \mathrm{CH}_{3}\right)$, $2.54(16 \mathrm{H}, \mathrm{s}, \equiv \mathrm{CH}), 6.54(8 \mathrm{H}, \mathrm{d}, \mathrm{J} 22 \mathrm{~Hz},=\mathrm{CH}), 6.69(8 \mathrm{H}, \mathrm{s},=\mathrm{CH}), 6.99(8 \mathrm{H}, \mathrm{d}, \mathrm{J} 22$ $\mathrm{Hz},=\mathrm{CH}) ;{ }^{13} \mathrm{C}-\mathrm{NMR}\left(300 \mathrm{MHz}, \mathrm{CDCl}_{3}\right) \delta(\mathrm{ppm})-5.43\left(\mathrm{CH}_{3}\right),-1.30\left(\mathrm{CH}_{3}\right), 84.46(\mathrm{sp}-\mathrm{C})$, 95.91 (sp-CH), $144.76\left(\mathrm{sp}^{2}-\mathrm{CH}\right), 148.0\left(\mathrm{sp}^{2}-\mathrm{CH}\right), 150.0\left(\mathrm{sp}^{2}-\mathrm{CH}\right), 151.54\left(\mathrm{sp}^{2}-\mathrm{CH}\right) ;{ }^{29} \mathrm{Si}-$ NMR (300 MHz, $\left.\mathrm{CDCl}_{3}\right) \delta(\mathrm{ppm})-47.12(8 \mathrm{Si}),-31.42(1 \mathrm{Si}),-21.72(4 \mathrm{Si})$.

G3

Into a $100 \mathrm{~mL}$ round bottom flask was added $1.33 \mathrm{~g}(1.06 \mathrm{mmol})$ of $\mathrm{G} 2,20 \mathrm{~mL}$ ( $0.192 \mathrm{~mol})$ of dichloromethylsilane, $15 \mathrm{~mL}$ of anhydrous THF and a catalytic amount of CPA. Then the flask was sealed by a teflon stopcock. The reaction system was heated to about $55^{\circ} \mathrm{C}$ by an oil bath and was stirred at $55^{\circ} \mathrm{C}$ for $20 \mathrm{~h}$. After cooling to room temperature, the reaction flask was connected to a vacuum system. The excess 
dichloromethylsilane and all THF were removed, an oily G3-Cl product was obtained. Then $30 \mathrm{~mL}$ of fresh anhydrous THF was transferred to the flask under Ar. This solution was added dropwise into $200 \mathrm{~mL}, 0.5 \mathrm{M}$ ethynylmagesium chloride/THF solution through an addition funnel. The mixture was stirred at room temperature for 1 day. Then about $200 \mathrm{~mL}$ hexane was added, and the mixture was washed with $1 \mathrm{~L}$ of dilute aqueous $\mathrm{HCl}$ (2 M) five times. The organic solution was dried over anhydrous $\mathrm{MgSO}_{4}$. After the solvent was removed through evaporation, the product was purified by flash chromatography on a silica gel column eluted with a solution of hexane/ethyl acetate (ratio: 4 to 1 ) to give 2.22 g oily product $\mathrm{G} 3$ in a $76 \%$ yield. ${ }^{1} \mathrm{H}-\mathrm{NMR}\left(300 \mathrm{MHz}, \mathrm{CDCl}_{3}\right) \delta(\mathrm{ppm}) 0.251(12 \mathrm{H}, \mathrm{s}$, $\left.\mathrm{CH}_{3}\right), 0.267\left(24 \mathrm{H}, \mathrm{s} . \mathrm{CH}_{3}\right), 0.410\left(48 \mathrm{H}, \mathrm{s}, \mathrm{CH}_{3}\right), 2.53(32 \mathrm{H}, \mathrm{s}, \equiv \mathrm{CH}), 6.517(16 \mathrm{H}, \mathrm{d}, \mathrm{J}$ $22 \mathrm{~Hz},=\mathrm{CH}), 6.662(8 \mathrm{H}, \mathrm{s},=\mathrm{CH}), 6.679(8 \mathrm{H}, \mathrm{s},=\mathrm{CH}), 6.707(8 \mathrm{H}, \mathrm{s},=\mathrm{CH}), 6.965(16$ $\mathrm{H}, \mathrm{d}, \mathrm{J} 22 \mathrm{~Hz},=\mathrm{CH}$ ), one unassigned peaks at 1.404 (small, s); ${ }^{13} \mathrm{C}-\mathrm{NMR}(300 \mathrm{MHz}$, $\left.\mathrm{CDCl}_{3}\right) \delta(\mathrm{ppm})-5.353\left(\mathrm{CH}_{3}\right),-4.612\left(\mathrm{CH}_{3}\right),-1.310\left(\mathrm{CH}_{3}\right), 84.42(\mathrm{sp}-\mathrm{C}), 95.98(\mathrm{sp}-\mathrm{CH})$, $144.67\left(\mathrm{sp}^{2}-\mathrm{CH}\right), 147.37\left(\mathrm{sp}^{2}-\mathrm{CH}\right), 148.21\left(\mathrm{sp}^{2}-\mathrm{CH}\right), 150.29\left(\mathrm{sp}^{2}-\mathrm{CH}\right), 151.40\left(\mathrm{sp}^{2}-\mathrm{CH}\right)$, $151.59\left(\mathrm{sp}^{2}-\mathrm{CH}\right)$, one unassigned peak at 30.28 .

\section{Dendrimer A}

Into a $100 \mathrm{~mL}$ round bottom flask was added $1.64 \mathrm{~g}(3.25 \mathrm{mmol})$ of $\mathrm{G} 1,12 \mathrm{~mL}$ ( $0.110 \mathrm{~mol})$ of chlorodimethylsilane, $15 \mathrm{~mL}$ of anhydrous THF and a catalytic amount of CPA. Then the flask was sealed by a teflon stopcock. A safety shield was used while doing this experiment. The reaction system was heated to about $55^{\circ} \mathrm{C}$ by an oil bath. The 
oil bath was removed (sometimes a cooling bath was needed) as soon as the reaction solution started to reflux. The temperature was controlled to let the exothermic reaction gently reflux. After the exothermic period, the oil bath was replaced to keep the temperature at $55^{\circ} \mathrm{C}$ for $16 \mathrm{~h}$. After cooling to room temperature, the reaction flask was connected to a vacuum system. The excess chlorodimethylsilane and all THF were removed, and $30 \mathrm{~mL}$ of fresh anhydrous THF was transferred to the flask under Ar. Then this solution was added dropwise into $200 \mathrm{~mL}, 0.5 \mathrm{M}$ ethynylmagesium chloride/THF solution through an addition funnel. The mixture was stirred at room temperature for 1 day. Then about $200 \mathrm{~mL}$ hexane was added, and the mixture was washed with $1 \mathrm{~L}$ of dilute aqueous $\mathrm{HCl}(2 \mathrm{M})$ five times. The organic solution was dried over anhydrous $\mathrm{MgSO}_{4}$. After the solvent was removed through evaporation, the product was first purified by flash chromatography on a silica gel column eluted with a solution of hexane/ethyl acetate (ratio: 4 to 1), then recrystallized from hexane to give $2.9 \mathrm{~g}$ pure white, solid product $\mathrm{A}$ in $76 \%$ yield. m.p.: $107.5-108.5^{\circ} \mathrm{C}$; CI-MS $\left(\mathrm{M}+\mathrm{NH}_{4}{ }^{+}\right) \mathrm{m} / \mathrm{z} 1199$ (50), 1198 (69), 1197 (100), 1196 (65), 1195 (92), 278 (63), 261 (21), 194 (26), 170 (41), 150 (36), 100 (54); IR $\left(\mathrm{cm}^{-1}\right): 705.9,740.9,895.9,1012.6,1174.3,1264.5$ (Si$\left.\mathrm{CH}_{3}\right), 1421.6,2033.3$ (vs, C=C), 2986.0, 3053.9, 3283.0 (vs, =C-H); ${ }^{1} \mathrm{H}-\mathrm{NMR}(300$ $\left.\mathrm{MHz}, \mathrm{CDCl}_{3}\right) \delta(\mathrm{ppm}) 0.24\left(60 \mathrm{H}, \mathrm{s}, \mathrm{CH}_{3}\right), 2.43(8 \mathrm{H}, \mathrm{s}, \equiv \mathrm{CH}), 6.59(8 \mathrm{H}, \mathrm{d}, \mathrm{J} 21 \mathrm{~Hz}$, $=\mathrm{CH}), 6.66(8 \mathrm{H}, \mathrm{s},=\mathrm{CH}), 6.78(8 \mathrm{H}, \mathrm{d}, \mathrm{J} 21 \mathrm{~Hz},=\mathrm{CH}) ;{ }^{13} \mathrm{C}-\mathrm{NMR}\left(300 \mathrm{MHz}, \mathrm{CDCl}_{3}\right)$ $\delta(\mathrm{ppm})-5.26\left(\mathrm{CH}_{3}\right),-1.66\left(\mathrm{CH}_{3}\right), 88.23(\mathrm{sp}-\mathrm{C}), 94.44(\mathrm{sp}-\mathrm{CH}), 147.60\left(\mathrm{sp}^{2}-\mathrm{CH}\right), 148.91$ 
$\left(\mathrm{sp}^{2}-\mathrm{CH}\right), 149.00\left(\mathrm{sp}^{2}-\mathrm{CH}\right), 150.92\left(\mathrm{sp}^{2}-\mathrm{CH}\right) ;{ }^{29} \mathrm{Si}-\mathrm{NMR}\left(200 \mathrm{MHz}, \mathrm{CDCl}_{3}\right) \delta(\mathrm{ppm})-$

$31.89(1 \mathrm{Si}),-25.26(8 \mathrm{Si}),-22.78(4 \mathrm{Si})$.

\section{Dendrimer B}

Into a $100 \mathrm{~mL}$ round bottom flask was added $1.32 \mathrm{~g}(1.12 \mathrm{mmol})$ of dendrimer $\mathrm{A}$, $15 \mathrm{~mL}$ ( $0.144 \mathrm{~mol})$ of dichloromethylsilane, $10 \mathrm{~mL}$ of anhydrous THF and a catalytic amount of CPA. Then the flask was sealed by a teflon stopcock. A safety shield was used while doing this experiment. The reaction system was heated to about $55^{\circ} \mathrm{C}$ by an oil bath. The oil bath was removed (sometimes a cooling bath was needed) as soon as the reaction solution started to reflux. The temperature was controlled to maintain a gentle reflux. After the exothermic period, the oil bath was replaced to keep the temperature at $55^{\circ} \mathrm{C}$ for $16 \mathrm{~h}$. After cooling to room temperature, the reaction flask was connected to a vacuum system. The excess dichloromethylsilane and all THF were removed, and $30 \mathrm{~mL}$ of fresh anhydrous THF was transferred to the flask under Ar. Then this solution was added dropwise into $150 \mathrm{~mL}, 0.5 \mathrm{M}$ ethynylmagesium chloride/THF solution through an addition funnel. The mixture was stirred at room temperature for 1 day. Then about 150 $\mathrm{mL}$ hexane was added, and the mixture was washed with $1 \mathrm{~L}$ of dilute aqueous $\mathrm{HCl}(2 \mathrm{M})$ five times. The organic solution was dried over anhydrous $\mathrm{MgSO}_{4}$. After the solvent was removed through evaporation, the product was first purified by flash chromatography on a silica gel column eluted with a solution of hexane/ethyl acetate (ratio: 4 to 1 ), then recrystallized from hexane to give $1.18 \mathrm{~g}$ pure white, solid product in $55 \%$ yield. m.p.: 
94-95 ${ }^{\circ}$; MALDI Mass $m / z 1946$ (1932); ${ }^{1} \mathrm{H}-\mathrm{NMR}\left(300 \mathrm{MHz}, \mathrm{CDCl}_{3}\right) \delta(\mathrm{ppm}) 0.15$ $\left(48 \mathrm{H}, \mathrm{s}, \mathrm{CH}_{3}\right), 0.22\left(12 \mathrm{H}, \mathrm{s}, \mathrm{CH}_{3}\right), 0.40\left(24 \mathrm{H}, \mathrm{s}, \mathrm{CH}_{3}\right), 2.52(16 \mathrm{H}, \mathrm{s}, \equiv \mathrm{CH}), 6.465(8$ $\mathrm{H}, \mathrm{d}, \mathrm{J} 21 \mathrm{~Hz},=\mathrm{CH}), 6.62(16 \mathrm{H}, \mathrm{s},=\mathrm{CH}), 6.68(8 \mathrm{H}, \mathrm{s},=\mathrm{CH}), 6.975(8 \mathrm{H}, \mathrm{d}, \mathrm{J} 21 \mathrm{~Hz}$, $=\mathrm{CH}) ;{ }^{13} \mathrm{C}-\mathrm{NMR}\left(300 \mathrm{MHz}, \mathrm{CDCl}_{3}\right) \delta(\mathrm{ppm})-4.93\left(\mathrm{CH}_{3}\right),-3.44\left(\mathrm{CH}_{3}\right),-3.42\left(\mathrm{CH}_{3}\right)$, $-1.33\left(\mathrm{CH}_{3}\right), 84.68$ (sp-C), 95.65 (sp-CH), 142.31 (sp $\left.{ }^{2}-\mathrm{CH}\right), 147.34\left(\mathrm{sp}^{2}-\mathrm{CH}\right), 148.28$ $\left(\mathrm{sp}^{2}-\mathrm{CH}\right), 150.99$ (sp 2 -CH), $151.53\left(\mathrm{sp}^{2}-\mathrm{CH}\right), 154.77\left(\mathrm{sp}^{2}-\mathrm{CH}\right) ;{ }^{29} \mathrm{Si}-\mathrm{NMR}(200 \mathrm{MHz}$, $\left.\mathrm{CDCl}_{3}\right) \delta(\mathrm{ppm})-47.53(8 \mathrm{Si}),-32.15(1 \mathrm{Si}),-23.49(4 \mathrm{Si}),-14.61(8 \mathrm{Si})$.

\section{Dendrimer C}

Into a $100 \mathrm{~mL}$ round bottom flask was added $0.63 \mathrm{~g}(0.326 \mathrm{mmol})$ of dendrimer $\mathrm{B}$, $12 \mathrm{~mL}(0.110 \mathrm{~mol})$ of chlorodimethylsilane, $10 \mathrm{~mL}$ of anhydrous THF and a catalytic amount of CPA. Then the flask was sealed by a teflon stopcock. The reaction system was heated to about $55^{\circ} \mathrm{C}$ by an oil bath and was stirred at $55^{\circ} \mathrm{C}$ for $16 \mathrm{~h}$. After cooling to room temperature, the reaction flask was connected to a vacuum system. The excess chlorodimethylsilane and all THF were removed, and $30 \mathrm{~mL}$ of fresh anhydrous THF was

transferred to the flask under Ar. Then this solution was added dropwise into $100 \mathrm{~mL}, 0.5$ M ethynylmagesium chloride/THF solution through an addition funnel. The mixture was stirred at room temperature for 1 day. Then about $100 \mathrm{~mL}$ hexane was added, and the mixture was washed with $1 \mathrm{~L}$ of dilute aqueous $\mathrm{HCl}(2 \mathrm{M})$ five times. The organic solution was dried over anhydrous $\mathrm{MgSO}_{4}$. After the solvent was removed through evaporation, the product was first purified by flash chromatography on a silica gel column 
eluted with a solution of hexane/ethyl acetate (ratio: 4 to 1), then recrystallized from hexane to give $0.472 \mathrm{~g}$ pure white, solid product in $44 \%$ yield. m.p.: $54-55^{\circ} \mathrm{C}$; MALDI Mass $m / z$ 3323.7 (3279); ${ }^{1} \mathrm{H}-\mathrm{NMR}\left(300 \mathrm{MHz}, \mathrm{CDCl}_{3}\right) \delta(\mathrm{ppm}) 0.12\left(48 \mathrm{H}, \mathrm{s}, \mathrm{CH}_{3}\right), 0.21$ $\left(36 \mathrm{H}, \mathrm{s}, \mathrm{CH}_{3}\right), 0.24\left(96 \mathrm{H}, \mathrm{s}, \mathrm{CH}_{3}\right), 2.41(16 \mathrm{H}, \mathrm{s}, \equiv \mathrm{CH}), 6.52-6.79(72 \mathrm{H}, \mathrm{m},=\mathrm{CH})$;

${ }^{13} \mathrm{C}-\mathrm{NMR}\left(300 \mathrm{MHz}, \mathrm{CDCl}_{3}\right) \delta(\mathrm{ppm})-5.36\left(\mathrm{CH}_{3}\right),-4.91\left(\mathrm{CH}_{3}\right),-3.17\left(\mathrm{CH}_{3}\right),-3.10$ $\left(\mathrm{CH}_{3}\right),-1.67\left(\mathrm{CH}_{3}\right), 88.29$ (sp-C), 94.39 (sp-CH), $147.06\left(\mathrm{sp}^{2}-\mathrm{CH}\right), 147.25\left(\mathrm{sp}^{2}-\mathrm{CH}\right)$, $147.71\left(\mathrm{sp}^{2}-\mathrm{CH}\right), 148.73\left(\mathrm{sp}^{2}-\mathrm{CH}\right), 149.23\left(\mathrm{sp}^{2}-\mathrm{CH}\right), 151.69\left(\mathrm{sp}^{2}-\mathrm{CH}\right), 151.79\left(\mathrm{sp}^{2}-\mathrm{CH}\right)$, $152.19\left(\mathrm{sp}^{2}-\mathrm{CH}\right)$.

\section{Tris[(trimethylsilyl)ethynyl]silane, 9}

A $1 \mathrm{~L}$ 3-neck round bottom flask was charged with (trimethylsilyl)acetylene (19.29 g, $0.197 \mathrm{~mol})$ and dry THF $(600 \mathrm{~mL})$. At $0^{\circ} \mathrm{C}$, ethylmaganisium chloride $(2 \mathrm{M}, 98.4 \mathrm{~mL}$, $0.197 \mathrm{~mol}$ ) was slowly added into this solution. The solution was then warmed to room temperature and stirred for $24 \mathrm{~h}$. Trichlorosilane $(6.62 \mathrm{~mL}, 65.6 \mathrm{mmol})$ in dry THF (50 $\mathrm{mL}$ ) was slowly added into the flask at $0^{\circ} \mathrm{C}$. The mixture was stirred at room temperature for $20 \mathrm{~h}$ then was washed with $10 \%$ aqueous $\mathrm{NH}_{4} \mathrm{Cl}$ solution $(200 \mathrm{~mL})$ four times. The organic solution was dried over anhydrous $\mathrm{Na}_{2} \mathrm{SO}_{4}$. After the solvent was removed, the crude solid was purified by recrystalization to afford $12.93 \mathrm{~g}$ ( $40.4 \mathrm{mmol}, 61.6 \%$ yield) white, solid tris[(trimethylsilyl)ethynyl]silane, 9. m.p.: $58-59^{\circ} \mathrm{C} ; \mathbf{I R}\left(\mathrm{cm}^{-1}\right): 705.8$, 806.3, 848.4, $1253.6\left(\mathrm{Si}_{-} \mathrm{CH}_{3}\right), 1418.8,2111.0$ (vs, $\left.\mathrm{Si}-\mathrm{H}\right), 2186.5$ (vs, $\mathrm{C} \equiv \mathrm{C}$ ), 2900.3, 2962.7, 3049.1; GC-MS m/z 320.05 (2, M), 305.10 (37, M-Me), 231 (19), 73 (100); 
${ }^{1} \mathrm{H}-\mathrm{NMR}\left(300 \mathrm{MHz}, \mathrm{CDCl}_{3}\right) \delta(\mathrm{ppm}) 0.19\left(27 \mathrm{H}, \mathrm{s}, \mathrm{CH}_{3}\right), 4.48(1 \mathrm{H}, \mathrm{s}, \mathrm{SiH})$ with weak satellites due to $\mathrm{J}_{\mathrm{Si}-\mathrm{H}}=192 \mathrm{~Hz} ;{ }^{13} \mathrm{C}-\mathrm{NMR}\left(300 \mathrm{MHz}, \mathrm{CDCl}_{3}\right) \delta(\mathrm{ppm})-0.55\left(\mathrm{CH}_{3}\right), 102.43$ (sp-C), 118.09 (sp-C). ${ }^{29} \mathrm{Si}-\mathrm{NMR}\left(200 \mathrm{MHz}, \mathrm{CDCl}_{3}\right.$ ) $\delta$ (ppm) -92.82 (1 Si), -16.89 (3 Si).

\section{Tris[(trimethylsilyl)ethynyl]silyl acetylene, 10 (Route I)}

To a $50 \mathrm{~mL}$ three neck round-bottom, over-dried flask which was equipped with a magnetic stirring bar and a condenser, was added carbon tetrachloride $(12 \mathrm{~mL}$, distilled from $\left.\mathrm{P}_{2} \mathrm{O}_{5}\right)$, tris[(trimethylsilyl)ethynyl] silane, $9,(3.806 \mathrm{~g}, 11.9 \mathrm{mmol})$, and benzoylperoxide $(0.3 \mathrm{~g})$ in an argon atmosphere. The solution was refluxed under the inert atmosphere until complete disappearance of starting material, 9, which was indicted by $\mathrm{GC}$ analysis (ca. $24 \mathrm{~h}$ ). A brown, solid product was obtained after the excess benzoylperoxide was filtered under $\mathrm{Ar}$, and the excess $\mathrm{CCl}_{4}$ was removed by vacuum distillation. Anhydrous THF $(20 \mathrm{~mL})$ was transferred to the flask under Ar to dissolve the solid. The resulting solution was added dropwise into $40 \mathrm{~mL}, 0.5 \mathrm{M}$ ethynylmagesium chloride/THF solution at room temperature. The mixture was stirred at room temperature for 2 day. Then about $30 \mathrm{~mL}$ hexane was added, and the mixture was washed with 200 $\mathrm{mL}$ of dilute aqueous $\mathrm{HCl}(2 \mathrm{M})$ five times. The organic solution was dried over anhydrous $\mathrm{MgSO}_{4}$. After the solvent was removed through evaporation, the residue product was purified by flash chromatography on a silica gel column eluted with a solution of hexane/ethyl acetate (98:2) to give $1.02 \mathrm{~g}$ solid product in yield of $24.9 \%$. m.p.: 91 92 ${ }^{\circ} \mathrm{C}$ IR $\left(\mathrm{cm}^{-1}\right): 705.6,740.6,791.8,849.7,1264.9\left(\mathrm{Si}_{-}-\mathrm{CH}_{3}\right), 1421.4,2046.6$ (terminal 
$\mathrm{C} \equiv \mathrm{C}), 2190(\mathrm{w}$, central $\mathrm{C} \equiv \mathrm{C}), 2965.1,2985.1,3053.1,3281.2(\mathrm{vs}, \equiv \mathrm{C}-\mathrm{H}) ; \mathrm{GC}-\mathrm{MS} \mathrm{m} / \mathrm{z}$

344.4 (2.2, M), 329.4 (92.3, M-Me), 231.3 (57), 83 (22), 73 (100). ${ }^{1} \mathrm{H}-\mathrm{NMR}(300 \mathrm{MHz}$, $\left.\mathrm{CDCl}_{3}\right) \delta(\mathrm{ppm}) 0.19\left(27 \mathrm{H}, \mathrm{s}, \mathrm{CH}_{3}\right) .2 .58(1 \mathrm{H}, \mathrm{s}, \equiv \mathrm{CH}) ;{ }^{13} \mathrm{C}-\mathrm{NMR}\left(300 \mathrm{MHz}, \mathrm{CDCl}_{3}\right)$ $\delta(\mathrm{ppm})-0.61\left(\mathrm{CH}_{3}\right), 81.60(\mathrm{sp}-\mathrm{C}), 95.19(\mathrm{sp}-\mathrm{CH}), 103.08(\mathrm{sp}-\mathrm{C}), 117.49$ (sp-C).

\section{Tris[(trimethylsilyl)ethynyl]silyl acetylene, 10 (Route II)}

A $50 \mathrm{~mL}$ round bottom flask was charged with tris[(trimethylsilyl)ethynyl]silane $(1.13 \mathrm{~g}, 3.53 \mathrm{mmol})$ and THF $(15 \mathrm{~mL})$. At room temperature, $0.5 \mathrm{M}$ ethynylmagesium chloride/THF solution $(20 \mathrm{~mL})$ was slowly added to this stirred solution. After stirred at room temperature for $26 \mathrm{~h}$, the reaction mixture was worked up by dilute aqueous $\mathrm{HCl}$ (2M), extracted by hexane and dried over anhydrous $\mathrm{MgSO}_{4}$. A mixture of tris[(trimethylsilyl)ethynyl]silyl acetylene, tetra[(trimethylsilyl)ethynyl]silane, bis[(trimethylsilyl)ethynyl]diacetylenesilane was obtained. After purification by flash column chromatography, and recrystalization from hexane, $0.34 \mathrm{~g}$ solid product was obtained in yield of $27.9 \%$. m.p.: $89-92^{\circ} \mathrm{C}$. purity: $90 \%$ (indicted by GC analysis), still contain some impurities.

\section{Octaphenylcyclotetrasilane, 12}

A $1 \mathrm{~L} 3$ neck round bottom flask which was equipped with a magnetic stirring bar, a condenser and an addition funnel, was charged with magnesium metal $(23.23 \mathrm{~g}, 0.96$ $\mathrm{mol})$ and THF ( $300 \mathrm{~mL})$. At room temperature, 1,2-dibromoethane (37.6 g, $0.2 \mathrm{~mol})$ was 
slowly added into the stirring mixture (about 3 hours) to give magnesium bromide. Then the solution of dichlorodiphenylsilane $(40.5 \mathrm{~mL}, 0.195 \mathrm{~mol})$ in $400 \mathrm{~mL}$ THF was slowly added into the rapidly stirred mixture at room temperature over 40 minutes. The mixture was refluxed overnight prior to removal of salts and excess magnesium metal by filtration. After stirring the salts in water, the white precipitate was collected by filtration, dried and soxhlet extraction using benzene as the solvent (1 week) afforded pure product $(16.83 \mathrm{~g}$, $0.023 \mathrm{~mol}$ ) in yield of $47 \%$. m.p.: $322-324^{\circ} \mathrm{C}$.

\section{Octachlorocyclotetrasilane, 13}

A $250 \mathrm{~mL}$ 3-neck round bottom flask, equipped with a magnetic stirring bar and a condenser, was charged with octaphenylcyclotetrasilane, $12,(7.0 \mathrm{~g}, 9.6 \mathrm{mmol})$, anhydrous aluminum chloride $(0.3 \mathrm{~g})$ and benzene $(150 \mathrm{~mL})$. At room temperature, anhydrous $\mathrm{HCl}$ gas was flowed through the stirring mixture for $1 \mathrm{~h}$. The reaction started quickly and was accompanied by the warming of the flask and the clear yellow color of the solution changed from the white solid/liquid mixture. After $1 \mathrm{~h}$ of $\mathrm{HCl}$ gas introduction, argon was passed through the solution for 30 minutes to get rid of the remaining $\mathrm{HCl}$. Then the small amount of aluminum chloride and polymers were removed by filteration under argon, the solvent was distilled to give a yellow, solid product. This crude product was then sublimed at $80^{\circ} \mathrm{C} / 0.1 \mathrm{mmHg}$ to give pure 13 ( $1.88 \mathrm{~g}, 4.75 \mathrm{mmol}$ ) in yield of $49.45 \%$. EI-M m/z 395.7 (2.62), 397.7 (1.70), 393.7 (2.13), 295.7 (100), 297.8 (92), 293.8 (51), 197.7 (68). 


\section{Perchloronated tetrasilane, 14}

A $250 \mathrm{~mL}$ 3-neck round bottom flask, equipped with a magnetic stirring bar and a condenser, was charged with octaphenylcyclotetrasilane $(9.0 \mathrm{~g}, 12.3 \mathrm{mmol})$, anhydrous aluminum chloride $(0.4 \mathrm{~g})$ and benzene $(150 \mathrm{~mL})$. At room temperature, anhydrous hydrogen chloride gas was flowed through the stirring mixture for $1 \mathrm{~h}$. The reaction was started in a short time, fact that can be noticed quickly due to the warming of the flask and clear yellow color of the solution changed from the white solid/liquid mixture. After $1 \mathrm{~h}$ of $\mathrm{HCl}$ gas introduction, the small amount of aluminum chloride and polymers were filtered off under argon, the solvent was distillated out to give a yellow, solid product. This crude product was then sublimed at $65^{\circ} \mathrm{C} / 0.1 \mathrm{mmHg}$ to give pure14 $(2.01 \mathrm{~g}, 4.31$ mmol) in yield of 35\%. EI-MS m/z 466 (5.22), 464 (4.30), 468 (3.24), 431 (2.11), 365 (4.29), 335 (26.3), 333 (43.11), 331 (41.1), 329 (16.5), 296 (5.35), 294 (3.23), 233 (28.7), 231 (16.3), 198 (44.7), 196 (31.6), 168 (2.52) 133 (38), 98 (22.3), 63 (100). Literature MS data $m / z 462$ (8), 427 (6), 392 (1), 364 (2), 329 (100), 294 (21), 231 (56), 196 (39), 168 (6), $161(5), 133(39), 98(18), 63(42) .^{57}$

\section{Octapropargyloxycyclotetrasilane, 15}

A $100 \mathrm{~mL}$ round bottom flask was charged with octachlorocyclotetrasilane, $\mathbf{1 3}$ (2.45 g, $6.19 \mathrm{mmol})$, benzene $(50 \mathrm{~mL})$ and imidazole $(3.37 \mathrm{~g}, 49.5 \mathrm{mmol})$ under Ar. At room temperature, propargyl alcohol $(6.5 \mathrm{~mL}, 0.112 \mathrm{~mol})$ was slowly added to this stirred mixture. After stirring at room temperature overnight, the mixture was filtered under $\mathrm{Ar}$, 
and the solvent was distilled out. The resulting mixture was distilled under reduced pressure to give $3.4 \mathrm{~g}$ (6.16 mmol, $99.5 \%$ yield) of pure octapropargyloxycyclotetrasilane. b.p.: $118-120^{\circ} \mathrm{C} / 0.25 \mathrm{mmHg}$; $\mathbf{I R}\left(\mathrm{cm}^{-1}\right)$ : $675.3,846.6,1101.1,2124.5$ (vs, $\mathrm{C} \equiv \mathrm{C}$ ), 2879.4, 2934.1, 3289.5 (vs, =C-H); CI-MS $\left(\mathrm{M}+\mathrm{NH}_{3}\right) \mathrm{m} / \mathrm{z} 514\left(\mathrm{M}-\mathrm{OCH}_{2} \mathrm{C} \equiv \mathrm{CH}, 73\right), 266$ (100); ${ }^{1} \mathrm{H}-\mathrm{NMR}\left(300 \mathrm{MHz}, \mathrm{CDCl}_{3}\right) \delta(\mathrm{ppm}) 2.45(8 \mathrm{H}, \mathrm{t}, \mathrm{J} 3 \mathrm{~Hz}, \equiv \mathrm{CH}), 4.47(16 \mathrm{H}, \mathrm{d}, \mathrm{J}$ $\left.3 \mathrm{~Hz}, \mathrm{OCH}_{2}\right) ;{ }^{13} \mathrm{C}-\mathrm{NMR}\left(300 \mathrm{MHz}, \mathrm{CDCl}_{3}\right) \delta(\mathrm{ppm}) 51.88\left(\mathrm{sp}^{3}-\mathrm{CH}_{2}\right), 73.87$ (sp-C), 80.43 (sp-CH); ${ }^{29} \mathrm{Si}-\mathrm{NMR}\left(200 \mathrm{MHz}, \mathrm{CDCl}_{3}\right) \delta(\mathrm{ppm})-82.84$.

\section{Octaethynylcyclotetrasilane, 16}

Into a $100 \mathrm{~mL}$ round bottom flask, equipped with a magnetic stirring bar and an addition funnel, was added $0.45 \mathrm{~g}(1.14 \mathrm{mmol})$ of 13 , octachlorocyclotetrasilane. At $-72^{\circ} \mathrm{C}$, ethynylmagesium chloride/THF solution ( $60 \mathrm{~mL}, 0.5 \mathrm{M}$ ) was slowly added into the flask while stirring. After stirred at $-72^{\circ} \mathrm{C}$ for $1 \mathrm{~h}$, the mixture was slowly warmed to room temperature and stirred overnight. Dry hexanes $(35 \mathrm{~mL})$ were added into the mixture, and the precipitation was removed by filtration under Ar. After the solvent was removed by distillation, a solid salt was obtained, which was insoluble in organic solvents. 16 was not observed.

\section{Octaallylcyclotetrasilane, 17}

Into a $100 \mathrm{~mL}$ round bottom flask, equipped with a magnetic stirring bar and an addition funnel, was added $1.26 \mathrm{~g}(3.03 \mathrm{mmol})$ of 13 , octachlorocyclotetrasilane. At $0^{\circ} \mathrm{C}$, 
allylmagesium chloride/THF solution $(50 \mathrm{~mL}, 2 \mathrm{M})$ was slowly added into the flask while stirring. After stirred at $0^{\circ} \mathrm{C}$ for $1 \mathrm{~h}$, the mixture was slowly warmed to room temperature and stirred for 3 days. Dry hexanes $(40 \mathrm{~mL})$ were added into the mixture, and the precipitation was removed by filtration under Ar. After the solvent was removed by distillation, a small amout of solid product was obtained, whose NMR spectra shown no evidence of the presence of 17 .

\section{Dendrimer 18}

Into a $100 \mathrm{~mL}$ round bottom flask was added $0.12 \mathrm{~g}(0.217 \mathrm{mmol})$ of 15 , octapropargyloxycyclotetrasilane, $5 \mathrm{~mL}$ (excess) of dichloromethylsilane, $15 \mathrm{~mL}$ of anhydrous benzene and a catalytic amount of CPA. Then the flask was sealed by a teflon stopcock. The reaction was started in one hour, fact that can be noticed due to the warming of the flask and changing of the color. The reaction system was stirred at room temperature for 3 days. The reaction flask was connected to a vacuum system. The excess dichloromethylsilane was removed, and $30 \mathrm{~mL}$ of anhydrous benzene was added. Then this solution was transfered under $\mathrm{Ar}$ through a transfer line into another $100 \mathrm{~mL}$ round bottom flask which contained imidazole $(0.24 \mathrm{~g}, 3.53 \mathrm{mmol})$. At room temperature, propargyl alcohol ( $2 \mathrm{~mL}, 34.4 \mathrm{mmol}$ ) was added dropwise into this stirred mixture. After stirring at room temperature overnight, the mixture was filtered under Ar, and the solvent was removed by distillation. The obtained final product was a mess from NMR analysis, which was inseparable and difficult to characterize. 


\section{References}

(1) Tomalia, D.A.; Naylor, A.M.; Goddard III, W.A. Angew. Chem., Int. Ed. Engl. 1990, 29,138 .

(2) Mekelburger, H.B.; Jaworek, W.; Vogtle, F. Angew. Chem., Int. Ed. Engl. 1992, 31, 1571.

(3) Frechet, J.M.J. Science 1994, 263, 1710.

(4) Issberner, J.; Moors, R.; Vogtle, F. Angew. Chem., Int. Ed. Engl. 1994, 33, 2413.

(5) Moorefield, C.R.; Newkome, G.R. In Advances in Dendritic Molecules, Newkome, G.R., Ed.; JAI Presss: Greenwich, CT, 1994, Vol.1, page 1.

(6) Dagani, R. C\&EN, 1996, june 3, 30.

(7) van der Made, A.W.; van Leeuwen, P.W.N.M.; de Wilde, J.C.; Brandes, R.A.C. Adv. Mater. 1993, 5, 466.

(8) Kim, Y.H.; Webster, O.W. Macromolecules. 1992, 25, 5561.

(9) Zhou, Y.; Bruening, M.L.; Bergbreiter, D.E.; Crooks, R.M.; Wells, M. J. Am. Chem. Soc. 1996, 118, 3773.

(10) Frechet, J.M.J.; Henmi, M.; Gitsov, I.; Aoshima, S.; Leduc, M.R.; Grubbs, R.B. Science, 1995, 269, 1080.

(11) Muzafarov, A.M.; Gorbatsevich, O.B.; Rebrov, E.A.; Ignat', G.M.; Chenskaya, T.B.; Myakushev, V.D.; Bulkin, A.F.; Papkov, V.S. Vysokomol. Soedin. 1993, 35, 1867.

(12) Knapen, J.W.J.; van der Made, A.W.; de Wilde, J.C.; van Leeuwen, P.W.N.M.; Wijkens, P.; Grove, D.M.; van Koten, G. Nature, 1994, 372, 659. 
(13) Well, M.; Crooks, R.M. J. Am. Chem. Soc. 1996, 118, 3988.

(14) Jansen, J.F.G.A.; de Brabander-van denBerg, E.M.M.; Meijer, E.W. Science, 1994, $266,1226$.

(15) Jansen, J.F.G.A.; Meijer, E.W. J. Am.Chem. Soc. 1995, 117, 4417.

(16) Xu, Z.; Moore, J.S. Angew. Chem. Int. Ed. Engl. 1993, 32, 1354.

(17) Xu. Z;; Moore, J.S. ibid, 1993, 32, 246.

(18) Xu, Z.; Moore, J.S. Acta Polym. 1994, 45, 83.

(19) Bochkarev, M.N.; Katkova, M.A. Russ. Chem.Rev. 1995, 64, 1035.

(20) Baker, A.S.; John, D.; U.S. Patent, 3,669,939, 1972.

(21) Hawker, C.J.; Lee, R.; Frechet, J.M.J. J. Am. Chem. Soc. 1991, 113, 4583.

(22) Zimmerman, S.C.; Zeng, F.; Reichert, D.E.C.; Kolotuchin, S.V. Science, 1996, 271, 1095.

(23) Rebrov, E.A.; Muzafarov, A.M.; Paapkov, V.S.; Zhdanov, A.A. Dokl. Akad.Nauk SSSR 1989, 309, 376.

(24) Uchida, H.; Kabe, Y.; Yoshino, K.; Kawamate, A.; Tsumuraya, T.; Masamune, S. J. Am. Chem. Soc. 1990, 112, 7077.

(25) Mathias, L.J.; Carothers, T.W. J. Am. Chem. Soc. 1991, 113, 4043.

(26) Morikawa, A.; Kakimoto, M.; Imai, Y. Macromolecules 1991, 24, 3469.

(27) van der Made, A.W.; van Leeuwen, P.W.N.M. J. Chem. Soc., Chem. Commun. $1992,1400$. 
(28) (a) Roovers, J.; Toporowski, P.M.; Zhou, L.-L. Polym. Prepr. (Am. Chem. Soc., Div. Polym. Chem.) 1992, 32, 182. (b) Zhou, L.-L.; Roovers, J. Macromolecules 1993, 26, 963. (c) Roovers, J.; Zhou, L.-L.; Toporowski, P.M.; van der Zwan, M.; Iatrou, H.; Hadjichristidis, N. Macromolecules, 1993, 26, 4324.

(29) Seyferth, D.; Son, D.Y. Organometallics, 1994, 13, 2682.

(30) Seyferth, D.; Kugita, T. Organometallics 1995, 14, 5362.

(31) Alonso, B.; Cuadrado, I.; Moran, M.; Losada, L. J. Chem. Soc., Chem. Commun. $1994,2575$.

(32) Lorenz, K.; Mulhaupt, R.; Frey, H. Macromolecules, 1995, 28, 6657.

(33) Lambert, J.B.; Pflug, J.L.; Stern, C.L. Angew. Chem., Int. Ed. Engl. 1995, 34, 98.

(34) Lambert, J.B.; Pflug, J.L.; Denari, J.M. Organometallics, 1996, 15, 615.

(35) Sekiguchi, A.; Nanjo, M.; Kabuto, C.; Sakurai, H. J. Am. Chem. Soc. 1995, 117, 4195.

(36) Suzuki, H.; Kimata, Y.; Satoh, S.; Kuriyama, A. Chem. Lett. 1995, 293.

(37) MacLean, D.I.; Sacher, R.E. J. Orgaomet. chem. 1974, 74, 197.

(38) Kruerke, U. J. Orgaomet. chem 1970, 21, 83.

(39)Ukevics, E.; Voronkov, M.G. Organic Insertion Reactions of Group IV Elements, Consultant Bureau: New York, 1963.

(40)Brandsma, L, Preparative Acetylenic Chemistry, 2nd Edition, Elsevier, New York, 1988, p.114.

(41) Hengge, E.; Janoschek, R. Chem. Rev. 1995, 95, 1495. 
(42) (a) Smith, C.L.; Gooden R. J. Organomet. Chem. 1974, 81, 33. (b) Gilman, H.; Peterson, D.J.; Jarvie, A.W.; Winkler, H.J.S. J. Am. Chem. Soc. 1960, 82, 2076

(43) (a) Steele, A.R.; Kipping, J.S. J. Chem. Soc. 1929, 2545. (b) Richter, M.; Neumann, W.P. J. Organomet. Chem. 1969, $20,81$.

(44) (a) Ishikawa, M.; Kumadaa, M. J. Organomet. Chem. 1972, 42, 325. (b) Hengge,

E.; Schuster, H.G.; Peter, W. J. Organomet. Chem. 1980, 186, C45.

(45) (a) Carlson, C.W.; West, R. Organometllics 1983, 2, 1792. (b) Carlson, C.W.;

Matsumura, K.; West, R. J. Organomet. Chem. 1980, 194, C5.

(46) (a) Watanabe, H.; Inose, J.; Fukushima, K.; Kougo, Y.; Nagai, Y. Chem. Lett. 1983,

1711. (b) Watanabe, H.; Muraoka, T.; Kageyama, M.; Yoshizumi, K.; Nagai, Y.J.

Organomet. Chem. 1981, 216, C45. (c) Watanabe, H.; Kato, M.; Okawa, T.; Kougo, Y.; Nagai, Y.; Goto, M. Appl. Organomet. Chem. 1987, 1, 157.

(47) Weidenbruch, M.; Thom, K.-L.; Pohl, S.; Saak, W. Monatsh. Chem. 1988, 119, 65.

(48) Matsumoto, H.; Minemura, M.; Taktsuna, K.; Nagai, Y. Goto, M. Chem. Lett. 1985, 1005.

(49) Watanabe, H.; Muraoka, T.; Kageyama, M.; Yoshizumi, K.; Nagai, Y. Organometlics 1984, 3, 141.

(50) Hengge, E.; Kovar, D. Z. Anorg. Allg. Chem. 1979, 48, 163.

(51) Kovar, D.; Utvary, K.; Hengge, E. Monatsh, Chem. 1979, 110, 1295.

(52) Hengge, E.; Kovar, D. Angew. Chem., Int. Ed. Engl. 1981, 20, 678. 
(53) (a) Chen, Y.S.; Gaspar, P.P. Organometllics 1982, 1, 1410. (b) Matsumoto, H.; Yokoyam, N.; Sakamoto, A.; Armki, Y.; Endo, R.; Naagai, Y. Chem. Lett. 1986, 1643.

(54) (a) 51(b). (b) Nagai, Y.; Matsumoto, H. Chem. Abstr. 1988, 109, 23128 b.

(55) (a) Watanabe, H.; Kougo, Y.; Kato, M.; Kuwabara, H.; Okawa, T.; Nagai, Y. Bull. Chem. Soc. Jan. 1984, 57, 3019. (b) 44(c).

(56) Hssler, K.; Kovar, D.; Sollradl, H.; Hengge, E. Z. Anorg. Allg. Chem. 1982, 488, 27.

(57) Raml W., Hengge, E. Z. Naturforsch. 1979, B 34, 1457. 


\section{SYNTHESIS OF CERAMIC PRECURSOR POLYMERS}

\section{Literature Survey}

Among the high-performance non-oxide ceramics, silicon carbide ( $\mathrm{SiC}$ ) offers unique potential as a thermomechanical material due to its stiffness and especially its exceptional structural stability under environmental extremes. Intense research over the past 20 years has been focused on the production of $\mathrm{SiC}$ materials from organosilicon precursors. ${ }^{1}$ Preceramic polymers represent a useful strategy for the formation of fibers, coatings and composite matrices. The advantages of the pyrolysis of preceramic polymers include (a) the ability to prepare ceramics with complex shapes which otherwise are difficult to obtain by conventional powder processing methods (e.g., fibers, films); (b) processing temperatures lower than those of conventional technologies.

The composition and structure of the precursor polymers will determine the composition of the final ceramic, as well as its physical and mechanical properties. For example, because of the presence of $\mathrm{C}$ and $\mathrm{O}$ impurities in Nicalon fiber, excessive loss in weight and mechanical strength above ca. $1200^{\circ} \mathrm{C}$ limits its usefulness as a high temperature reinforcement phase for composites. ${ }^{2}$ An ideal preceramic polymer should possess most of the following properties: (i) a high molecular weight to prevent any volatilization of oligomers; (ii) a cage or ring structure to decrease the elimination of volatile fragments resulting from backbone cleavage; (iii) viscoelastic properties (fusibility, malleability, or solubility) to enable the polymer in the desired shape before the pyrolytic 
process; (iv) presence of latent reactivity (functional substituents) to obtain thermosetting or curing properties; and (v) low organic group content to increase ceramic yield and avoid the production of undesired free carbon excess.

Research on polymeric precursors to silicon carbide began in the mid-1970's with the reports by Yajima of the successful application of a "polycarbosilane" derived from thermal isomerization of polydimethylsilane as a "processable" precursor to $\mathrm{SiC}$ fiber (Nicalon), as shown in Scheme 1. Since that time much effort has been devoted to develop novel polymeric precursors which can be pyrolyzed to form silicon carbide in high yield and purity. ${ }^{4,5}$ Of particular interest has been the use of such precursors to prepare continuous, weavable, ceramic fibers for use as the reinforcement phase in both ceramic and metal matrix composites. ${ }^{6}$ To date, Nicalon fiber has been the only widely available commercial product to emerge from this effort. This fiber is available in several grades that vary in modulus, strength, and thermal stability.

Most of the recent work is devoted to reduce oxygen and free carbon content in the fiber and more generally, to an improvement of the mechanical properties at high temperature. The general rule-of-thumb in this search for high-yield $\mathrm{SiC}$ precursors is that linear polymers exhibit a low ceramic yield due to thermally induced "chain-unzipping" processes that lead to volatile, low molecular weight fragments and, consequently, that cross-linked structures are a virtual requirement for suitable precursors in order to avoid this material loss. ${ }^{7}$ The presence of hydrogen attached to silicon provides a thermosetting mechanism which minimizes mass loss due to depolymerization. ${ }^{8}$ Polymers that possess a nominal 1:1 ratio of $S i$ to $C$ and that undergo pyrolysis so as to preserve this 1:1 


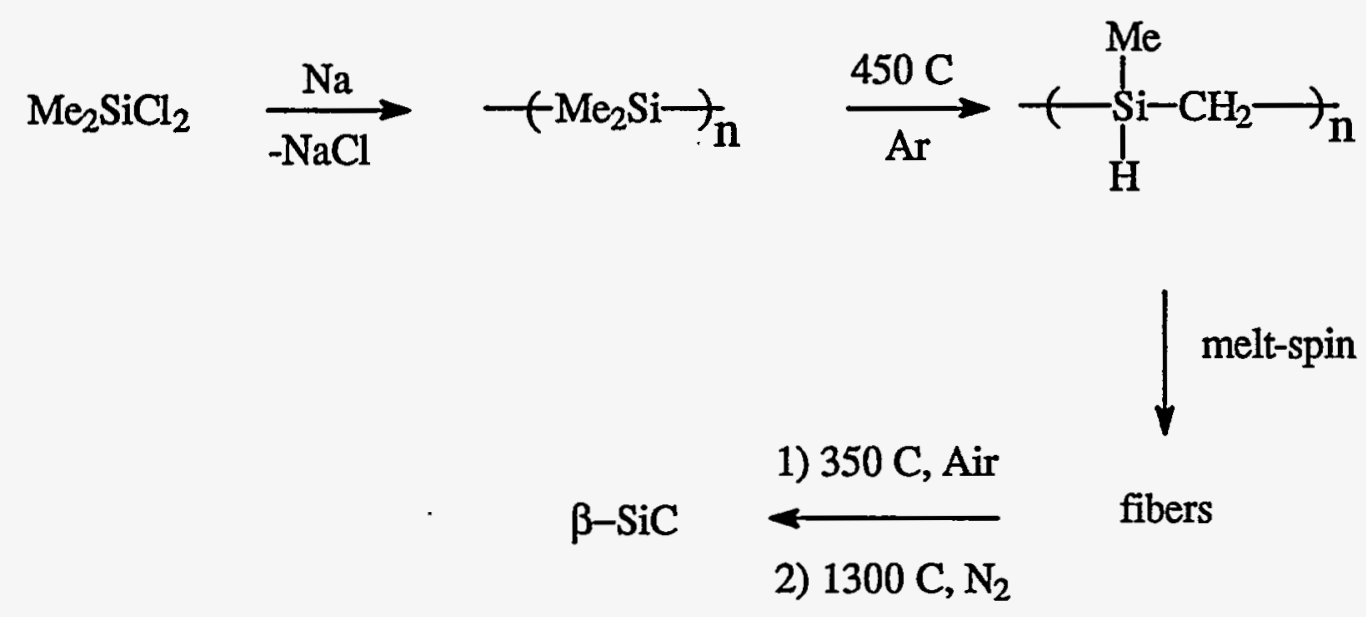

Scheme 1

stoichiometry have been of particular interest. ${ }^{9,10}$

A variety of polycarbosilanes (PCS) have been reported to have essentially a 1:1 $\mathrm{Si}: \mathrm{C}$ ratio, but no information has been given on the thermal treatment of PCSs for obtaining $\mathrm{Si} / \mathrm{C} \approx 1 .^{1}$ In $1986, \mathrm{Smith}^{11}$ claimed the preparation of poly(silamethylene) by ring-opening polymerization of small amounts of 1,3-disilacyclobutane in heptane, using Pt-group metal derivatives as catalysts (Scheme 2). The polymer was reported to yield $85 \%$ of $\mathrm{SiC}$ when pyrolyzed $1 \mathrm{~h}$ at $900^{\circ} \mathrm{C}$ under argon. TGA showed a $10.1 \%$ weight loss at $900^{\circ} \mathrm{C}$ and $\mathrm{IR}$ spectra indicated that cross-linking involving dehydrocondensation of Si$\mathrm{H}$ and $\mathrm{C}-\mathrm{H}$ bonds began at $500^{\circ} \mathrm{C}$. The Si-H loss was practically complete at $700^{\circ} \mathrm{C}$, and crystallization of the residue started at $900^{\circ} \mathrm{C}$. The polymer was said to be fusible, but no further details were given, especially about the synthesis of the monomer, and the linear structure of the polymer was not proven. ${ }^{12}$ 

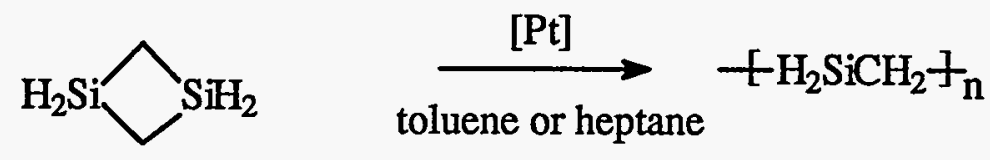

$75-100 \mathrm{C}$

Scheme 2

Interrante and co-workers have developed two different routes to synthesize polycarbosilanes that have essentially a " $\mathrm{SiH}_{2} \mathrm{CH}_{2}$ "composition. ${ }^{13}$ They found that their 1:1 Si:C ratio was effectively preserved on pyrolysis, owing to their ability to thermoset through loss of $\mathrm{H}_{2}$ from $\mathrm{Si}$. The first route involves ring-opening polymerization of 1,1,3,3-tetrachlorodisilacyclobutane with platinum catalyst, and yields a high molecular weight, linear polymer. Direct reduction of this polymer in benzene led to poly(silamethylene) with $\mathrm{Mn}=12,300 .{ }^{12 \mathrm{~b}}$ This polymer has all of the desirable features of an ideal $\mathrm{SiC}$ matrix sources but one, a reasonable cost. Considering the tedious synthesis of the monomer (pyrolysis of 1,1-dichlorosilacyclobutane at $840^{\circ} \mathrm{C}$ ), this method is only suitable for the preparation of very small amounts of PCS. The second route is shown in Scheme 3. A highly branched hydridopolycarbosilane was prepared by Grignard coupling of $\mathrm{Cl}_{3} \mathrm{SiCH}_{2} \mathrm{Cl}$ with $\mathrm{Mg}$ in diethyl ether, followed by reduction with $\mathrm{LiAlH}_{4}{ }^{9 \mathrm{a}}$ This synthesis is amenable to large scale production. IR and NMR data suggested almost exclusive head-to-tail coupling as no evidence of $\mathrm{Si}-\mathrm{Si}$ or Si- $-\mathrm{CH}_{2}-\mathrm{CH}_{2}-\mathrm{Si}$ units was found. The chlorinated intermediate possessed an average of 15.4 units and its composition $\left[\mathrm{CH}_{2} \mathrm{SiCl}_{1.7}(\mathrm{OEt})_{0.15}(\mathrm{Et})_{0.15}\right]_{\text {n }}$, showed the participation of ether in the reaction. Reduction led to an oligomer/polymer mixture $\left[\mathrm{CH}_{2} \mathrm{SiH}_{1.85}(\mathrm{Et})_{0.15}\right]_{\mathrm{n}}$ with $\mathrm{M}_{\mathrm{n}}=745$ and a broad 
$\mathrm{Cl}_{3} \mathrm{SiCH}_{2} \mathrm{Cl} \underset{\text { reflux } 5 \text { days }}{\mathrm{Mg} / \mathrm{Et}_{2} \mathrm{O}}\left[\mathrm{Cl}_{2} \mathrm{SiCH}_{2}\right]_{\mathrm{n}} \stackrel{\mathrm{LiAlH}_{4} / \mathrm{H}_{2} \mathrm{O} / \mathrm{HCl}}{\longrightarrow}-\left[\mathrm{H}_{2} \mathrm{SiCH}_{2}\right]_{\mathrm{n}}$

Scheme 3

distribution. When pyrolyzed to $1000^{\circ} \mathrm{C}$ under $\mathrm{N}_{2}$, overall ceramic yields of $58-80 \%$ were obtained. Its low cross-linking temperature $\left(80-200^{\circ} \mathrm{C}\right)$ and molecular weight might raise problems in fiber preparation, however, it could be suitable for matrix application.

The one-step synthesis of poly(methylsilane), (-[MeHSi]x-), which was developed first by Harrod and co-workers, ${ }^{9 \mathrm{~b}}$ involves dehydrocoupling of commercially available $\mathrm{MeSiH}_{3}$ as shown in Scheme 4. After 8 days of reaction, a completely hydrocarbonsoluble polymer can be isolated with $>90 \%$ yield. The $M_{n}$ is $\approx 1200$. The polymer is air sensitive and standard thermogravimetric analysis (TGA) experiments were not . reproducible. The polymer first undergoes a major rearrangement from poly(silane) to poly(carbosilane) at $400^{\circ} \mathrm{C}$. Above $400^{\circ} \mathrm{C}$, the resulting poly (carbosilane) decomposes to a hydrogenated form of SiC. Further heating to $1000^{\circ} \mathrm{C}$ for $1 \mathrm{~h}$, provides $\beta$-SiC mixed with small amounts of $\alpha$-SiC polytypes. Chemical analyses of material heated to $1100^{\circ}$ gave the average formula $\mathrm{Si}_{1} \mathrm{C}_{0.9} \mathrm{H}_{<0.2} \mathrm{O}_{0.1}$.

Corey and co-workers ${ }^{14}$ tried polymerization of monomer $\mathrm{H}_{3} \mathrm{SiCH}_{2} \mathrm{CH}_{2} \mathrm{SiH}_{3}$ with the combination catalyst $\mathrm{Cp}_{2} \mathrm{MCl}_{2} / \mathrm{BuLi}(\mathrm{M}=\mathrm{Ti}, \mathrm{Zr})$ to get a linear polymer that contains alternating $-\mathrm{CH}_{2} \mathrm{CH}_{2}$ - and $-\mathrm{SiH}_{2} \mathrm{SiH}_{2}$ - units, as shown in Scheme 5. However the polymerization reactions resulted in formation of completely insoluble polymer usually 
$\mathrm{MeSiH}_{3} \stackrel{0.2 \mathrm{~mol} \% \mathrm{Cp}_{2} \mathrm{TiMe}_{2} / \text { toluene }}{\longrightarrow} \mathrm{H}_{2}+\mathrm{H}-[\mathrm{MeSiH}]_{\overline{\mathrm{x}}} \mathrm{H}$

Scheme 4

within $30 \mathrm{~min}$ to $1 \mathrm{~h}$. They thought the reason was that the polymer contained secondary silyl units in the backbone which could, in the presence of catalyst, undergo further dehydrocondensation with other similar units or with remaining monomer, leading to cross-linked material.

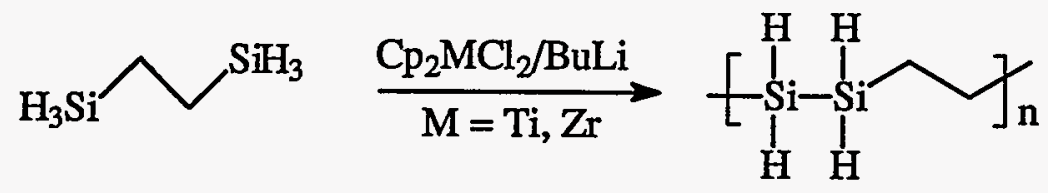

Scheme 5

Polysilaethylene, ${ }^{12 b}$ prepared by the ring-opening polymerization of $1,3-$ disilacyclobutane, pyrolyzes with $87 \%$ ceramic yield as a result of the presence of $\mathrm{Si}-\mathrm{H}$ functionality which cross-links the polymer at lower temperature than those required for depolymerization.

This section of the thesis is devoted to preparation of a series of carbosilane monomers. Polymerization of these monomers could result in the formation of ceramic precursor polymers which possess the ideal 1:1 stoichiometry of Si to C. 


\section{Results and Discussions}

In order to increase ceramic yield, functionalities which afford thermal crosslinking are needed in the polymer. The presence of unsaturation in the polymer main chain . should also allow for relatively low-temperature cross-linking, and indeed linear silyleneacetylene polymers are thermally converted with high char yields ${ }^{5}$ to $\mathrm{SiC}$ (and varying amounts of carbon depending upon the substituents on silicon) with no volatilization of the backbone silicon or acetylenic carbons. Presumably this result is due both to thermal cross-linking and to the considerably greater bond strength of the silicon-acetylene bond relative to either a silicon-silicon or silicon-alkyl bond.

As part of a general search for more efficient polymeric precursors of $\mathrm{SiC}$, we first tried to synthesize a silylene-acetylene polymer with small pendant groups. The synthesis of monomer $\mathrm{ClSiH}_{2} \mathrm{C} \equiv \mathrm{CSiH}_{2} \mathrm{Cl}, 2$, is shown in Scheme 6. We have spent considerable effort attempting to obtain the bis(chlorosilyl)acetylene. Phenylsilane, which was obtained by reducing of trichlorophenylsilane with $\mathrm{LiAlH}_{4}{ }^{16}$ was treated with $\mathrm{PCl}_{5}(1: 1$ ratio) in $\mathrm{CCl}_{4}$ at room temperature to give phenylchlorosilane. ${ }^{17}$ Then dilithium acetylide, which was quantitatively generated via a reaction of trichloroethylene with three equivalents of $\mathrm{n}-\mathrm{BuLi},{ }^{\text {5a }}$ was used to couple with the phenylchlorosilane to give bis(phenylsilyl)acetylene, 1 , in $59 \%$ yield. Attempts to synthesize monomer 2 from bis(phenylsilyl)acetylene by lectrophilic cleavage of Si-Ph bond with $\mathrm{HCl} / \mathrm{AlCl}_{3}$ failed. We found that $\mathrm{HCl} / \mathrm{AlCl}_{3}$ not only cleaved the $\mathrm{Si}-\mathrm{Ph}$ bond easily, but also cleaved the $\mathrm{Si}-\mathrm{C} \equiv \mathrm{CH}$ bond easily. Because of the low selectivity, we failed to get monomer 2 from compound 1 , so the attempted 


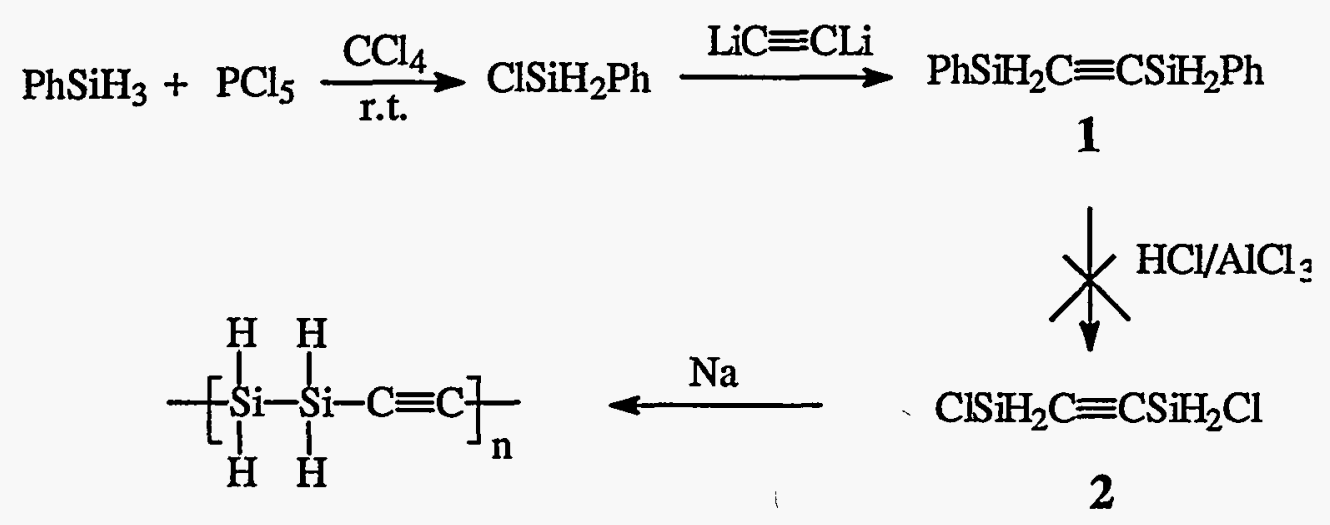

Scheme 6

synthesis of silylene-acetylene polymers was abordoned through this route.

Our next strategy, therefore, was to modify the structure of carbosilane monomer in order to increase the selectivity of cleavage. Bis(tri-4-methoxyphenylsilyl)acetylene, 5, was thus selected. It was anticipated that an electron withdrawing group in the paraposition of the benzene ring would make the electrophilic cleavage of $\mathrm{Si}-\mathrm{Ph}$ bond easier. As shown in Scheme 7, 4-bromoanisole was reacted with magnesium metal in THF to form a Grignard solution which was quenched with trichlorosilane to give tri(4 methoxyphenyl)silane, 3 , in yield of $81 \%$. Compound 3 was then treated with carbon tetrachloride in the presence of benzoylperoxide, and refluxed at Ar atmosphere for $24 \mathrm{~h}$, to give tri(4-methoxyphenyl)chlorosilane, 4 , in a quantitative yield. Dilithium acetylide was used to couple with 4 to afford compound 5 in yield of $68 \%$.

As shown in scheme 8, we tried to synthesize compound 6 from compound 5 . After dissolving compound 5 in benzene and then at the presence of $\mathrm{AlCl}_{3}$ as catalyst, dry $\mathrm{HCl}$ gas was flowed through the mixture for $1 \mathrm{~h}$. From GC and GC-MS analysis, we 
<smiles>COc1ccc(Br)cc1</smiles>

$\underset{\text { 1) } \mathrm{Mg} / \mathrm{THF}}{\stackrel{\text { } \mathrm{HSiCl}_{3}}{\longrightarrow}}$

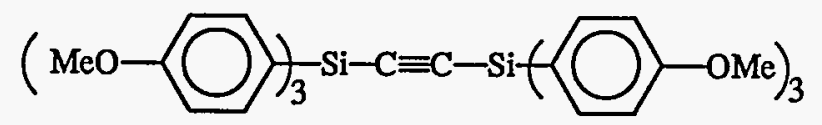

5

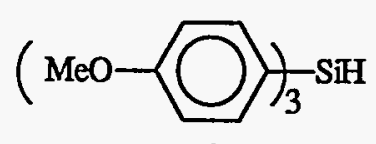

3 $\mid \begin{aligned} & \mathrm{CCl}_{4} \\ & (\mathrm{PhCOO})_{2} \mathrm{O}\end{aligned}$
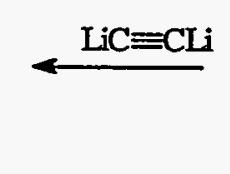

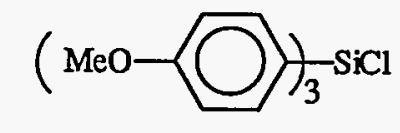

4

Scheme 7

knew that starting material 5 had reacted, 4-methoxybenzene was produced, but no compound 6 was observed. The reason might be the same: the selectivity of cleavage reaction was low, both $\mathrm{Si}-\mathrm{Ph}$ bond and $\mathrm{S}-\mathrm{C} \equiv \mathrm{CH}$ bond were cleaved off by $\mathrm{HCl}$ gas. Through these experiments, we know that in the electrophilic cleavage of Si-C bonds, there is no selectivity between a phenyl group and a $\mathrm{C} \equiv \mathrm{C}$ group. Although it is well known that the phenyl group can be cleaved more easily than the methyl group.

An alternative approach to the synthesis of organosilicon precursor polymers was explored. In this approach, we tried to synthesize polymer $-\left[\mathrm{SiH}_{2} \mathrm{SiH}_{2} \mathrm{CH}_{2} \mathrm{CH}_{2}\right]_{\mathrm{n}}-, 11$, which has a 1:1 ratio of $\mathrm{Si}$ to $\mathrm{C}$, and has a sp $\mathrm{sp}^{3}$ carbon-carbon bond in the main chain. Key

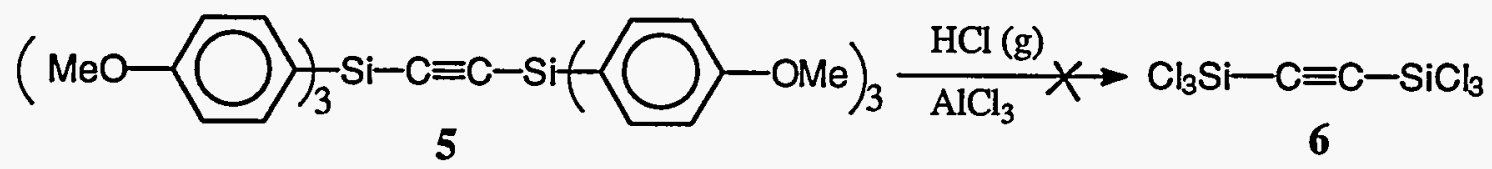

Scheme 8 
monomer 10 was synthesized from compound 9 , which was prepared by modification of literature methods (as shown in scheme 9). Vinyltrichlorosilane was reacted with one equivalent of phenylmagnesium bromide to give vinylphenyldichlorosilane, 7 , in yield of 43.1\%. ${ }^{18}$ Catalytic hydrosilylation of vinylphenyldichlorosilane with phenyldichlorosilane using CPA as catalyst afforded 1,2-bis(dichlorophenylsilyl)ethane, 8 , which was then reduced by $\mathrm{LiAlH}_{4}$ to give 1,2-bis(phenylsilyl)ethane, 9 , in a total yield of $48.2 \%{ }^{14}$

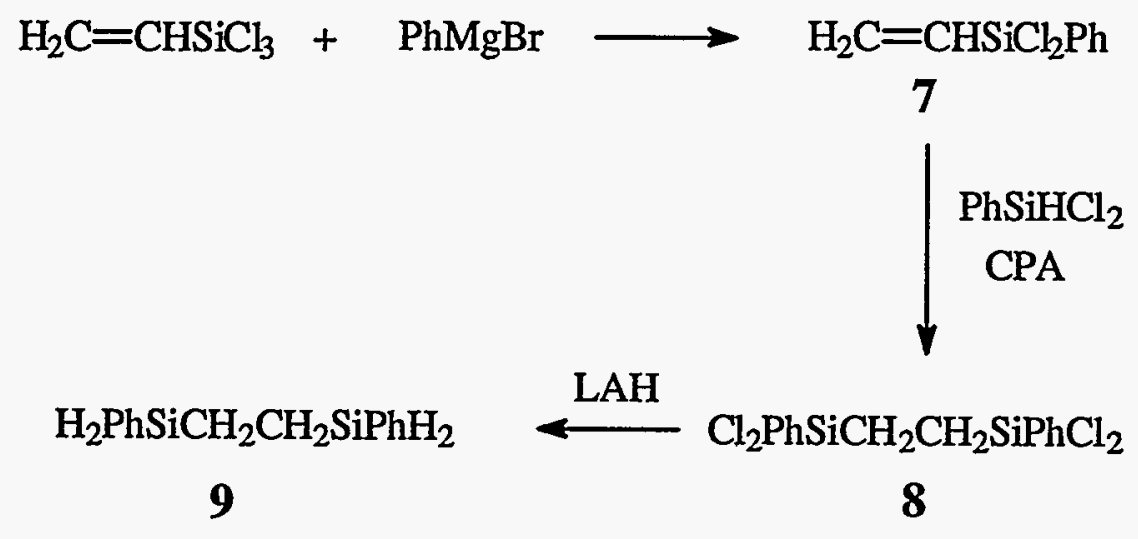

Scheme 9

After dissolving compound 9 in xylene and then in the presence of $\mathrm{AlCl}_{3}$ as catalyst, dry $\mathrm{HCl}$ gas was flowed through the mixture for $1 \mathrm{~h}$. Starting material 9 was reacted, 1,2-bis(chlorosilyl)ethane, 10, was produced according to GC and GC-MS analysis. After the solvent was removed by distillation, an inseparable mixture was obtained. So crude $\mathbf{1 0}$ was used without removing the solvent. After this solution of $\mathbf{1 0}$ was added into a sodium sand dispersion and refluxed for $5 \mathrm{~h}$, compound 12 was obtained 


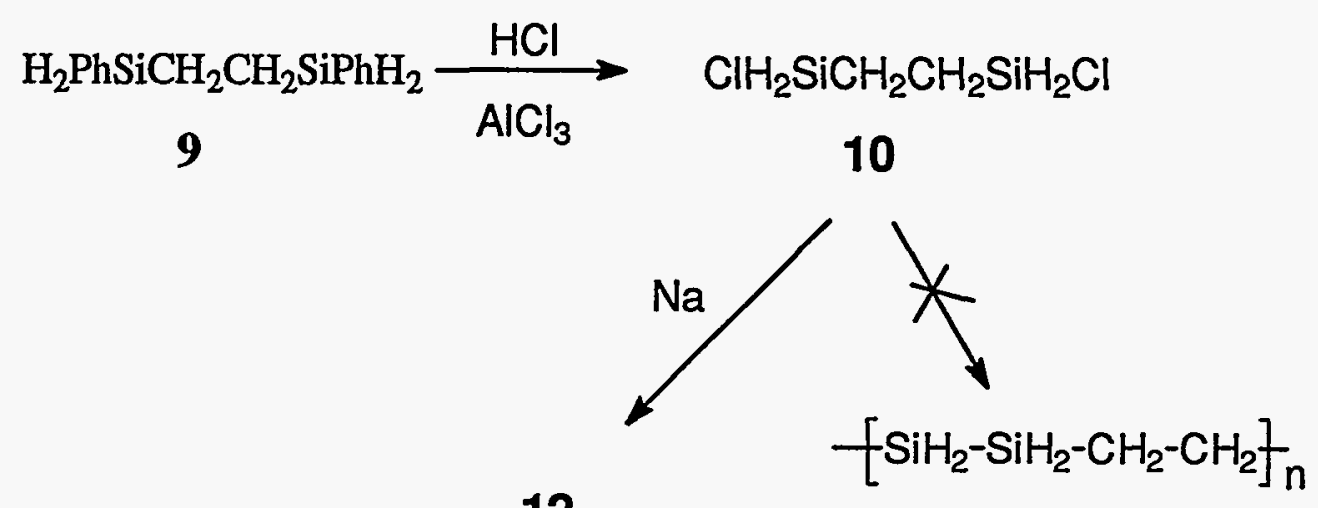

12

11

Scheme 10

instead of polymer 11, as shown in Scheme 10. The reason we believe is that the solution of $\mathbf{1 0}$ is too dilute.

Compound 12 was obtained in a small amount in the solution of benzene. This dilute solution is stable at room temperature. But the separation of $\mathbf{1 2}$ from benzene failed. Only the GC-MS spectra of $\mathbf{1 2}$ was obtained. It is difficult to identify $\mathbf{1 2}$ only from its mass data. As shown in Scheme 11, we think that 1,2-disilacyclobutane, 13, might be formed first. This four-membered ring compound might be stable in dilute solution. It was also possible that 13 was converted into 14 or 15 , or some other compounds during the refluxing time.

Gusel'nikov and coworkers ${ }^{19}$ found that 1,1,2,2-tetramethyl-1,2-disilacyclobutane, 16, could undergo spontaneous polymerization rapidly when warmed to room temperature from $77 \mathrm{~K}$, as shown in Scheme 12. But in our synthesis, no polymer was obtained. From GC and TLC analysis, 12 was the only product. 


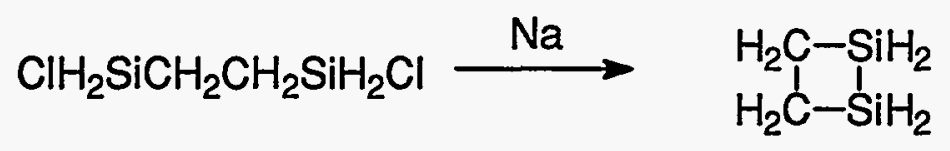

10

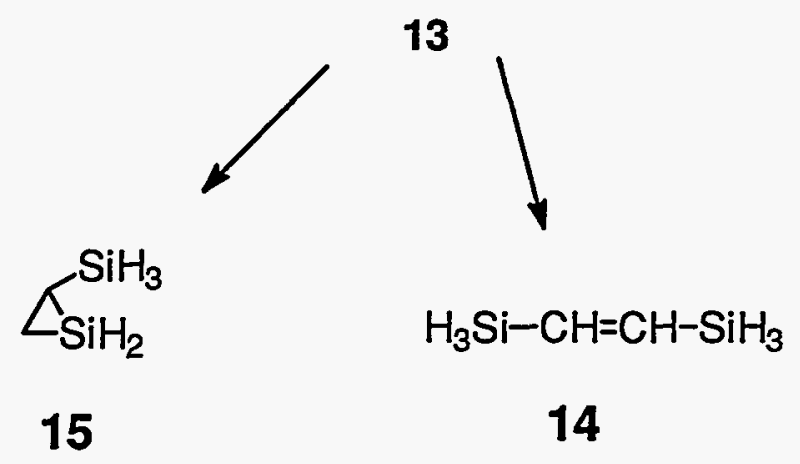

Scheme 11

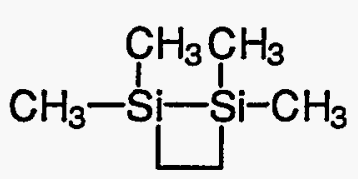

16

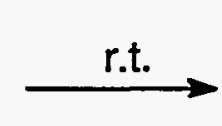

Scheme 12

\section{Conclusions}

Attempted synthesis of organosilicon ceramic precursor polymer was tried in several ways. The key monomers were not successfully synthesized because of the low selectivity between a phenyl group and a $\mathrm{C} \equiv \mathrm{C}$ group in the electrophilic cleavage of Si-C bond. When sodium sand was used to couple with 1,2-bis(chlorosilyl)ethane, instead of 
getting polymer - $\left[\mathrm{SiH}_{2} \mathrm{SiH}_{2} \mathrm{CH}_{2} \mathrm{CH}_{2}\right]_{\mathrm{n}}$-, a small molecular weight compound, 12, was obtained.

\section{Experimental}

Characterizations of synthesized compounds were based on MS, IR, ${ }^{1} \mathrm{H}-\mathrm{NMR}$, ${ }^{13} \mathrm{C}-\mathrm{NMR}$. and ${ }^{29} \mathrm{Si}-\mathrm{NMR}$. The exact masses were obtained from a Kratos MS 50 mass spectrometer with 10,000 resolution. The infrared spectra were recorded on a Bio-Rad Digilab FTS-7 spectrometer from neat samples. The ${ }^{1} \mathrm{H}$ and ${ }^{13} \mathrm{C}$ NMR spectra were collected on a Varian VXR-300 MHz spectrometer in deuterated chloroform solution unless otherwise specified. ${ }^{13} \mathrm{C}$ NMR spectra are proton decoupled. The ${ }^{29} \mathrm{Si}-\mathrm{NMR}$ spectra were collected on a BRUKER AC-200 MHz spectrometer. Reactions were monitored by Hewlett Packard 5890 series II GC and Hewlett Packard tandem GC-IR-MS (5890A GC-5965A IR-5970 Series MS) parallel connected.

THF was distilled over Na-benzophenone and ether was distilled over $\mathrm{CaH}_{2}$ immediately before use. Commercially available reagents were used as received unless otherwise specified. Scientific Adsorbents $40 \mu$ silica gel was utilized in flash chromatography.

\section{Bis(phenylsilyl)acetylene, 1}

To a $250 \mathrm{~mL}$ oven-dried, three-neck round bottom flask, equipped with a magnetic stirring bar and a pressure-equalizing graduated addition funnel, was added $50 \mathrm{~mL}$ dry 
THF. The system was flushed with Ar. The flask was cooled to $-78^{\circ} \mathrm{C}$ and $\mathrm{n}$-butyllithium (2.5 $\mathrm{M}$ in hexane, $86.2 \mathrm{~mL}, 0.216 \mathrm{~mol})$ was added. Trichloroethylene $(6.48 \mathrm{~mL}, 0.072$ mol) was added dropwise through the addition funnel at $-78^{\circ} \mathrm{C}$ while efficient stirring was maintained. The addition lasted about 20 minutes. After the addition, the mixture was allowed to gradually warm to room temperature. A lot of white salts precipitated out during this period. Following continuous stirring for one hour, the mixture was cooled back to $-78^{\circ} \mathrm{C}$ and phenylchlorosilane $(19.56 \mathrm{~g}, 0.14 \mathrm{~mol})$ was added through the addition funnel (lasted $10 \mathrm{~min}$.). Stirring was continued for one hour at $-78^{\circ} \mathrm{C}$, and then for two hours at room temperature. To the reaction mixture was added pentane $(80 \mathrm{~mL})$ and then $\mathrm{NH}_{4} \mathrm{Cl}$ solution $(150 \mathrm{~mL})$. The organic layer was separated and dried over anhydrous $\mathrm{MgSO}_{4}$. The solvent was removed by distillation. The resulting mixture was distilled under reduced pressure to give $11.4 \mathrm{~g}$ ( $0.048 \mathrm{~mol}, 59 \%$ yield) of bis(phenylsilyl)acetylene,

1. b.p.: $110^{\circ} \mathrm{C} / 1.5 \mathrm{mmHg} ;{ }^{1} \mathrm{H}-\mathrm{NMR}\left(300 \mathrm{MHz}, \mathrm{CDCl}_{3}\right) \delta(\mathrm{ppm}) 4.76(4 \mathrm{H}, \mathrm{s}, \mathrm{SiH})$, 7.49 to $7.80(10 \mathrm{H}$, multiplet, $=\mathrm{CH}) ;{ }^{13} \mathrm{C}-\mathrm{NMR}\left(300 \mathrm{MHz}, \mathrm{CDCl}_{3}\right) \delta(\mathrm{ppm}) 109.68$ (spC), $128.10\left(\mathrm{sp}^{2}-\mathrm{C}\right), 128.25\left(\mathrm{sp}^{2}-\mathrm{CH}\right), 130.38\left(\mathrm{sp}^{2}-\mathrm{CH}\right), 135.21$ ( $\left.\mathrm{sp}^{2}-\mathrm{CH}\right)$. GC-MS m/z $238\left(\mathrm{M}^{+}, 1.4\right), 159$ (6.74) 129 (14.5), 105 (100), 78 (64).

\section{Tri(4-methoxyphenyl)silane, 3}

To a $250 \mathrm{~mL}$ oven-dried, three-neck round bottom flask, equipped with a magnetic stirring bar, a condenser and a pressure-equalizing graduated addition funnel, was added dry THF $(100 \mathrm{~mL})$, and pieces of magnesium metal $(8.09 \mathrm{~g}, 0.332 \mathrm{~mol})$. Then through the 
addition funnel, a few drops of 4-bromoanisole was added while stirring. After the reaction started, the remaining 4-bromoanisole was slowly added into the flask (4 h). After completion of the addition of the 4-bromoanisole $(51.81 \mathrm{~g}, 0.277 \mathrm{~mol})$, the mixture was stirred at room temperature overnight. Then this Grignard solution was transferred into another $250 \mathrm{~mL}$ flask. Trichlorosilane $(8.4 \mathrm{~mL}, 0.0832 \mathrm{~mol})$ was slowly added into this solution at $0^{\circ} \mathrm{C}$, and the mixture was stirred at room temperature overnight. To the reaction mixture was added diethyl ether $(150 \mathrm{~mL})$ and then saturated $\mathrm{NH}_{4} \mathrm{Cl}$ solution $(200 \mathrm{~mL})$. The organic layer was separated and dried over anhydrous $\mathrm{MgSO}_{4}$. The solvent was removed and $23.65 \mathrm{~g}$ of white, crystalline tri(4-methoxyphenyl)silane was obtained (0.0676 mol, $81 \%$ yield). m.p.: $68-69^{\circ} \mathrm{C}$. EI-MS m/z $350\left(\mathrm{M}^{+}, 31\right), 349$ (M-H, 16), 273 (40), 242 (46), 28 (100); ${ }^{1} \mathrm{H}-\mathrm{NMR}\left(300 \mathrm{MHz}, \mathrm{CDCl}_{3}\right) \delta(\mathrm{ppm}) 3.80$ (9 H, s, $\left.\mathrm{OCH}_{3}\right), 5.42(1 \mathrm{H}, \mathrm{s}, \mathrm{SiH}), 6.916(6 \mathrm{H}, \mathrm{d}, \mathrm{J} 8.7 \mathrm{~Hz},=\mathrm{CH}), 7.480(6 \mathrm{H}, \mathrm{d}, \mathrm{J} 9 \mathrm{~Hz},=\mathrm{CH})$; ${ }^{13} \mathrm{C}-\mathrm{NMR}\left(300 \mathrm{MHz}, \mathrm{CDCl}_{3}\right) \delta(\mathrm{ppm}) 55.01\left(\mathrm{CH}_{3}\right), 113.79\left(\mathrm{sp}^{2}-\mathrm{CH}\right), 124.87\left(\mathrm{sp}^{2}-\mathrm{C}\right)$, $137.18\left(\mathrm{sp}^{2}-\mathrm{CH}\right), 160.90\left(\mathrm{sp}^{2}-\mathrm{C}\right)$.

\section{Tri(4-methoxyphenyl)chlorosilane, 4}

To a $100 \mathrm{~mL}$ two-neck round bottom flask, equipped with a magnetic stirring bar, and a condenser, was added tri(4-methoxyphenyl)silane ( $3.5 \mathrm{~g}, 10 \mathrm{mmol})$, benzoylperoxide $(0.3 \mathrm{~g})$ and carbon tetrachloride $\left(50 \mathrm{~mL}\right.$, distilled from $\left.\mathrm{P}_{2} \mathrm{O}_{5}\right)$. The solution was refluxed under Ar atmosphere for $24 \mathrm{~h}$. The solvent was distilled out and a quantitative yield of liquid $5(3.82 \mathrm{~g}, 9.93 \mathrm{mmol})$ was obtained. EI-MS m/z $384.2(\mathrm{M}$, 
9.8), $353.2\left(\mathrm{M}-O C H_{3}, 20.6\right), 310.1$ (30.7), 234.1 (15.4), 121.9 (35.1), 104.9 (100). ${ }^{1} \mathbf{H}-$ NMR $\left(300 \mathrm{MHz}, \mathrm{CDCl}_{3}\right) \delta(\mathrm{ppm}) 3.821\left(9 \mathrm{H}, \mathrm{s}, \mathrm{OCH}_{3}\right), 6.945(6 \mathrm{H}, \mathrm{d}, \mathrm{J} 6.9 \mathrm{~Hz},=\mathrm{CH})$, $7.562(6 \mathrm{H}, \mathrm{d}, \mathrm{J} 7.2 \mathrm{~Hz},=\mathrm{CH}) ;{ }^{13} \mathrm{C}-\mathrm{NMR}\left(300 \mathrm{MHz}, \mathrm{CDCl}_{3}\right) \delta(\mathrm{ppm}) 55.07\left(\mathrm{CH}_{3}\right)$, $113.77\left(\mathrm{sp}^{2}-\mathrm{CH}\right), 124.43\left(\mathrm{sp}^{2}-\mathrm{C}\right), 136.8\left(\mathrm{sp}^{2}-\mathrm{CH}\right), 161.5\left(\mathrm{sp}^{2}-\mathrm{C}\right)$.

\section{Bis(tri-4-methoxyphenylsilyl)acetylene, 5}

To a $100 \mathrm{~mL}$, three-neck round-bottom flask, equipped with a magnetic stirring bar and a pressure-equalizing graduated addition funnel, was added $20 \mathrm{~mL}$ dry THF. The system was flushed with Ar. The flask was cooled to $-78^{\circ} \mathrm{C}$ and n-butyllithium $(2.5 \mathrm{M}$ in hexane, $17.36 \mathrm{~mL}, 43.5 \mathrm{mmol})$ was added. Trichloroethylene ( $1.3 \mathrm{~mL}, 14.5 \mathrm{mmol})$ was added dropwise through the addition funnel at $-78^{\circ} \mathrm{C}$ while an efficient stirring was maintained. After the addition the mixture was allowed to gradually warm to room temperature. Following continuous stirring for an hour, the mixture was cooled back to $-78^{\circ} \mathrm{C}$ and tri(4-methoxyphenyl)chlorosilane $(11.27 \mathrm{~g}, 29.3 \mathrm{mmol})$ was slowly added through the addition funnel. Stirring was continued for one hour at $-78^{\circ} \mathrm{C}$, and then for two hours at room temperature. To the reaction mixture was added methylene chloride $(30 \mathrm{~mL})$ and then $\mathrm{NH}_{4} \mathrm{Cl}$ solution $(50 \mathrm{~mL})$. The organic layer was separated and dried over anhydrous $\mathrm{MgSO}_{4}$. The solvent was removed by distillation and $7.1 \mathrm{~g}$ of white, crystalline 5 was obtained $(9.8 \mathrm{mmol}, 68 \%$ yield $)$. m.p.: $179-180^{\circ} \mathrm{C} ;$ EI-MS m/z 722.4 (M, 2.1), 599.3 (2.16), 373.1 (39), 349.1 (100), 253.1 (9.8); ${ }^{1} \mathrm{H}-\mathrm{NMR}$ (300 MHz, $\left.\mathrm{CDCl}_{3}\right) \delta(\mathrm{ppm}) 3.816\left(9 \mathrm{H}, \mathrm{s}, \mathrm{OCH}_{3}\right), 6.908(6 \mathrm{H}, \mathrm{d}, \mathrm{J} 8.8 \mathrm{~Hz},=\mathrm{CH}), 7.581(6 \mathrm{H}, \mathrm{d}, \mathrm{J} 8.4$ 
$\mathrm{Hz},=\mathrm{CH}) ;{ }^{13} \mathrm{C}-\mathrm{NMR}\left(300 \mathrm{MHz}, \mathrm{CDCl}_{3}\right) \delta(\mathrm{ppm}) 55.02\left(\mathrm{CH}_{3}\right), 113.68\left(\mathrm{sp}^{2}-\mathrm{CH}\right), 114.03$ (sp-C), $124.72\left(\mathrm{sp}^{2}-\mathrm{C}\right), 137.07\left(\mathrm{sp}^{2}-\mathrm{CH}\right), 161.02\left(\mathrm{sp}^{2}-\mathrm{C}\right)$.

\section{Vinylphenyldichlorosilane, 7}

To a $1 \mathrm{~L}$, three-neck round bottom flask, equipped with a magnetic stirring bar and a pressure-equalizing graduated addition funnel, was added dry THF $(100 \mathrm{~mL})$ and vinyltrichlorosilane (49 g, $0.303 \mathrm{~mol})$. At room temperature, phenylmagnesium bromide $(300 \mathrm{~mL}, 1 \mathrm{M})$ was added dropwise into the flask. After the mixture was stirred at room temperature overnight, the salt was removed by filtration under $\mathrm{Ar}$, and the solvent was removed by distillation. The remaining product was distilled at $61^{\circ} \mathrm{C} / 0.3 \mathrm{mmHg}$ to give vinylphenyldichlorosilane ( $26.5 \mathrm{~g}, 0.131 \mathrm{~mol})$ in yield of $43.1 \%$. EI-MS $\mathrm{m} / \mathrm{z} 201.95(\mathrm{M}$, 16), 203.95 (11), 174.95(36), 176.95 (26), 124.85 (11), 126.85 (5.8), 104.05 (100), 105.05 (20), 77 (46); ${ }^{1} \mathrm{H}-\mathrm{NMR}\left(300 \mathrm{MHz}, \mathrm{CDCl}_{3}\right) \delta(\mathrm{ppm}) 6.18\left(\mathrm{~m}, 1 \mathrm{H}, \mathrm{sp}^{2}-\mathrm{CH}\right), 6.33$ (m, 2H, sp $\left.{ }^{2}-\mathrm{CH}_{2}\right), 7.73-7.76$ (m, 5H, phenyl); ${ }^{13} \mathrm{C}-\mathrm{NMR}\left(300 \mathrm{MHz}, \mathrm{CDCl}_{3}\right) \delta(\mathrm{ppm})$ $128.33\left(\mathrm{sp}^{2}-\mathrm{C}\right), 131.67\left(\mathrm{sp}^{2}-\mathrm{C}\right), 131.71\left(\mathrm{sp}^{2}-\mathrm{C}\right), 131.76\left(\mathrm{sp}^{2}-\mathrm{C}\right), 133.69(\mathrm{sp}-\mathrm{C}), 138.64$ $\left(\mathrm{sp}^{2}-\mathrm{C}\right)$

\section{1,2-Bis(phenylsilyl)ethane, 9}

Phenyldichlorosilane (11.98 g, $67.6 \mathrm{mmol})$ was added dropwise to vinylphenyldichlorosilane (13.74, g, $67.6 \mathrm{mmol})$ containing a catalytic amount of CPA. After a few drops of phenyldichlorosilane were added, the reaction was initiated by heating for a few 
seconds. The heat gun was removed and the remainder of the chlorosilane was added. The reaction mixture was heated to approximately $90^{\circ}$ for $5 \mathrm{~h}$, cooled, and then dissolved in THF (50 mL) and added dropwise to a dispersion of $\mathrm{LiALH}_{4}(4.5 \mathrm{~g})$ in THF (200 mL). After the addition was complete, the mixture was refluxed for $5 \mathrm{~h}$. The residue was then removed by filtration and the solvent was removed by distillation. The residue was extracted five times with pentane, the pentane extracts combined and then washed with water. The organic layer was dried over $\mathrm{Na}_{2} \mathrm{SO}_{4}$ and the pentane removed in vacuum. The product was distilled at $110^{\circ} \mathrm{C} / 0.1 \mathrm{mmHg}$ to afford $7.9 \mathrm{~g}(32.58 \mathrm{mmol}$, yield $48.2 \%)$ of 1,2-bis(phenylsilyl)ethane, 9. EI-MS m/z 242 (M, 1.3), 241 (2), 213 (5.7), 183 (23.3), 164 (93.2), 135 (93), 107 (100), 105 (90); ${ }^{1} \mathrm{H}-\mathrm{NMR}\left(300 \mathrm{MHz}, \mathrm{CDCl}_{3}\right) \delta(\mathrm{ppm}) 1.13$ (m, 4H, $\left.\mathrm{CH}_{2}\right), 4.46$ (s, 4H, $\left.\mathrm{SiH}_{2}\right), 7.47,7.67$ (m, $10 \mathrm{H}$, phenyl); ${ }^{13} \mathrm{C}-\mathrm{NMR}(300 \mathrm{MHz}$, $\left.\mathrm{CDCl}_{3}\right) \delta(\mathrm{ppm}) 4.42\left(\mathrm{sp}^{3}-\mathrm{CH}_{2}\right), 127.97\left(\mathrm{sp}^{2}-\mathrm{CH}\right), 129.60\left(\mathrm{sp}^{2}-\mathrm{CH}\right), 132.17\left(\mathrm{sp}^{2}-\mathrm{C}\right)$, $135.22\left(\mathrm{sp}^{2}-\mathrm{CH}\right)$.

\section{1,2-Bis(chlorosilyl)ethane, 10}

To a $100 \mathrm{~mL}$, two-neck round bottom flask, equipped with a magnetic stirring bar and a condenser, was added dry xylene $(40 \mathrm{~mL}), 1,2$-bis(phenylsilyl)ethane $(3.2 \mathrm{~g}, 13.2$ mmol) and a catalytic amount of anhydrous $\mathrm{AlCl}_{3}$. At room temperature dry $\mathrm{HCl}$ gas was flowed through it until the starting material was completely reacted from GC analysis (ca. $1 \mathrm{~h}$.). Then Ar was used to flow through the solution for 20 minutes. Under Ar, small amount of solid was removed by filtration, 1,2-bis(chlorosilyl)ethane was obtained as the 
only product from GC analysis. GC-MS m/z 159 (M, 8.9), 157 (12.4), 130 ((8), 93 ( $50.7), 65(100), 58(77)$. This product was used in the next step as starting material without removing the solvent.

\section{Compound 12}

To a $250 \mathrm{~mL}$, three-neck round bottom flask, equipped with a condenser, an addition funnel and a mechanical stirrer, was added anhydrous xylene $(140 \mathrm{~mL})$ and sodium metal $(1.80 \mathrm{~g}, 78.3 \mathrm{mmol})$ under Ar. The flask was heated to $120^{\circ}$ (oil bath temperature) for 20 minutes while the mixture was stirred vigorously. Then the temperature was cooled to $60^{\circ} \mathrm{C}$ and a fine sodium sand dispersion was formed. 1,2bis(chlorosilyl)ethane (made above) was added through the addition funnel dropwise (ca. 20 minutes). After addition was complete, the mixture was stirred under gentle refluxing for five hours and then cooled to room temperature. The excess sodium was filtered out under Ar. Distillation of the solution under $90^{\circ} \mathrm{C}$ afforded a small amount of $\mathbf{1 2}$ and benzene. GC-MS of 15: m/z 89 (M, 14.4), 88 (6.1), 87 (6.7), 86 (16.8), 75 (6.1), 69 (3.3), 60 (35.2), 59 (100), 58 (75.5), 57 (36.1).

\section{References}

(1) Birot, M.; Pillot, J.P.; Dunogues, J. Chem. Rev. 1995, 95, 1443.

(2) Pysher, D.J.; Goretta, K.C.; Hodder Jr, R.S.; Tressler, R.E. J. Am. Ceram. Soc. 1988, 72, 284. 
(3) (a).Yajima, S.; Okmura, K.; Hyashi, J.; Imura, M. J. Amer. Ceram. Soc. 1976, 59[78], 324; (b). Yajima, S.; Hasegwa, Y.; Hyashi, J.; Omori, M. J. Mater. Sci. 1978, 13[12], 2569; (c). Yajim, S. "Silicon Carbide Fibers", in Handbook of composites, edited by, Watt. W. and Perov, B.V. North-Holland, Amsterdam, Netherlnds, 1985, pp. 201-37.

(4) Line, R.M.; Babonneau, F. Chem. Mter. 1993, 5. 260.

(5) (a). Ijadi-Maghsoodi, S.; Pang, Y.; Barton, T.J. J. Polym. Sci. : Part A: Polym. Chem., 1990, 28, 955. (b). Pang, Y.; Ijadi-Maghsoodi, S.; Barton, T.J. Macromolecules, 1993, 26, 5671.

(6) (a). Okamura, K. "Ceramic Fiber and Whisker Requirements to Advanced Structural Inorganic Composite", in Advanced Structural Composites, Edited by P. Vicenzini, Elsevier Science Publ. B.V., Amsterdam, 1991, pp. 19-34. (b). Lipowitz, J. Am. Ceram. Soc. Bull. 1991, 70[12], 1888. (c) Cooke, T.F. J. Amer. Ceram. Soc. 1991, 74[12], 2959.

(7) (a). Wynne, K.J.; Rice, R.W. Annu. Rev. Mater. Sci. 1984, 14, 297-334. (b). Seyferth, D. In Inorganic and Organometallic Polymers; Zeldin, M.; Wynne, K.; Allcock, H.R., Eds.; ACS Symposium Series 360; American Chemical Society: Washington, DC, 1988, Chapter 3, pp 21-42.

(8) Wu, H.J.; Interrante, L.V. Chem. Mater. 1989, 1, 564.

(9) (a). Whitmarsh, C.K.; Interrante, L.V. Organometallics 1991, 10, 1336-1344. (b). Zhang, Z.-F.; Babonneau, F.; Laine, R.M.; Mu, Y.; Harrod, J.F.; Rahn, J.A. J.Am. Ceram. Soc. 1991, 74, 670-673. 
(10) Reid, A.W.; Rand,B.; Emsley, R.J.P. Mat. Res. Soc. Symp. Proc. , 1994, Vol.346, 843.

(11) Smith, T.L. U.S. Patent 4,631,179, 1986, Chem. Abstr. 1987, 106, 106920.

(12) (a) Wu, H.J.; Interrante, L.V. Polym. Prepr. 1992, 33, 210. (b) Wu, H.J.;

Interrante, L.V. Macromolecules 1992, 25, 1840.

(13) (a) Interrante, L.V.; Whitmarsh, C.W.; Sherwood, W.; Wu, H.J.; Lewis, R.; Maciel, G. Mat. Res. Soc. Symp. Proc. , 1994, Vol.346, 593. (b) Shen, Q.H.; Interrante, L.V Macromolecules, 1996, 29, 5788.

(14) Shaltout, R.M.; Corey, J.Y. Organometallics 1996, 15, 2866.

(15) Miller, R.D.; Michl, J. Chem. Rev. 1989, 89, 1359.

(16) Ward, L.G.L. Inorg. Synth. 1968, 11, 161.

(17) Mawaziny, S. J. Chem. Soc. (A), 1970, 1641.

(18) Corriu, R.; Royo, G. J. Organomet. chem. 1968, 14, 291.

(19) Gusel'nikov, L.E.; Volnin, E.A.; Gladkova, N.K.; Volkova, V.V. XIth International Symposium on Organosilicon Chemistry, Sept. 1-6, 1996, Universite Montpellier II, France, PA76. 


\section{GENERAL CONCLUSIONS}

In the first section of this thesis, a series of carbosilane dendritic polymers were synthesized and characterized, which involves the first synthesis of silylene-vinylene dendrimers. In the synthesis of the carbosilane dendritic polymers, both divergent and convergent controlled methods were used. Octapropargyloxycyclotetrasilane was synthesized from octachlorocyclotetrasilane in the synthetic study of cyclotetrasilane based dendritic polymers. The dendritic polymers were characterized by MS, FTRR, ${ }^{1} \mathrm{H}-\mathrm{NMR}$, ${ }^{13} \mathrm{C}-\mathrm{NMR}$ and ${ }^{29} \mathrm{Si}-\mathrm{NMR}$.

In the second section of this thesis, the synthesis of a silylene-acetylene precursor polymer was attempted in several ways. Low selectivity between a phenyl group and a $\mathrm{C} \equiv \mathrm{C}$ group in the electrophilic cleavage of Si-C bond was found in this synthetic study. Coupling of 1,2-bis(chlorosilyl)ethane with sodium sand failed to produce polymer -[ $\left[\mathrm{SiH}_{2} \mathrm{SiH}_{2} \mathrm{CH}_{2} \mathrm{CH}_{2}\right]_{\mathrm{n}}^{-}$, instead, a small molecular weight compound, 12, was obtained. 


\section{ACKNOWLEDGMENTS}

There are many people that I would like to thank for their support during the past few years. First of all, I wish to express my sincere appreciation to my major professor

Thomas J. Barton, for his encouragement and inspiration. His invaluable support and help will always be greatly appreciated.

I would like to express my appreciation to all the faculty, staff and students who helped me throughout my study, especially to the members of Barton research group for their friendship and help. Particularly, I would like to thank Dr. Sina Ijadi-Maghsoodi for his invaluable advice and daily help; Mrs. Kathie Hawbaker, for her kind help on many occasions.

I would like to thank my parents, sister and brother, who always love and support me. A special note of thanks goes to my beloved wife, Youmin, whose endless love makes me happy everyday.

This work was performed at Ames Laboratory under Contract No. W-7405-Eng82 with the U.S. Department of Energy. The United States government has assigned the DOE report number IS-T 1801 to this thesis. 